\title{
ENERGY LABORATORY
}

MASSACHUSETTS INSTITUTE OF TECHNOLOGY

$$
\text { DOE/ET/37218-1 }
$$
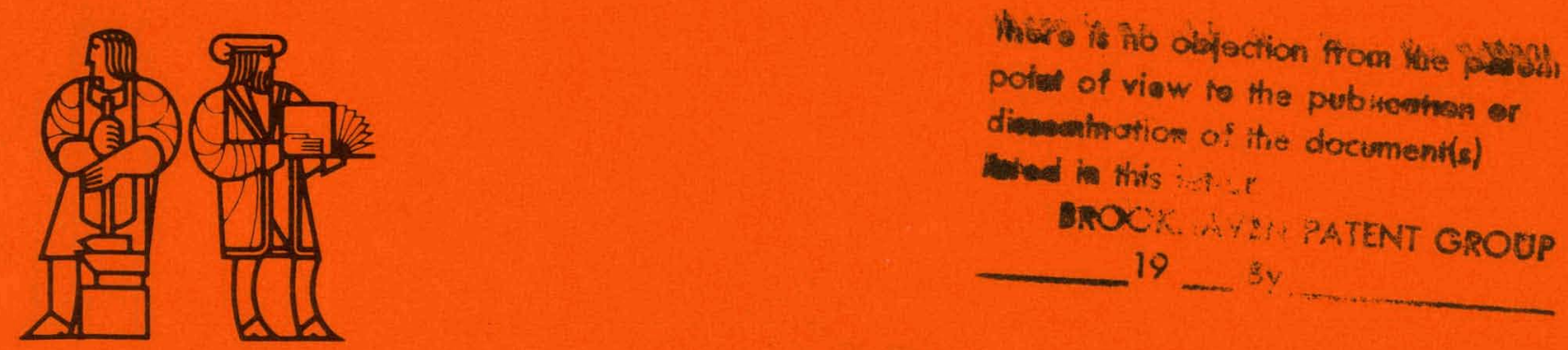


\section{DISCLAIMER}

This report was prepared as an account of work sponsored by an agency of the United States Government. Neither the United States Government nor any agency Thereof, nor any of their employees, makes any warranty, express or implied, or assumes any legal liability or responsibility for the accuracy, completeness, or usefulness of any information, apparatus, product, or process disclosed, or represents that its use would not infringe privately owned rights. Reference herein to any specific commercial product, process, or service by trade name, trademark, manufacturer, or otherwise does not necessarily constitute or imply its endorsement, recommendation, or favoring by the United States Government or any agency thereof. The views and opinions of authors expressed herein do not necessarily state or reflect those of the United States Government or any agency thereof. 


\section{DISCLAIMER}

Portions of this document may be illegible in electronic image products. Images are produced from the best available original document. 
"Development of Computer Code Models for Analysis of Subassembly Voiding in the LMFBR"

Interim Report of the MIT Sodium Boiling Project Covering Work through September 30, 1979

Energy Laboratory Report No. MIT-EL-80-005

December 1979 
NOTICE

This report was prepared as an account of work sponsored by the United States Government and two of its subcontractors. Neither the United States nor the United States Department of Energy, nor any of their employees, nor any of their contractors, subcontractors, or their employees, makes any warranty, express or implied, or assumes any legal liability or responsibility for the accuracy, completeness or usefulness of any information, apparatus, product or process disclosed, or represents that. its use would not infringe privately owned rights. 
DEVELOPMENT OF COMPUTER CODE MODELS FOR: ANALYSIS OF SUBASSEMBLY VOIDING IN THE LMFBR

Edited by:

w. Hinkle

Contributing Authors:

M. Granziera

P. Griffith

W. Hinkle

M. Kazimi

A. Levin

M. Manahan

A. Schor

N. Todreas

R. Vilim

G. Wilson

Energy Laboratory

Department of Mechanical Engineering and

Department of Nuclear Engineering

Massachusetts Institute of Technology

Cambridge, Massachusetts 02139

\section{Interim Report of the MIT Sodium Boiling Project}

Covering Work Through September. 30, 1979

Project Sponsored by

U.S. Department of Energy

General Electric Co. and

Hanford Engineering Development Laboratory

Energy Laboratory Report No. MIT-EL-80-005 
Page

Title Page . . . . . . . . . . . . . . . . . . . i

Table of Contents .. . . . . . . . . . . . . . . . . ii

List of Figures. . . . . . . . . . . . . . . . . . . . vi

List of Tables .. . . . . . . . . . . . . . . . . . . . ix

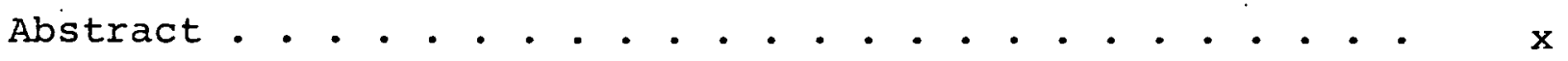

I. INTRODUCTION . . . . . . . . . . . . . . . . . . I-1

A. Background . . . . . . . . . . . . . . . . I-1

B. Objective and Scope . . . . . . . . . . . . I-3

References . . . . . . . . . . . . . . . I-6

II. REVIEW OF ANALYSIS REQUIREMENTS AND AVAILABLE CODES. II-I

A. Introduction . . . . . . . . . . . . . II-1

B. Review of Analysis Requirements . . . . . . . II-1

1. Ground Rules . . . . . . . . . . . . . II-1

2. Results... . . . . . . . . . . . II-2

a. Rod Bundle Representation . . . . . II-2

b. Two-Phase Flow Model . . . . . . . II-5

c. Heat Transfer Package . . . . . . . II-6

d. Numerical Method . . . . . . . II-7

C. Review of Available Codes. . . . . . . . . . II-8

1. Codes Considered . . . . . . . . . . II-8

2. Results . . . . . . . . . . . . . II-9

D. Comparison of Accident Analysis Requirements and Codes . . . . . . . . . . . . . . . . . II-9

E. Conclusions and Recommendations . . . . . . . II-9

1. Code/Model Requirements . . . . . . . . II-9

a. Bundle Representation . . . . . . : II-9

b. Two Phase Model . . . . . . . . II-16

c. Numerical Model . . . . . . . . II-16

2. Present Code Capabilities . . . . . . . II-16

3. Recommended Code Development . . . . . . II-16

a. Porous Body/Two Fluid Model . . . . II-16

b. Porous Body/Mixture Model . • • . II-17

References . . . . . . . . . . . . . . II-18 
III. TWO FLUID CODE DEVELOPMENT . . . . . . . . . . . . . III-l

A. Introduction . . . . . . . . . . . . . . III-1

B. Adaptation of THERMIT. . . . . . . . . . . . III-2

1. Rod Bundle Representation . . . . . . . III-2

a. Radially Variable Equivalent

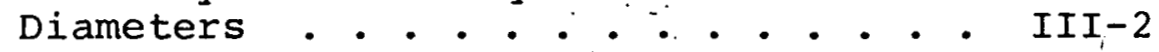

b. Heater and Fuel Rod Models. . . . . III-2

c. Representation of Plenum/Blanket

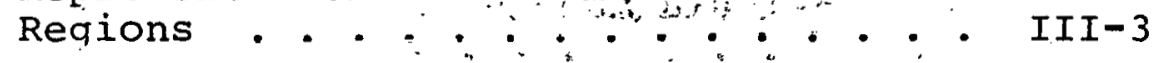

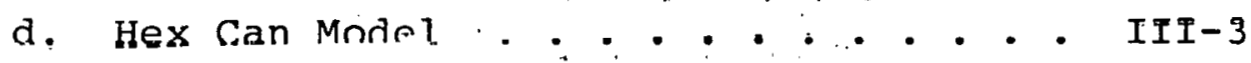

e. Sodium Physical Properties . . . . . III-4

2. Numerical Method . . . . . . . . . III-5

a. Faster Approach to steady State . . III-5

b. Other Ways to Reduce Running Time .. III-6

3. Input/Output Routines . . . . . . . . III-6

a. Input Geometry Preprocessor. . . . . III-6

b. Temperature Field Interpolation ... . III-7

C. Development of NATOF-2D . . . . . . . . . . III-9

D. Development and Implementation of Constitutive

Equations and Models............... III-10

1. Mass Exchange... . . . . . . . . III-10

2. Momentum Exchange . . . . . . . . . $\therefore$ III-10

a. Inclusion of $\Gamma$ in the $z$-Direction

Momentum Equation .. . . . . . . III-1I

b. Expressions for $K, F_{W, l}$ and $F_{\dot{W}, v} \cdot \cdot$ III-12

3. Heat Transfer . . . . . . . . . . . III-I4

a. Convective Heat Transfer . . . . . . III-11

b. Radial Heat Conduction in the Liquid

Region . . . . . . . . . . . . III-16

r. Code Testing and Application . . . . . . . . III-22

1. THERMIT Analysis of THORS Test $71 \mathrm{H}$ Run 101 . III-22

2. NATOF-2D Analysis of SLSF-P3A Experiment. . III-36

F. Summary-Present status and Plans for FY1980 . . III-41

1. Work Completed During FY1979 . . . . . . III-4I

2. Plans for FYl980 . . . . . . . . . . III-42

Appendix A: THORS Heater Pin Physical Properties

and Geometry ............ III-45 
$\underline{\text { Page }}$

Appendix B: Model for Heat Loss to Surrounding Structure . . . . . . . . . . . III-46

Appendix C: Sodium Physical Property Correlations . III-51

Appendix D: Old and New Models for the Mass Exchange Coefficient . . . . . . III-57

Appendix E: Proposed Correlation for Two. Phase Convective Heat Transfer in LMFBR Rod Bundles...... . . . . . . III-66

Appendix F: Details of Radial Heat Conduction Model Added to THERMIT . . . . . . III-72

References . . . . . . . . . . . . . III-79

IV. MIXTURE MODEL CODE DEVELOPMENT • . • . . . . . . . . . IV-1

A. Introduction . . . . . . . . . . . . . . IV-1

B. Model Selection . . . . . . . . . . . . IV-2

C. Model Formulation and Coding . . . . . . . . . IV-6

D. Code Testing and Application . . . . . . . . IV-10

1. Selection of Test Problem . . . . . . . IV-10

2. Results . . . . . . . . . . . I IV-13

E. Investigation of Numerical Method . . . . . . . IV-16

F. Summary-Present Status and Plans for FY1980 . . IV-20

1. Work Completed During FY1979 . . . . . . . IV-20

2. Plans for FY1980 . . . . . . . . . . IV 20

References . ............ . . . . . . IV-23

V. DEVELOPMENT OF A MODEL TO PREDICT FLOW OSCILLATIONS IN LOW-FLOW SODIUM BOILING . . . . . . . . . . . V V-1

A. Introduction . . . . . . . . . . . . . . V V-l

B. Model Formulation . . . . . . . . . . . V-2

1. Hydrodynamic Model . . . . . . . . . $\mathrm{V}-2$

2. Thermal Model . . . . . . . . . . . V $\mathrm{V}-5$

3. Solution Procedure. . . . . . . . . V-7

C. Experimental Apparatus . . . . . . . . . : V-9

D. Preliminary Analytical Results . . . . . . . V-13

E. Preliminary Experimental Results . . . . . . . V-18

F. Comparison of Sodium and Water Experimental Results ............ . . . . . . . V V 19 
$\underline{\text { Page }}$

G. Summary-Present status and Plans for FY1980 . . V V-20

1. Work Completed During FY1979 . . . . . . V-20

2. Plans for FY1980 . . . . . . . . . . V V-20

References . . . . . . . . . . . . . . $\mathrm{V}-2 \mathrm{l}$

VI. PROGRAM COORDINATION . . . . . . . . . . . . V VI-1

A. Introduction . . . . . . . . . . . . . . VI-I

B. FY1979 Coordination Activities . . . . . . . . VI-I

1. Projcct Meetings and Reports . . . . . . . VI-1

a. Meet1ng̣s.............. . V VI-1

b. Reports . . . . . . . . . . VI-2

2. Other Activities . . . . . . . . . . VI-2

a. Behavior of Sodium (BONA) Working

Group Meetings . . . . . . . . . VI-2

b. Other Meetings . . . . . . ... VI-3

C. Plans for FYl980... . . . . . . . . . . . VI-3

1. Project Meetings and Reports . . . . . . VI-3

2. Other Activities . . . . . . . . . . VI-3 


\section{List of Figures}

Figure

$\underline{\text { Page }}$

III-1 Comparison of $\Gamma_{e}$ and $k$ for Various Values of $\alpha$ and $\left(T_{\ell}-T_{S}\right)$

III-13

III-2 New Radial Heat Conduction Model - Results of Four Channel Test Case

III-3 New Radial Heat Conduction Model - Geometry for Second Test Case

III -18

III -20

III-4 New Radial Heat Conduction Model - Results of Second Test Case

III-5 Cross Section View of THORS Bundle $6 \mathrm{~A}$ Test

Section (ORNL Dwg. 78-6760R)

III-6 Axial Dimensions of THORS Bundle 6A Test Section (ORNL Dwg. 74-13251)

III -21

$\operatorname{IIT}-23$

III- 24

III-7 Measured Flow Variables from THORS Bundle 6A, Test $71 \mathrm{H}$, Run 101

III -25

III-8 Bottom Boundary Condition: Inlet Velocity to THORS Bundle $6 \mathrm{~A}$, Test $71 \mathrm{H}$, Run 101

III- 27

III-9 Top Boundary Condition: Outlet Pressure from THORS Bundle 6A, Test $71 \mathrm{H}$, Run 101

III-28

III-10 Temperature Prediction Six Inches Downstream of Heated Section Outlet for THORS Bundle 6A, Test $71 \mathrm{H}$, Run 101, for Three Different Hex Can Models

III-11 Temperature in the Test Section as a Function of Axial and Radial position at 15 Seconds for THORS Bundle 6A, Test $71 \mathrm{H}$, Run 101

III-12 Comparison of Predicted and Observed Development of Saturation Conditions in Test Section, THORS Bundle 6A, Test $71 \mathrm{H}$, Run 101

III-13 Growth of Void Fraction in Test Section as Predicted by Single Channel Simulation, THORS Bundle 6A, Test $71 \mathrm{H}$, Run 101

III-14 Temperature Prediction Six Inches Downstream of Heat section outlet for THORS Bundle 6A, Test $71 \mathrm{H}$, Run 101

III-15 NATOF-2D Prediction of Temperature at Top of III -38 
Figure

$\underline{\text { Page }}$

III-16 NATOF-2D Prediction of Axial Variation of

III-39

Coolant Temperature at Various Times for SLSFP3A Experiment

III-17 NATOF-2D Void Predictions vs. Time at Three

I I I -40

Different Axial Positions for SLSF-P3A

Experiment

B-la Model for Heat Loss to Surrounding structure True Geometry

I I I -47

Model for Heat Loss to Surrounding structure -

$\operatorname{III}-47$ Assumed Goometry

D-1 New Model for Mass Exchange Coefficient Assumed Geometry for Bubbly Flow

$\operatorname{III}-60$

$\dot{D}-2$

New Model for Mass Exchange Coefficient Assumed Geometry for Annular Flow.

III -62

D-3 Comparison of Old and New Models for Mass Exchange Coefficient - Interfacial Area vs.

III -65 $\alpha$ for Different Values of $P / D$

E-1 The Suppression Function, $S$, in Equation (E-I)

III -68

E-2 The Reynolds Number Function, F, in Equation $(E-2)$

F-1 New Radial. Heat Conduotion Model - Noddl

$111-74$

Confiquration Used for nerivation of Equations $(\mathrm{F}-2)$ and $(\mathrm{F}-3)$

$\mathrm{F}-2$

New Radial Heat Conduction Model. - Nomenclature

$\operatorname{III}-74$ Used in Derivation of Effective Conduction Heat Transfer Coefficient

IV-1 19-Pin Assembly Layout and Calculational Mesh Overlay Used for Simulation of French Steady State Boiling Experiment

IV-2 Predicted Exit Temperature Distribution with Liquid Conduction and without Wire Wrap Model, French steady state Boiling Experiment

IV-3 Predicted Exit Temperature Distribution without Conduction and without Wire Wrap Model, French Steady state Boiling Experiment 
viii

Figure

$\underline{\text { Page }}$

$\mathrm{V}-2$

Schematic of Water Test Loop Used to Simulate Low Flow Sodium Boiling

$\mathrm{V}-10$

$\mathrm{V}-3$

Example of Computer Result for $Q_{1}, Q_{2}$ vs. Time

$\mathrm{V}-15$

$\mathrm{V}-4$

Code Prediction of Bubble Pressure vs. Time

$V-16$

$\mathrm{V}-5$

Code Prediction of Total Bubble Length vs. Time

$\mathrm{V}-17$ 


\section{List of Tables}

Table

Page

I I- I

Analysis Requirements - Specific Accidents

II-3

II-2

Results - Review of Computer Codes

$I I-10$

II- 3

Accident Analysis Requirements

II -14

II -4

Computer code Characteristics

I I -15

$\operatorname{III-1}$

Event Sequence Times as Predicted by NATOF-2D

for SLSF-P 3A Experiment

$\operatorname{III}-37$

IV -1

Two-Phase Flow Models

IV -3

IV-2

Two-Phase Model Comparison

IV -5

$\mathrm{V}-1$

Key to Component Numbers Used in Figure $\mathrm{V}-2$.

IV -6 
ABSTRACT

The research program discussed in this report was started in FY1979 under the combined sponsorship of the U.S. Department of Energy (DOE), General Electric (GE) and Hanford Engineering Development Laboratory (HEDL). The objective of the program is to develop multi-dimensional computer codes which can be used for the analysis of subassembly voiding incoherence under postulated accident conditions in the LMFBR. This work is expected to contribute to LMFBR safety analysis in two ways. First, it will provide a capability for obtaining more dependable information concerning the effects of subassembly voiding incoherence in LMFBR's of current design. Second, it wili provide the calculational tools needed to develop new designs with featurco that could inhibit radial void growth and thus, enhance the reactor safety.

Two codes are being developed in parallel. The first will use a two fluid ( 6 equation). model which is more difficult to develop but has the potential for providing a code with the utmost in flexibility and physical consistency for use in the long term. The other will use a "mixture": (< 6 equation) model which is less general but may be more amenable to interpretation and use of experimental data and therefore, easier to develop for use in the near term. To assure that the models developed are not design dependent, geometries and transient conditions typical of both foreign and U.S. designs are being considered.

In addition to the code development, a study is being conducted which is aimed at obtaining a basic understanding of flow oscillations observed in low power, low flow sodium boiling experiments conducted at ORNL using the THORS test facility. This study includes water tests to simulate low power low flow sodium boiling flow oscillations and development of an analytical model to predict the oscillations.

During FY1979 an effort has also been made to coordinate tilis program with other related DOE sponsored programs and activities concerned with sodium boiling R\&D. The objectives of this effort are: (1) to assure maximum use is made of data and information available from related programs and (2) to facilitate eventual acquisition and use of the codes being developed by the appropriate DOE contractors and laboratories.

This report describes work completed on each of the above tasks through september $30,1979$. 


\section{INTRODUCTION}

A. Background

One of the most important safety concerns associated with large commercilal sized LMFBR's is the effect of sodium boiling on the consequences of hypothetical accidents. It is well known that void formation within the reactor core would cause a reactivity and power increase, and under certain circumstances, could lead to dryout, overheating of the fuel pins and pin failure. There are indications however, that. for specific accidents involving subassemblies and cores of the present designs, there are inherent rate limiting effects that retard the onset of dryout and sustain longer cooling of the fuel. Additional R\&D on sodium boiling behavior will greatly help in understanding these effects and may lead to the development of more favorable designs that can terminate all postulated accidents with limited core damage.

The currently available experimental data concerning sodium voiding under simulated LMFBR accident conditions was obtained from the OPERA, TREAT R.Series, THORS and SLSF experiments (Ref. 1). These experiments have included inpile and out-of-pile tests with full length simulated LMFBR subassemblies ranging in size from the 7-pin bundle used in the early OPERA tests to the 19 and 37-pin bundles used in the SLSF P Series tests. Analytical studies by ANL (Ref. 2) have presented convincing arguments, however, that without a specially designed test bundle, a minimum of 61 pins is 
needed to adequately represent the coolant and thermal-hydraulic conditions for a typical LMFBR subassembly. Also, results of some of the tests completed to date have indicated that twodimensional boiling incoherence effects are of considerable importance in some accident sequences. (For example, in the case of the Loss of Piping Integrity (LOPI) accident, SLSF P Series test data indicates that such effects would lead to temporary quasi-steady boiling withnut dryout in the case or an inlet nozzle pipe break of the guillotine type for FFTF.) Therefore, tests with larger bundles are planned. However, computer codes that can be used for analyzing such tests and extrapolating to full size reactor conditions do not presently exist.

The adequacy of a computer code used for LMFBR safety analysis is determined by its ability to predict both the results of separate effects and integral experiments, and to conservatively bound the uncertainties which are involver in an extrapolation to a full size reactor system. The end result must be an understanding of the accident progression and the availability of accepted analytical methods which can realistically assess the risk and associated uncertainties. To meet these requirements, the U.S. LMFBR Safety $\dot{\pi}$ \& Program lade Epunsored development of a number of computer codes, including the integrated system codes MELT (Ref. 3) and SAS (Ref. 4). However, these codes cannot represent the two-dimensional incoherence effects which may affect sodium boiling progression and limit 1ts rate under some of the test and/or reactor conditions that must be analyzed. 
In the past few years, some attempts (Ref. 5-7) have been made to analyze the effect of incoherent boiling by using modified versions of SAS and COBRA (Ref. 8). However, the onedimensional channel model used in SAS cannot adequately describe intrasubassembly phenomena. The COBRA code also has some basic limitations, i.e., its treatment of boundary conditions requires the system pressure to be constant and the time dependent inlet. flow must be prespecified. Additionally, COBRA has numerical stability problems when used for two phase conditions in the LMFBR assemblies, unless unreal liquid/vapor density ratios are specified.

There have also been attempts to develop new codes. Miao and Theofanous (Ref. 9) have developed a two-dimensional (2D) code, HEV-2D, based on the homogenous equilibrium model for subassembly thermal-hydraulic analyses. Chen et al. (Ref. 10) have extended their single phase forced diversion model (Ref. 11) to include phase change capability. A code based on a slug annular flow model, similar to that developed by chen et. al. (Ref. 10) was also independently developed by Shih (Ref. 12). All of these codes have fundamental model limitations, however, and are expected to have a limited range of applicability. Consequently, further work on model and code development is needed.

B. Objective and Scope

The objective of the research program discussed in this report is to develop computer code models for multi-dimensional analysis of subassembly voiding under postulated accident conditions in the TMPRR. This includes conditions vithin line of Assurance 2 (LOA 2) for the Loss of Flow (LOF), Loss of Piping 
Integrity (LOPI), Loss of Shutdown Heat Removal System (LSHRS), and Local Fault (LF) Accidents. It also includes the Transient Overpower (TOP) Accident up the point of fuel dispersal and fuel coolant interaction.

Two codes are being developed in parallel. The first will use a two fluid (6 equation) model which is more difficult to develop but has the potential for providing a code iwith the utmost flexibility and physical consistenny for use in tho long term. The other will use a "mixture" (< 6 equation) model which is less general but may be more amenable to interpretation and use of available experimental data and therefore, easier to develop for use in the near term. To assure that the codes being developed are not design dependent, geometries and transient conditions typical of both foreign and U.S. designs are being considered in the code testing and application.

In addition to the code development, a study is being conducted which is aimed at obtaining a basic understanding of flow oscillations observed in low power, low flow sodium boiling experiments conducted at ORNL using the THORS test facility (Ref. 13). This study includes both experimental and analytical work. The experimental work is being done using a water test loop designed to provide a one-dimensional simulation of the sodium experiments. The analytical work involves development of: (1) a simple analytical model which can predict the oscillations observed in the water tests and (2) establishment of a set of criteria for comparison of water to sodium.

During FY1979 an effort has also been made to coordinate this program with other related DOE sponsored programs and activities concerned with sodium boiling R\&D. The objectives 
of this effort are: (1) to assure that maximum use is made of data and information available from related programs and (2) to facilitate eventual acquisition and use of the codes being developed by the appropriate DOE contractors and laboratories. The following sections of this report describe work completed on each of the above tasks through September 30, 1979. Section II outlines results of a preliminary study which formed the basis for several decisions concerning the code development. Section III discusses work completed on the two fluid code development and outlines work planned for FY1980. Section IV provides a similar discussion of the mixture model code development. Section V discusses the study of flow oscillations observed in low flow, low power sodium boiling experiments. Section VI outlines completed/planned future efforts to coordinate this program with other related DOE sponsored R\&D activities. 


$$
\mathrm{I}-6
$$

\section{References}

1. Hinkle, W.D., Tschamper, P.M., Fontana, M.H., Henry, R.E. and A. Padilla," LMFBR Safety and Sodium Boiling "Paper Presented at ENS/ANS International Topical Meeting on Nuclear Reactor Safety, October 16-19, 1978, Brussels, Belgium.

2. Marr, W.W. and M.A. Grolmes; "Effects of Bundle Size on Sodium Boiling in the Simulation of an FTR Pump Coastdown Transient," Trans. Am. Nuc. Soc.; 22, 432 (1975).

3. Lewis, C.H., N.P. Wilburn, "MELT IIII-A: An Improved Neutrunlcs, l'hermal-Hydraulics Modeling code for Fast Reactor Safety Analysis," HEDL-TME-76-73, December 1976.

4. SLeverisin, M. F., Bohl, W.R., Dunn, F.E., Ileames, T.J., Hoppner, G. and L.L. Smith, "Current Status and Experimental Basis of the SAS LMFBR Accident Analysis Code," Proc. ANS Conf. Fast Reactor Safety, USAËC CONF-74040103, Beverly Hills, California, 1974.

5. Dunn, F.E. "SAS3D Prediction of Intrasubassembly Boiling "Incoherence," Trans. Am. Nucl. Soc., 28, 431 (1978).

6. Marr, W.W. and J.T. Hwang, "An Approach for Treating Two-Dimensional Coolant Boiling in the LMFBR Fuel subassembly," Trans. Am. Nucl. Soc., 27, 459 (1977).

7. "Advanced Safety Analysis," GEFR-14038-14, Fourteenth Quarterly Report, General Electric Company, March 1978.

8. Rowe, D.S., "A Mathematical Model for Transient Subchannel Analysis of Rod-Bundle Nuclear Fuel Elements," J. of Heat Transfer, Trans. ASME, Series C, Vol. 95, No. 2, 211, May 1973.

9. Miao, C. and T.G. Theofanous, "A Numerical Simulation of the Two-Dimensional Boiling (Voiding) in LMFBR Subassemblies,". Int. Fast Reactor Safety Conf., Chicago, Ill., October 1976.

10. "Reactor Development Program Frogress Reporl," ANL-RDP-73, July 1978 .

11. Chen, W.L. et.al., "A Simple Forced Diversion Model for Study of Thermal-Hydraulic Transients in an LMFBR Subassembly," Nucl. Eng. Design, 45, 53 (1978).

12. Shih, T.A., "The SOBOIL Program: A Transient, Multichannel, Two-phase Flow Model for Analysis of Sodium Boiling in LMFBR Fuel Assemblies, "Technical Note ST-TN-79008, General Electric Co., Advanced Reactor Systems Dept., March 1979.

13. Ribando, R.J., et. al., "Sodium Boiling in a Full Length 19-Pin Simulated Fuel Assembly (THORS Bundle 6A)," ORNL/TM6553, Oak Ridge National Laboratory, January 1979. 


\section{REVIEW OF ANALYSIS REQUIREMENTS \\ AND AVAILABLE CODES}

\section{A. Introduction}

Before starting work on the code development, a preliminary study was conducted for the purpose of answering several questions concerning the project scope and approach. These questions were as follows:

1) What are the code/model requirements for analysis of sodium boiling and voiding incoherence under postulated LMFBR accident conditions?

2) To what extent do previously available codes fail to meet these requirements?

3) What is the recommended scope and approach for additional code/model development?

4) Can any of the previously available codes provide a starting point for this work?

\section{B. Review of Analysis Requirements}

1. Ground Rules

Before the first of the above questions could be answered, it was necessary to identify the range of LMFBR accident conditions and geometries to be considered. In order to do this the following set of ground rules was decided upon.

a. Consider Loss of Flow (LOF), Loss of Piping Integrity (LOPI), Loss of Shutdown Heat Removal System (LSHRS), Local Fault (LF) and Transient Overpower (TOP) Accidents.

b. Consider both the initiating phase and long term cooling for the LOF, LOPI, LSHRS and LF accidents. Assume no cladding or fuel melting during initiating phase. Allow for possibility of some fuel melting and cladding failure by the time long term cooling phase is reached. 


$$
I I-2
$$

c. Consider TOP accident only up to the point of cladding failure.

d. Consider single bundle, not whole core or loop. Code(s) should, however, be able to connect appropriately to full core or loop codes.

e. Consider both U.S. and foreign geometries.

2.

With these gruund rules in mind, each accident was considered and the amalysis requirements identified. These requirements were organized into four categories: bundle representation, two phase flow model, heat transfer package and numerical method. The results for each accident are summarized in Table: II-1. Overall conclusions are outlined below.*

\section{a. Bundle Representation}

1) A 2 or 3D analysis is needed for all of the accidents for which local incoherence effects might be important. This includes the LOF, LOPI, TOP ard LF accidents.

2) Either the porous body or subchannel approach could be used to represent. an LMFBR subassembly. A porous body approach is probably preferable, however, for the following reasons

a) The amount of detail in the rod bundle representation can be more easily varied than with the subchannel model. Thus, it is easier to adjust the detail to match the accident conditions being analyzed and minimize computation costs.

\footnotetext{
*These conclusions reflect the collective judgement of the MIT project group. They werc arrived at after review of available background information (Ref. Section I) and several meetings and discussions.
} 
Table II-l

Analysis Requirements - Specific Accidents

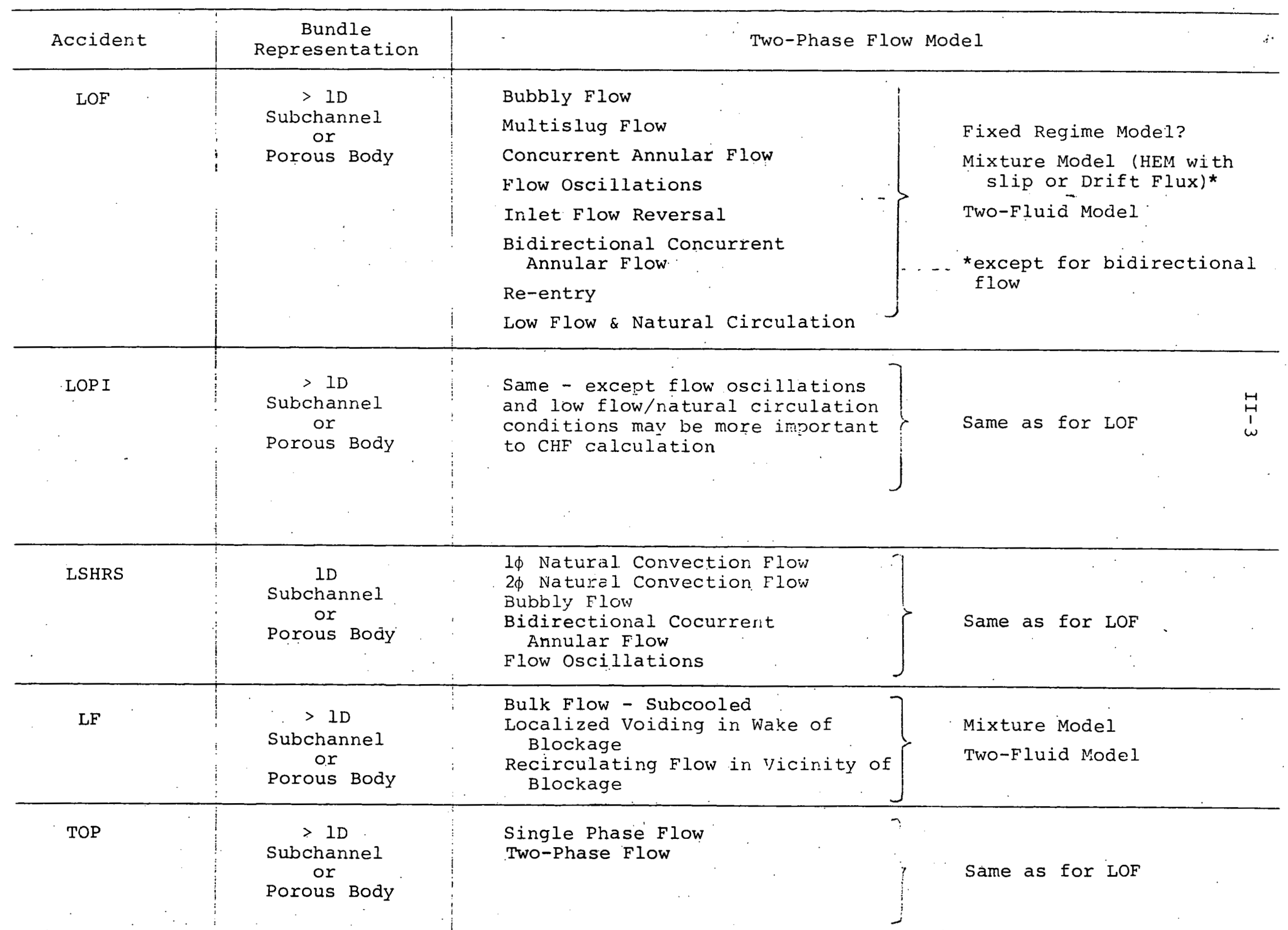


Table II-I

Analysis Requirements - Specific Accidents (continued)

\begin{tabular}{|c|c|c|}
\hline Accident & $\begin{array}{c}\text { Two-Phase Flow Correlations \& } \\
\text { Heat Transfer Package }\end{array}$ & Numerical Method \\
\hline LOF & $\begin{array}{l}\text { Good l and } 2 \phi \triangle P \text { Correlations (Axial for } \\
\text { l } \phi . \text { Axial \& Radial for } 2 \phi \text { ) } \\
\text { Good Fuel Pin Model } \\
\text { Good Model of Plenum/Blanket. Heat Capacity } \\
\text { Effects } \\
\text { Liquid Superheat on the Order of } 100^{\circ} \mathrm{C} \\
\text { Heat Transfer at Interface of Expanding } \\
\text { Void and Subcooled Liquid - Condensation } \\
\text { Effect o } \equiv \text { Non-Condensibles (Including } \\
\text { Fission Gas) } \\
\text { CHF (Film Dryout) } \\
\text { Post CHF Heat Trarsfer/Rewetting }\end{array}$ & $\begin{array}{l}\text { Lagrangian or Partly Lagrangian } \\
\text { (Fixed Regime) } \\
\text { Eulerian - Boundary Value } \\
\text { (Mixture and Two-Fluid) } \\
\text { Implicit or Partially Explicit }\end{array}$ \\
\hline LOPI & Same as LOF & Seme as LOF \\
\hline LSHRS & $\begin{array}{l}\text { Good } 1 \& 2 \phi \Delta \mathrm{P} \text { Correlations (Axial) } \\
\text { Natural Circulation Flow Boiling } \\
\text { Heat Transfer at Interface of Expanding } \\
\text { Void \& Subcooled Liquid - Condensation } \\
\text { Effect of Non-Condensibles (Including } \\
\text { Fission Gas) } \\
\text { CHF (Film Dryout) } \\
\text { Fost CHF Heat Transfer/Rewetting }\end{array}$ & $\begin{array}{l}\text { Same as LOF except differencing scheme } \\
\text { can be explicit or partially implicit. }\end{array}$ \\
\hline LF & $\begin{array}{l}\text { Good Fuel Pin Model (Including Axial } \\
\text { Conduct:on Effects) } \\
\text { Heat Transfer at Interface of Expanding } \\
\text { Void \& Subcooled Liquid - Condensation } \\
\text { Effect on Non-Condensibles (Including } \\
\text { Fission Gas) } \\
\text { CHF (Film Dryout) } \\
\text { Post CHF Feat Transfer/Rewetting }\end{array}$ & $\begin{array}{l}\text { Eulerian - Initial Value } \\
\text { Explicit or Partially Implicit }\end{array}$ \\
\hline TOP & $\begin{array}{l}\text { Tirbulent Mixing } \\
\text { Diversion Cross Flow } \\
\text { Sweeping Flow } \\
\text { Thermal Conduction }\end{array}$ & $\begin{array}{l}\text { Eulerian - Initial Value } \\
\text { Explicit or Partially Imolicit }\end{array}$ \\
\hline & i & . \\
\hline
\end{tabular}


b) This model provides a treatment of transverse momentum effects which is more exact than the one used in the subchannel model.

c) The amount of detail can be such as to make the model essentially equivalent to one which represents every subchannel -if necessary.

3). $R Z$ or $R Z \theta$ geometry would be easier to use for $2 D$ or 3D porous body code -- because of the hexagonal fuel pin arrangement in LMFBR assemblies; but XYZ geometry could also be used.

b. Two-Phase Flow Model

1) A wide range of flow regimes could occur for the accidents considered. These include bubbly, multislug, and cocurrent or bidirectional annular. The only model which has sufficient flexibility to represent all of these regimes. is the two fluid model. A mixture model could be used for all regimes except bidirectional annular. The fixed regime model can be used if the analysis is to focus on conditions associated with one regime. (For example, the multislug or concurrent annular model could be used to represent LOF conditions just prior to the onset of flow reversal.)

2) Sodium has a large liquid to vapor density ratio and tends to superheat [Ref. Item C.3) below]. This can result in larger local values of $\mathrm{d} \rho / \mathrm{dx}$ and $\mathrm{d} \rho / \mathrm{d} t$ leading to non-equilibrium conditions and oscillatory flow.

3) Two-phase $\Delta \mathrm{P}$ (axial and radial) would be important to determining the shape of an expanding two-phase region ("bubble"). Thus a good model and supporting data are needed. 
4) Low flow and natural circulation conditions (both low and high quality) are important for the LSHRS accident and the tail end of the initiating phase of the LOF and LOPI accidents.

5) Analysis of void progression should include consideration of the effect of non-condensibles (including fission gas) on void progression.

c. Heat Transfer Package

1) Fuel pin stored energy release vs. time is important for the LOF and LOPI accidents. Axial conduction could be important to the LF accident. Also, effect of the heat capacity of the fuel assembly structure in the fission gas plenum and blanket regions would be important for the LOPI and (to a lesser extent) LOF accidents. The fuel pin model should therefore include such effects.

2) Radial heat conduction in the liquid region could be important for low flow conditions because of the high thermal conductivity of sodium. (Heat conduction to the hex can could also be important for analyzing small rod bundle experiments. Ref. the SLSF P 3 and THORS Bundle 6 experiments, for example.)

3) Sodium superheat is expected to be less than $80^{\circ} \mathrm{C}$ in reactor configurations, but supporting. evidence based on reactor operational experiments is not yet available. Locally, superheat greater than $100^{\circ} \mathrm{C}$ may be possible. In small tcst facilities superheat greater than $100^{\circ} \mathrm{C}$ has been observed. Therefore, until such time the superheat mechanism is better understood, new analytical models and codes should be 
able to represent superheat on the order of $100^{\circ} \mathrm{C}$.*

4) The heat transfer mechanism at the interface between the expanding void and subcooled liquid regions would be important in determining void progression. Mixing and condensation at this interface would be affected by flow oscillations.

5) The condensation heat transfer model must be able to account for presence of non-condensible gases (including fission gas released from failed fuel, pins).

6) CHF probably occurs under cocurrent, countercurrent or stagnated annular flow conditions and results from depletion of the annular film. Evaporation, entrainment, interfacial shear and flow oscillation effects all. need to be considered in any dryout model. (However, development of a CHF model is considered to be low priority compared to development of a capability for analyzing boiling progression up to CHF.)

7) The heat transfer package should include capability for calculating the entire boiling curve. post CHF heat transfer may be significant for sodium because of its high surface tension lgood wetability) and high thermal conductivity.

d. Numerical Method

1) If a fixed regime model is used, the code would have to be based on a Lagrangian or partially Lagrangian approach.

2) For either the two fluid or mixture model, the code should be based on an Eulerian/boundary

\footnotetext{
*This conclusion is based on information and recommendations provided by P.W. Garrison of the Oak Ridge National Laboratory.
} 


$$
I I-8
$$

value approach in order to be able to represent the range of boundary conditions associated with the various accidents (except possibly for the LF accident).

3) The best differencing scheme (with respect to achieving a balance between avoiding numerical instability and increasing computation difficulty) approaches would be the following:

a) LOF/LOPI acidients - implicit or partially explicit

b) LSHRS/LF accidents - explicit or partially implicit

\title{
C. Review of Available codes
}

\section{Codes Considered}

Next a survey was made to determine the characteristics of available computer codes that might be used as a starting point tor this project. The following codes were considered (Refs. 1-22):

\author{
BACCHUS \\ BLOW- 3 \\ COULA- 1110 \\ COBRA-IIIP \\ COBRA-IV \\ COBRA-3M \\ COBRA-DF \\ COBRA-TF \\ COMMIX \\ FLICA-III \\ FLINA \\ FLINT \\ HEV-2D \\ NATREX \\ NATOF-ID \\ NATOF-2D \\ SABRE \\ SAS \\ SOBOIL \\ THERMIT \\ TRAC \\ WOSUB
}




$$
\text { II }-9
$$

\section{Results}

The results of this survey are shown in Table II-2. This table provides information concerning: bundle representation, two phase flow model, two phase flow correlations/heat transfer package, and numerical method.

D. Comparison of Accident Analysis Requirements and Codes

In order to answer the second, third, and fourth questions listed in Section II.A, a comparison was made of the accident analysis requirements and available codes. For a first cut, this comparison was made by choosing only a few of the more important requirements/code characteristics as a basis for comparison. These were the following:

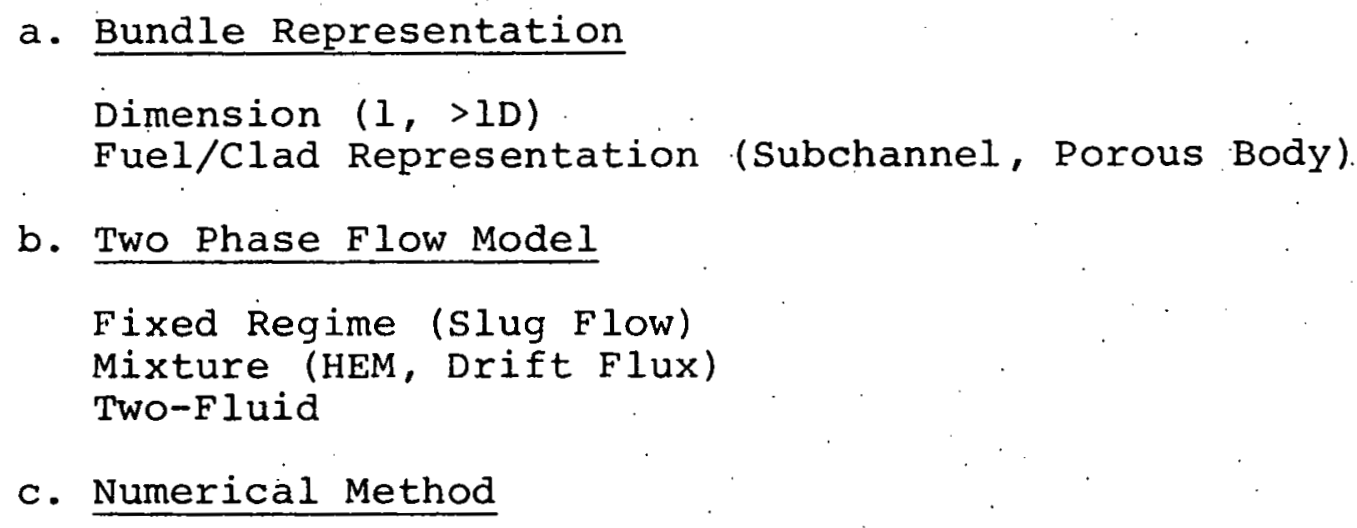

[No evaluation was made of the two-phase flow correlations and heat transfer package vs. analysis requirements.]

The results of this comparison are provided in Tables II- 3 and II-4. E. Conclusions and Rocommendations

1. Code/Model Requirements a. Bundle Representation

1) Dimension $-1,2$ and $3 D$, depending on the accident to be analyzed. A 3D code is needed to analyze effects of local voiding incoherences for postu- 
Table II-2

Results - Review of Computer codes.

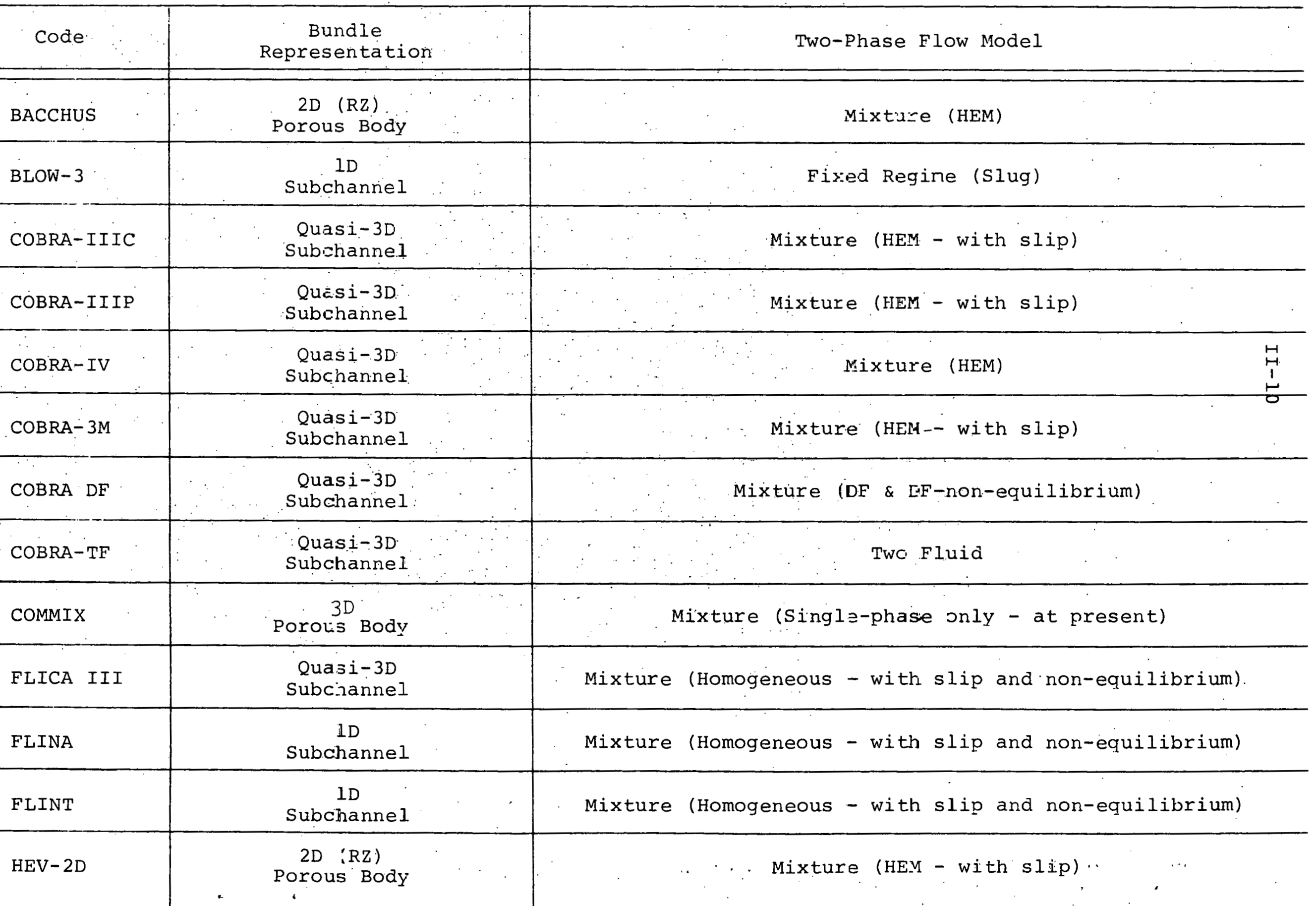


Table II-2

Results - Review of Computer codes

(continued)

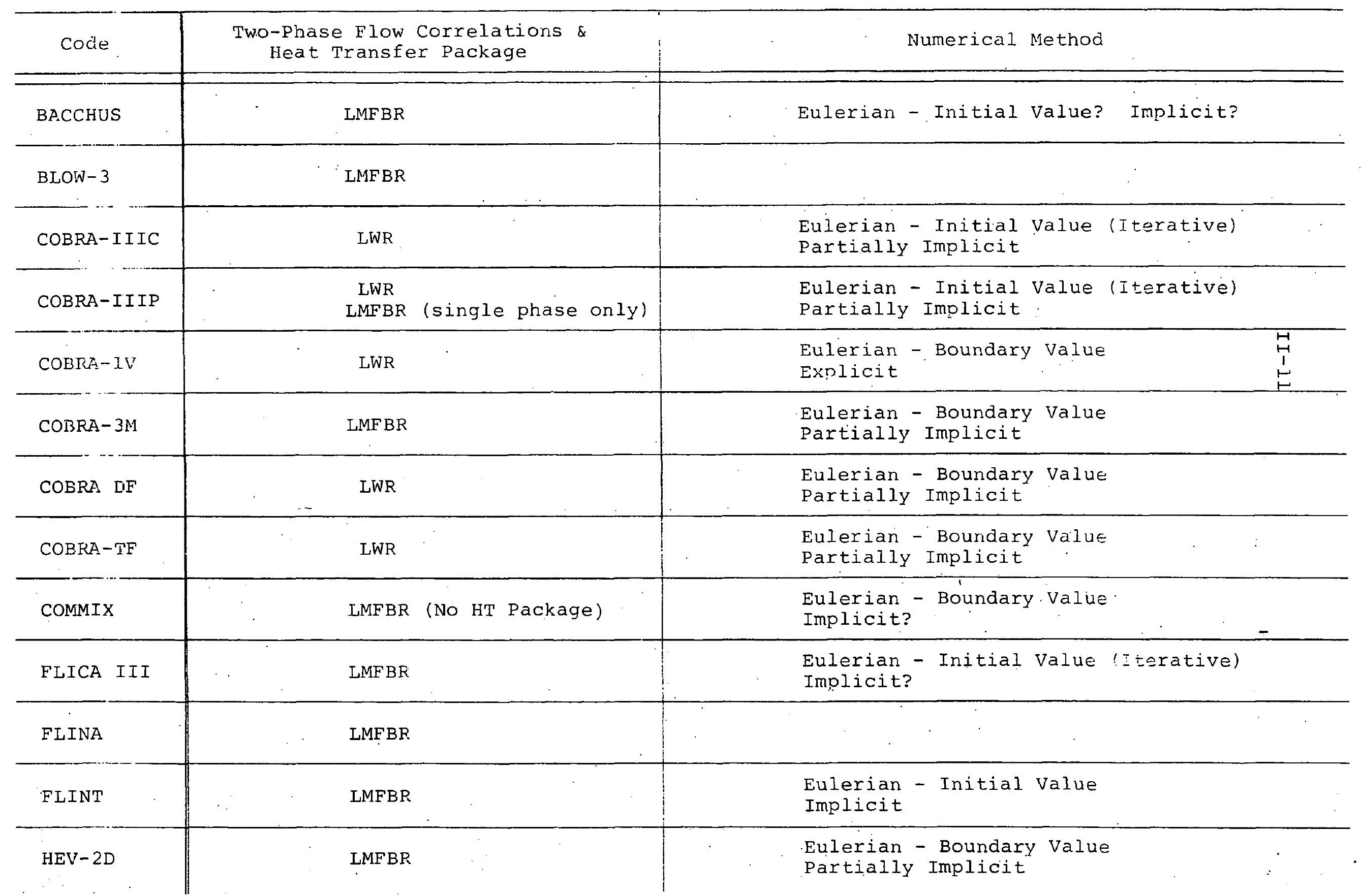


Table II-2

Results - Review of Computer codes (continued)

\begin{tabular}{|c|c|c|c|}
\hline Coàe & $\begin{array}{c}\text { Bindle } \\
\text { Representation }\end{array}$ & Two-Phase Flow Model & \\
\hline NATREX & $\begin{array}{c}\text { ID } \\
\text { Subchamnel }\end{array}$ & Mixture : IEM witt slip) & \\
\hline NATOF-ID & $\begin{array}{r}\text { ID } \\
\text { Porcus Body }\end{array}$ & Two Fluid & \\
\hline NATOF-2D & $\begin{array}{c}2 \mathrm{D}(\mathrm{RZ}) \\
\text { Poraus Body }\end{array}$ & Two Fluid & \\
\hline SABRE & $\begin{array}{l}\text { Quasi-3D } \\
\text { Subchanne-- }\end{array}$ & Mixture (HEM with slip) & $\stackrel{-1}{-}$ \\
\hline SAS & $\begin{array}{c}\text { ID } \\
\text { Subchanne- }\end{array}$ & Fixed Reçime (Slug:) & $\stackrel{i}{\sim}$ \\
\hline SOBOIL & $\begin{array}{c}\text { 2D } \\
\text { Subchannei }\end{array}$ & F'ixed Recime (Slug:) & \\
\hline THERMIT & $\begin{array}{c}30 \quad(X Y Z) \\
\text { Porcus BOCYY }\end{array}$ & Two Fluic & \\
\hline TRAC & $\begin{array}{c}3[\quad(R Z \theta) \\
\text { Porcis Bocy }\end{array}$ & Two Fluic̄ & \\
\hline WOSUB & $\begin{array}{l}\text { Quasi-3D } \\
\text { Subchannel }\end{array}$ & Mixture (Drift Flux) & \\
\hline
\end{tabular}


Table II-2

Results - Review of Computer codes (continued)

\begin{tabular}{|c|c|c|}
\hline Coće & $\begin{array}{c}\text { Two- Phase Flow Correlations \& } \\
\text { Heat Transfer Package }\end{array}$ & Numerical Method \\
\hline NATREX & LMFBR & $\begin{array}{l}\text { Eulerian } \\
?\end{array}$ \\
\hline NATOE-ID & LMFBR $\quad \ddots \cdots$ & $\begin{array}{l}\text { Eulerian - Boundary Value } \\
\text { Partially Implicit }\end{array}$ \\
\hline NATOF-2D & LMFBR & $\begin{array}{l}\text { Eulerian - Boundary value } \\
\text { Partially Implicit }\end{array}$ \\
\hline SABEE & LMFBR & $\stackrel{H}{+}$ \\
\hline SAES. & LMFBR & $\begin{array}{c}\text { Eulerian - Initial Value (Before Boiling) } \\
\text { Lagrangian or Partially Lagrangiar: (After Onset of } \\
\text { Boiling) }\end{array}$ \\
\hline SOBOII & LMFBR & $\begin{array}{l}\text { Eulerian - Initial Value (Liquid) } \\
\text { Langrangian (Vapor. Bubbles) }\end{array}$ \\
\hline TRAC & LWR & $\begin{array}{l}\text { Eulerian - Boundary Value } \\
\text { Partially Implicit }\end{array}$ \\
\hline WOSLE & LWR & $\begin{array}{l}\text { Eulerian - Initial Value } \\
\text { Implicit }\end{array}$ \\
\hline
\end{tabular}


Table II-4

Computer code Characteristics

\begin{tabular}{|c|c|c|c|c|c|c|c|}
\hline \multirow{2}{*}{ 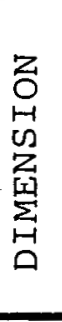 } & $\begin{array}{l}\text { FUEL/CLADDING } \\
\text { REPRESENTATION }\end{array}$ & \multicolumn{3}{|c|}{ SUBCHANNEL } & \multicolumn{3}{|c|}{ POROUS BODY } \\
\hline & $\begin{array}{l}\text { Numerical } \\
\text { Method } \\
\text { Model }\end{array}$ & Fixed Regine & Mixture & Two-Fluid & Fixed Regime & Mixture & Two-Fluid \\
\hline \multirow{3}{*}{$\stackrel{\circ}{\rightarrow}$} & $\begin{array}{l}\text { Eulerian - } \\
\text { Iritial Value }\end{array}$ & & $\begin{array}{l}\text { FLINA? } \\
\text { FLINT }\end{array}$ & & & & . \\
\hline & $\begin{array}{l}\text { Elilerian - } \\
\text { Bourdary Value }\end{array}$ & & NATREX? & & & & NATOF-1D \\
\hline & $\begin{array}{l}\text { Lagrangian or } \\
\text { Partly Lagrangian }\end{array}$ & $\begin{array}{l}\text { BLOW-3? } \\
\text { SAS }\end{array}$ & & & & • & ज \\
\hline \multirow[b]{2}{*}{$\begin{array}{l}\stackrel{D}{-1} \\
\wedge\end{array}$} & $\begin{array}{l}\text { Eulerian - } \\
\text { Iritial value }\end{array}$ & & $\begin{array}{l}\text { COBRA-IIIC } \\
\text { COBRA-IIIP } \\
\text { FLICA-III } \\
\text { WOSUB }\end{array}$ & $\cdot$ & & BACCHUS? & . \\
\hline & $\begin{array}{l}\text { Eulerian - } \\
\text { Boundary Value }\end{array}$ & & $\begin{array}{l}\text { COBRA-IV } \\
\text { COBRA-3M } \\
\text { COBRA-DF } \\
\text { SABRE? }\end{array}$ & COBRA-TF & & $\begin{array}{c}\text { COMMIX } \\
\text { HEV-2D }(R, z)\end{array}$ & $\begin{array}{l}\text { NATOF-2D (RZ) } \\
\text { TRAC (RZ } \theta) \\
\text { THERMIT }(X Y Z)\end{array}$ \\
\hline . & $\begin{array}{l}\text { Lagrangian or } \\
\text { Partly Lagrangian }\end{array}$ & SOBOIL & & & • & & . \\
\hline & & & & & & & \\
\hline
\end{tabular}


lated accidents in which both radial and azimuthal variations are important. Such accidents could include: (1) Local Fault Accidents and (2) Loss of Flow or Loss of Piping Integrity Accidents which occur under conditions involving severe azimuthal variations in local geometry.

2) Fuel/Clad Representation - Either the subrhannel or porous body could be used. The aubchannel model pivivias a llure detalled representation of fuel-coolant geometry. It would have disadvantages, however, with respect. to running time required for a complete representation of an LMFBR assembly. Also, it only treats transverse momentum effects in an approximate manner.

b. Two Phase Model

Either two fluid or mixture model could be used. The two-fluid model would be more general and take somewhat longer to develop. The mixture model would be simpler and take less time to develop -- and may have advantages with respect to interpretation and use of available experimental data.

c: Numerical Method

The Eulerian/boundary value approach and implicit or partially implicit differencing scheme:

\section{Present Code Capabilities}

At present there is no single code with the characteristics listed in E.1. (Ref. Table II-4).

3. Recommended Code Development

a. Porous Body/Two Fluid Model

Adapt XYZ LWR code THERMIT to sodium and LMFBR conditions. Continue parallel development of RZ code, NATOF-2D. 
b. Porous Body/Mixture Model

Develop three or four equation model/code based on THERMIT.

[The two-fluid code, THERMIT was recommended as a basis so that the theoretical and numerical differences between the mixture model and two fluid codes will be clearly understood when making comparisons. Also, this approach will make it possible to take advantage of an existing code structure and numerical method which represents the present state-cf-the-art. The reasons for choosing THERMIT, rather than other stateof-the-art codes such as TRAC or COMMIX were the following: (1) TRAC was written before THERMIT and therefore there were some improvements in THERMIT. Also, TRAC includes representation of an external loop and is therefore structured differently and much larger than THERMIT (which is designed specifically for core calculations). (2) Only a single-phase version of COMMIX was available, and the two-phase, two-fluid version was not expected to be available until mid-1979.] 
References

1. "French Studies on Sodium Boiling Applied to Fast Neutron Reactor Safety, State of the Art," Commisariat A L'Energie Atomique Report, Grenoble, August 1978.

2. Bottoni, M., Peppler, W., and D. Strueve,"Theortical Interpretation of Sodium Boiling Experiments in a 7-pin Bundle Under Flow Rundown Conditions with the Computer Code BLOW-3A," Institut fur Reactorentwicklung Gesellschaft fur Kernforschung, Karlsruhe, Undated technical paper: obtained from N. Todreas, MIT, 1978.

3. Bowring, R.W. ald F. lvoreno, "COBRA-IIIC/MIT Computer Cude Manual," MIT Dept. of Nuclear Engineering, Draft EPRI Report, March 1976.

4. Masterson, $R$, and L. Wolf, "COBRA-IIIP: An Improved Version of COBRA for Ful1-Core Light Water Reactor Analysis," Nuclear Engineering and Design, Vol. 48, pp. 293-310, August $1 \overline{978 .}$

5. Stewart, C.W., et.al., "COBRA-IV: The Model and the Method," BNWL-2214, Pacific Northwest Laboratories, March 1976.

6-8. Unpublished information obtained from Battelle Northwest Laboratories, 1978 .

9. Sha, W.T., et.al., "COMMIX-1: A Three-Dimensional Transient Single-Phase Component Computer Program for Thermal Hydraulic Analysis," ANL-77-96 (NUREG-0415), January 1978.

10. Menant, B., "Permanent Boiling in Rod Bundles: Calculations wi.th the FLICA-IIB Code," Paper Presented at Sixth Meeting of Liquid Metal Boiling Working: Group, Risley, UK, October $1-3,1975$.

11. Costa, J., et.al:, "Ebullition Du Sodium en Regime Transitoire Redistribution De Debit: Experiences et Calculs," Paper Presented at International Conference on Engineering of Fast Reactor for Safe and Reliable Operation, Karlsruhe, October 9-13, 1972 .

12. Grand, D. and A. Latrobe, "FLINT: A Code for Slow Flow Transients in a Single Channel," Paper Presented at Seventh Meeting of Liquid Metal Boiling Working Group, Petten, Holland, June 1-3, 1977.

13. Miao, C. and T. Theofanous, "A Numerical Simulation of the Two Dimensional Boiling (Voiding) in LMFBR Subassemblies," Paper Presented at International Meeting on Fast Reactor Safety and Related Physics, Chicago, ILL., October 5-8, 1976.

14. Latrobe, A., "A Comparison of Some Implicit Finite Difference Schemes Used in Flow Boiling Analysis," undated technical paper obtained from N. Todreas, MIT, 1978. 
15. Autruffe, M., "Theoretical study of Thermohydraulic Phenomena for LMFBR Accident Analysis," M.S. Thesis, Department of Mechanical Engineering, MIT, September 1978 .

16. Granziera, M.R. and M.S. Kazimi, "NATOF-2D: A Two Dimensional Two-Fluid Model for Sodium Flow Transient Analysis," Trans. ANS, 33, 515, November 197.9 .

17. Gosman, A.D., et.al., "The SABRE Code for Prediction of Coolant Flows and Temperaturs in Pin Bundle containing Blockages," AEEW-R905, 1973.

18. Stevenson, M.G., Bohl, W.R., Dunn, F.E., Heames, T.J., Hoppner, G. and L.L. Smith, "Current Status and Experimental Basis of the SAS LMFBR Accident Analysis Code," Proc. ANS Conf. Fast Reactor Safety, USAEC CONF-74040103, Beverly Hills, California, 1974 .

19. Shih, T.A., "The SOBOIL Program: A Transient, Multichannel, Two-phase Flow. Model for Analysis of Sodium Boiling in LMF.BR Fuel Assemblies," Technical Note ST-TN-79008, General Electric Co., Advanced Reactor Systems Dept., March 1979.

20. Reed, W.H. and H.B. Stewart, "THERMIT: A Computer Program for Three-Dimensional Thermal-Hydraulic Analysis of Light Water Reactor Cores," Mid-1978 draft of forthcoming EPRI report.

21. "TRAC-P1: An Advanced Best Estimate Computer Program for PWR LOCA Analysis," Las Alamos Scientific Laboratory, LA-7279-MS, Vol. I, June 1978.

22. Wolf, L, Faya, A., Levin, A., and L. Guillebaud, "WosuB A Subchannel Code for Steady-state Reactor Fuel Pin Bundles Vol. I, Model Description, MIT-EL-78-023, September 1978. 


\section{TWO FLUID CODE DEVELOPMENT}

\section{A. Introduction}

The objective of this task is to develop a calculational tool based on the two fluid model which can be used for analysis of sodium boiling. The two fluid model uses separate partial differential equations to express conservation of mass, momentum and energy for each individual fluid phase. Such a formalism allows very general and physically reasonable modelling of relative motion of the phases and thermal disequilibrium; but, this in turn requires mathematical expressions for the exchange of mass, momentum and energy. Accordingly, an important part of the work associated with this task is directed towarded obtaining such expressions.

On the basis of the recommendation of section II, it was decided that work on this task would follow two approaches. The first is to adapt the LWR XYZ code, THERMIT (Ref. 1) to sodium and LMFBR conditions. The second is to continue work which was started in FY1978 on development of an LMFBR RZ code, NATOF-2D. Both of these codes use a two-fluid, porous body representation and a semi-implicit method for the numerical solution of the fluid dynamics equations. Therefore, much of the work being carried out under this task is common to both. The work which has been completed during FY1979 is described in sections III.B through III.E* which follow. A summary and outline of work planned for FY1980 is given in section III.F.

\footnotetext{
* Note that all subtasks in section III.B and some in section 111.0 are also applicable to development of a mixture model code based on THERMIT (See Section IV).
} 


\section{B. Adaptation of THERMIT}

\section{Rod Bundle Representatives}

a. Radially Variable Equivalent Diameters

THERMIT is written in rectangular coordinates. In order to use the code to analyze LWR square array rod bundles (as was originally intended) only one axial hydraulic diameter was required as user input. In the case of LMFBR liexagunal arrays, however, this is not the case. Accordingly, the code has been modified so as to accept radially variable, axial heated and wetted equivalent diameter for use in the heat transfer and friction calculations respectively.

\section{b. Heater and Fuel Rod Models}

The LWR version of THERMIT contains a $\mathrm{UO}_{2}$ - Zircaloy fuel rod model. This model has been deleted and replaced by a boron nitride (BN) heater model with constant material properties similar to those used in the THORS experiments. The properties and details of rod geometry used are based on Ref. 2 and given in Appendix A. Since the code calculations are based on three zone geometry, the inner $\mathrm{BN}$ and heater ribbons were volume weight smeared as follows:

$$
\begin{aligned}
& \frac{\rho c_{p}}{p}=\frac{\int \rho c_{p} d v}{\int d v}=\left(\rho c_{p}\right)_{1}\left(\frac{R_{1}}{R_{2}}\right)^{2}+\left(\rho c_{\rho}\right)_{2}\left[1\left(\frac{R_{1}}{R_{2}}\right)^{2}\right] \\
& \frac{\rho c_{p}}{R^{2}}=3.275 \times 10^{6}\left(J / \mathrm{m}^{3}{ }^{\circ} \mathrm{K}\right) \\
& \bar{k}=\frac{\int k d v}{\int d v}=k_{1}\left(\frac{R_{1}}{R_{2}}\right)^{2}+k_{2}\left[1-\left(\frac{R_{1}}{R_{2}}\right)^{2}\right] \\
& \bar{k}=39.39 \mathrm{w} / \mathrm{m}^{\circ} \mathrm{K}
\end{aligned}
$$


Work is presently underway to incorporate a new fuel rod model. Initially, a model similar to the previous $\mathrm{UO}_{2}$ - Zircaloy model will be used. The only difference will be that the new model will use material properties and gap conductivity correlations appropriate for $\mathrm{LMFBR}\left(\mathrm{UO}_{2} / \mathrm{P}_{\mathrm{u}} \mathrm{O}_{2}\right.$ Stainless steel) fuel rods. Later, consideration will be given to incorporating a more detailed model such as used in COBRA-3M or SIEX.

c. Representation of Plenum/Blanket Regions

Work is presently underway to modify THERMIT to allow for axially varying fuel rod properties. This capability is necessary to be able to represent plenum/blanket regions of fuel assemblies. In the LWR version of THERMIT the fuel rod materials are assumed to extend for the full axial height of the system. Thus the thermal inertia of the fission gas plenum cannot be adequately modeled.

In the new version of THERMIT the user will be able to model a fuel rod by specifying the number of axial zones and the material in each zone. As many zones as desired may be specified, limited only by the number of axial meshes. This will allow the user considerable flexibility in modeling physical systems.

\section{d. Hex Can Model}

In the LWR version of THERMIT an adiabatic boundary condition around the radial perimeter of the region was requifed. The new version of THERMIT, however, provides the option of including heat loss to the surrounding structure. This capability was added as a result of attempts to model the THORS 
I I I -4

Bundle $6 \mathrm{~A}$ experiments (see section III.E.1). It was found that THERMIT couldn't adequately predict boiling inception, because there was no provision for modeling the heat losses to the hex can and surrounding insulation.

A multi-layer conduction model is used to represent the heat loss to the structure (see Appendix B for details). Heat flow in the radial direction only is conducted and azimuthal symmetry is assumed, Because of the large decrease in the sodium thermal conductivity at the onset of boiling, the heat loss from any fluid channel that has a void fraction greater than zero is neglected. If desired, the heat loss calculations can be bypassed entirely, simulating an adiabatic boundary condition.

It was found (Section III.E.1) that the inclusion of heat loss to the hex can and surrounding structure had a significant effect upon the prediction of boiling inception in the THORS experiment. It is expected that any attempt to model a transient for a geometry as small as a single fuel assembly will need to consider the thermal inertia of the surrounding structure, because the heat losses can be significant.

\section{r. Fndium Pliysical Prupertlca}

Fluid property correlations for water have been replaced by correlations for sodium. The sodium correlations were taken from Refs. 3 and 4. The correlations in Ref. 3 are based on more complete data than the correlations in Ref. 4. Correlations for liquid enthalpy, vapor conductivity, vapor viscosity, and liquid surface tension were not available 
in Ref. 3, however, and were therefore taken from Ref. 4. Appendix C contains a summary of the correlations used.

2. Numerical Method

a. Faster Approach to Steady State

THERMIT has a semi-implicit solution method (i.e., the maximum time step is limited by the courant velocity condition), and steady state solutions are found by starting from an initial guess and then running an unperturbed transient until an equilibrium solution is achieved. This equilibrium solution is the steady state solution from which a true transient may be started via the restart capability in the code. Initial application of the code to a representative test case indicated that the CPU time required in order to achieve a steady state solution was excessive. An investigation was therefore initiated to find a remedy to this problem.

As a result of this investigation, the decision. was made to: (1) convert the code to double precision and (2) provide an option to suppress transverse flow during approach to steady state. The second modification allows the user to run with the transverse flow suppressed, and then to restart with the transverse flow and run a few seconds of real time to adjust the transverse flow. The effect of these modifications was found to be the following:

Modification

Double precision supressed transverse flow $\simeq$ Decrease in CPU Time

7

$25-90$ 
b. Other Ways to Reduce Running Time

An effort will be made to identify and implement additional code modifications which significantly reduce running time. One possibility currently under consideration is to provide a means for automatic variation of the spatial mesh during a transient boiling calculation: Such a modification would enable the user to specify a fine mesh only for those parts of the transicnt where it is really needed (onset and early progression).

3. Input/Output Routines

a. Input Geometry Preprocessor

During input preparation for test cases being used for initial testing of the LMFBR version of THERMIT, it becomes obvious that if any significant number of calculations using different geometries is to be carried out, it would be extremely useful, if not indispensable, to automate the geometry set-up via a preprocessor. The need for this will be even greater when distorted geometries are analyzed.

A computer code that accomplishes this task has been written and it is now available as a stand alone module. This code receives as input the dimensions characterizing the liexayural fuel assembly (i.e., distance between flats, pin and wire-wrap diameters, pitch, spacer lead, etc.) and produces an output directly acceptable as input to THERMIT. only nominal geometry is currently treated. Code capabilities are the following: 
1) Two different diameters may be specified for wirewraps in the center and on the periphery of the assembly.

2) The wire-wraps may start at any angle with respect to one of the centerlines of the assembly (all wires should however start at the same angle).

3) The sides of the hexagonal can may be connected smoothly (i.e., via a non-zero radius of curvature).

If found desirable, this module may be incorporated directly into THERMIT, as a subroutine.

\section{b. Temperature Field Interpolation}

The more traditional subchannel representation for hexagonal assemblies uses a triangular grid. Codes using such a representation yield temperatures at locations other than those corresponding to the rectangular grid used in THERMIT. Therefore, in order to be able to compare THERMIT results with results obtained with these codes, it is necessary to have a two-dimensional interpolating scheme. Such a scheme would also be useful for obtaining a predicted temperature "reading" at the actual location of a thermocouple when comparing THERMIT results with test data.

A bilincar interpolation (Ref. 5) algorithm has been selected, being deemed adequate for this application. Basically, the formulation allows immediate determination of the function at some point, if the values of the function at four other distinct points are known. The general interpolating formula is: 


$$
T(x, y)=\left(\sum_{j=1}^{2} I_{j x}\right)\left(\sum_{k=1}^{2} L_{k y}\right)
$$

where

$$
L_{j x}=\frac{x-x_{i}}{x_{j}-x_{i}} \text {, for } i \neq j
$$

and

$$
L_{k y}=\frac{y-y_{i}}{y_{k}-y_{i}} \text {, for } i \neq k
$$

Note that in this scheme, the four base points are the vertices of a rectangle whose sides are parallel to the $x-y$ axes, that is, there are only two distinct $x$ - and $y$-coordinates. A code has been written which performs this two-dimensional interpolation as well as the automatic generation of the coordinates of the cell centers for a triangluar grid. As base points, the THERMIT-generated temperatures, in a cartesian grid, are used. The capability exists to directly access a THERMIT dump file, thus reducing to a minimum the user's effort. 
C. Development of NATOF-2D

Work on development of an RZ code (NATOF-2D) has proceeded in parallel with the work on THERMIT. This code uses a twofluid porous body formulation similar to that used in THERMIT. Initital work on its development preceeded the availability of THERMIT, however, and the detailed structure and numerics of the code have been developed independently.

The code uses a semi-implicit method for the numerical solution in which the convective terms are differentiated. implicitly in the velocity, while all the other differentiating terms are treated explicitly. With this scheme, the resulting set of algebraic equations is reduced to a matrix which is relatively easy to invert, while avoiding a stability criterion governed by the fluid sonic velocity.

A particular scheme was devised to solve this matrix inversion problem which takes advantage of the strongly anisotropic geometry of fuel assemblies, thus reducing considerably the time required to advance one time step. The time step size has a lower bound, limited by the phase speed. The coupling terms as well as the terms representing the interaction between fluid and structure are treated implicitly. This has a strong stabilizing effect, enabling the code to overcome the intrinsic numeric problems of ill-posedness of the two-fluid model. The code uses a pressure boundary condition.

A preliminary working version of the code is now available. Presently, the code incorporates the same constitutive equations/ models as used in THERMIT. The status of work on these equations/ models is discussed in section $D$. 
D. Development and Implementation of Constitutive Equations and Models

\section{Mass Exchange}

The phase change model currently used in THERMIT is a modified version of the Nigmatulin model described in References 6 and 7.* The modification is to the expressions used for $A$, the interfacial area of mass exchange. The new model provides three different expressions for $A$ in the equations for $\Gamma$, the mass exchange rate. The expression to be used is determined by the flow regime, which is assumed to depend only on the void fraction. The details of the model itself are provided in Appendix $D$.

\section{Momentum Exchange}

a. Inclusion of $\Gamma$ in the $z$-direction Momentum Equation

Both THERMIT and NATOF-2D use a non-conservative form of the two-fluid momentum equations, in order to facilitate the selection of a finite difference strategy. The general (conservative) form of the momentum equations, is the following:

$$
\begin{aligned}
\frac{\partial}{\partial t}\left(\alpha \rho_{v} u_{v}\right)+ & \frac{\partial}{\partial z}\left(\alpha \rho_{v} u_{v}^{2}\right)+\alpha \frac{\partial p}{\partial z}= \\
& u_{\ell} \Gamma_{e}+u_{v} \Gamma_{g}-k\left(u_{v}-u_{\ell}\right)-\alpha \rho_{v} g-F_{w, v}
\end{aligned}
$$

\footnotetext{
*Also see pages 34 and 35 of Ref. 1. Note, however, that errors are present in some of the equations on these pages and in the previous version of THERMIT. The correct equations are given in Appendix D.
} 
and

$$
\begin{aligned}
\frac{\partial}{\partial t}\left[(1-\alpha) \rho_{\ell} u_{\ell} I\right. & +\frac{\partial}{\partial z}\left[(1-\alpha) \rho_{\ell} u_{\ell}^{2}\right]+(1-\alpha) \frac{\partial p}{\partial z} \\
= & -u_{v} \Gamma_{c}-u_{\ell} \Gamma_{e}+k\left(u_{v}-u_{\ell}\right) \\
& -(1-\alpha) \rho_{\ell} g-F_{w, \ell}
\end{aligned}
$$

where

$\Gamma_{e}=$ rate at which liquid evaporates per unit volume $\left(\mathrm{kg} / \mathrm{m}^{3} \mathrm{sec}\right)$

$\Gamma_{C}=$ rate at which vapor condenses per unit volume* $\left(\mathrm{kg} / \mathrm{m}^{3} \mathrm{sec}\right)$

$\mathrm{K}=$ momentum exchange coefficient due to interfacial shear $\left(\mathrm{kg} / \mathrm{m}^{3} \mathrm{sec}\right)$

$F_{w, v}=$ wall friction term acting on the vapor $\left(\mathrm{N} / \mathrm{m}^{3}\right)$

$F_{W, l}=$ wall friction term acting on the liquid $\left(\mathrm{N} / \mathrm{m}^{3}\right)$

By differencing the first two terms in each of the equations by parts and using the two-fluid mass conservation equations to simplify, we obtain the non-conservative forms of the momentum equations:

$$
\alpha \rho_{v} \frac{\partial u_{v}}{\partial t}+\alpha \rho_{v} u_{v} \frac{\partial u_{v}}{\partial z}+\alpha \frac{\partial p}{\partial z}=-F_{i, v}\left(u_{v}-u_{\ell}\right)-\alpha \rho_{v} g-F_{w, v}(\text { III-6) }
$$

and

$$
\begin{aligned}
(1-\alpha) \rho_{\ell} \frac{\partial u_{\ell}}{\partial t} & +(1-\alpha) \rho_{\ell} u_{\ell} \frac{\partial u_{\ell}}{\partial z}+(1-\alpha) \frac{\partial p}{\partial z} \\
& =F_{i, \ell}\left(u_{v}-u_{\ell}\right)-(1,-\alpha) \rho_{\ell} g-F_{w, \ell}
\end{aligned}
$$

* Note that this is defined as less than zero. 
where

$$
\begin{aligned}
& F_{i, v}=k+\Gamma_{e} \\
& F_{i, \ell}=k-\Gamma_{c}
\end{aligned}
$$

Note that the total interfacial momentum exchange coefficients include both the momentum transfer due to shear (K), and the momentum transfer due to mass transfer $\left(\Gamma_{e}\right.$ and $\left.\Gamma_{c}\right)$. The current versions of THERMIT and NATOF-2D neglect the effect of $\Gamma_{e}$ and $\Gamma_{C}$ ' however it has been found that these factors become significant at high void fractions and large degrees of superheat (see Figure III-1). In making this comparison the flowregime-dependent Nigmatulin Model for $\Gamma$ (as described in Appendix D), and the Autruffe correlation for $K$ (as described in the following section) were used. In accordance with these findings, a modified version of THERMIT was created in include this effect. This version is currently in the final stages of testing.

$$
\text { b. Expressions for } K, F_{W, \ell}, \text { and } F_{W, v}
$$

The following correlations for interphase momentum exchange (K), liquid wall friction $\left(F_{w, l}\right)$ and vapor wall friction ( $\left.F_{w, v}\right)$ are currently used in both THERMIT and NATOF-2D:

$$
\begin{gathered}
K=\frac{4.31}{2 D_{H}} \rho_{\hat{v}}\left|u_{v}-u_{\ell}\right|[(1-\alpha)(1+75(1-\alpha))] 0.95 \\
F_{W, \ell}=\frac{0.18}{2 D_{H}}\left[\frac{(1-\alpha) \rho_{\ell} u_{\ell} D_{H}}{\mu_{\ell}}\right]-0.2 \rho_{\ell} u_{\ell}\left|u_{\ell}\right|
\end{gathered}
$$




$$
\begin{aligned}
& F_{W, \ell}=\frac{0.18}{2 D_{H}}\left[\frac{(1-\alpha) \rho_{\ell} u_{\ell} D_{H}}{\mu_{\ell}}\right]-0.2 \cdot \rho_{\ell} u_{\ell}\left|u_{\ell}\right|\left[\frac{(1-\alpha)}{(1-0.957)}\right] \\
& \quad \text { or } \alpha \geq 0.957 \\
& F_{W, v}=\frac{0.2}{2 D_{H}} a \rho_{v} u_{v}\left|u_{v}\right|\left[\frac{\alpha \rho_{v} u_{v} D_{H}}{\mu_{v}}\right]-0.2
\end{aligned}
$$

Thesc correlations were developed in Ref. 8 using experimental results from the KFK experiments in Karlsruhe (Ref. 9). They differ from other formulations found in the literature, since such formulations generally relate to a different two phase model or have been designed for oṭher flow patterns than the one which prevails in these experiments.

To date, the above correlations have been tested against tube dald under steady state conditions, and reasonable agreement with experiment has been obtained. Further work is needed, however, to develop correlations which account fur the effect of bundle geometry in the XY or $\mathrm{R}$ momentum exchange terms.

\section{Heat Transfer}

\section{a. Convective Heat Transfer}

An adequate heat transfer correlation for convective two phase flow in sodium cooled rod bundles is not available in the literature. Accordingly, a new correlation has been developed and implemented. This correlation is based on the assumption that the total heat transfer is the result of micro and macro convective effects. Thus: total convective boiling 
heat transfer is given by:

$$
\mathrm{h}=\mathrm{h}_{\mathrm{mic}}+\mathrm{h}_{\mathrm{mac}}
$$

The value of $h_{\text {mic }}$ is obtained from the following expression developed by Chen (Ref. 7):

$$
h_{\text {mic }}=0.00122 \frac{k_{L}{ }^{0.79} c_{p_{L}} 0.45 \rho_{L}{ }^{0.49} \Delta P^{0.75} g_{C}{ }^{0.25} s}{\sigma 0.5 \mu_{L}{ }^{0.29}}
$$

$$
\left(\frac{\Delta T}{\lambda \rho_{v}}\right)
$$

where,

$$
S=\left(\frac{\Delta T_{e}}{\Delta T}\right) 0.99
$$

and,

$$
\begin{aligned}
& \mathrm{k}_{\mathrm{L}}=\text { liquid thermal conductivity } \\
& \mathrm{c}_{\mathrm{p}_{\mathrm{L}}}=\text { Iiquid heat capacity } \\
& \rho_{\mathrm{L}}=\text { liquid density } \\
& \mathrm{g}_{\mathrm{C}}=\text { gravitational constant } \\
& \sigma=\text { surface tension } \\
& \mu_{\mathrm{L}}=\text { liquid viscosity } \\
& \lambda=\text { heat of vaporization } \\
& \rho_{\mathrm{v}}=\text { vapor density } \\
& \Delta \mathrm{T}_{\mathrm{e}}=\text { effective superheat for bubble growth in annular liquid } \\
& \mathrm{S}=\text { measure of the supprcssion of bubble growth by prosincc: } \\
& \quad \text { of two phase flow } \\
& \Delta \mathrm{T}=\text { wall temperature minus saturated liquid temperature } \\
& \Delta P=\text { pressure at wall minus liquid pressure }
\end{aligned}
$$


The value of $h_{\text {mac }}$ is obtained from the modified schad correlation:

$$
h_{\text {mac }}=R\left[\left(F R e_{L}^{0.3}\right)\left(\operatorname{Pr}_{L} \beta\right)^{\alpha}\right] \frac{\delta k_{L}}{D_{H}}
$$

where:

\begin{tabular}{|c|c|c|c|}
\hline & Two Phase & Vapor & Liquid \\
\hline$\delta$ & 1 & $k_{v} / k_{L}$ & 1 \\
\hline $\mathbf{R}$ & $\begin{array}{l}-16.15+24.96(P / D) \\
-8.55(P / D)^{2}\end{array}$ & .023 & $\begin{array}{l}-16.15+24.96(P / D) \\
-8.55(P / D)^{2}\end{array}$ \\
\hline$\beta$ & 1 & $\operatorname{Pr}_{v} / \operatorname{Pr}_{L}$ & 1 \\
\hline$\alpha$ & 0.3 & 0.4 & 0.3 \\
\hline $\mathbf{F}$ & {$\left[\frac{R e}{R_{L}}\right]^{0.3}$} & $\frac{\operatorname{Re}_{v}^{0.8}}{\operatorname{Re}_{L} 0.3}$ & 1 \\
\hline
\end{tabular}

Further details are provided in Appendix E.

b. Radial Heat Conduction in the Liquid Region

A radial heat conduction capability has been incorporated into the new version of THERMIT.* This capability was necessitated by the fact that sodium has a murh higher thermal conductivity than water (the coolant for which THERMIT was developed initially), and therefore, a mechanism should exist by which heat can be transferred between adjacent channels. Previously, the only way this could occur was through the mass exchange induced by transverse velocities. 
Presently, only liquid heat conduction is considered, because when a channel begins to boil it is assumed that the flow immediately becomes annular, with the liquid in a film around the fuel rod. Therefore, the edge of the channel will contain nearly all vapor, and because the thermal conductivity of the vapor is much smaller than that of the liquid, the conduction effect is negligible. In addition, only radial heat conduction is considered; although the model permits the incorporation of axial heat conduction if desired. The effects of axial conduction will be negligible except in low flow cases. Details of the model are given in Appendix $F$. The fully explicit version of the heat conduction model has been tested for two cases. The first was a four channel $(2 \times 2)$ case in which two of the channels were heated by fuel pins, and the other two were unheated. The transverse velocities were set equal to zero, so that any heat transfer between cells was due to conduction. As expected, the unheated channels showed a rise in temperature due to conduction from the heated channels. Figure III-2 shows the temperature rise along the channel at steady state. 


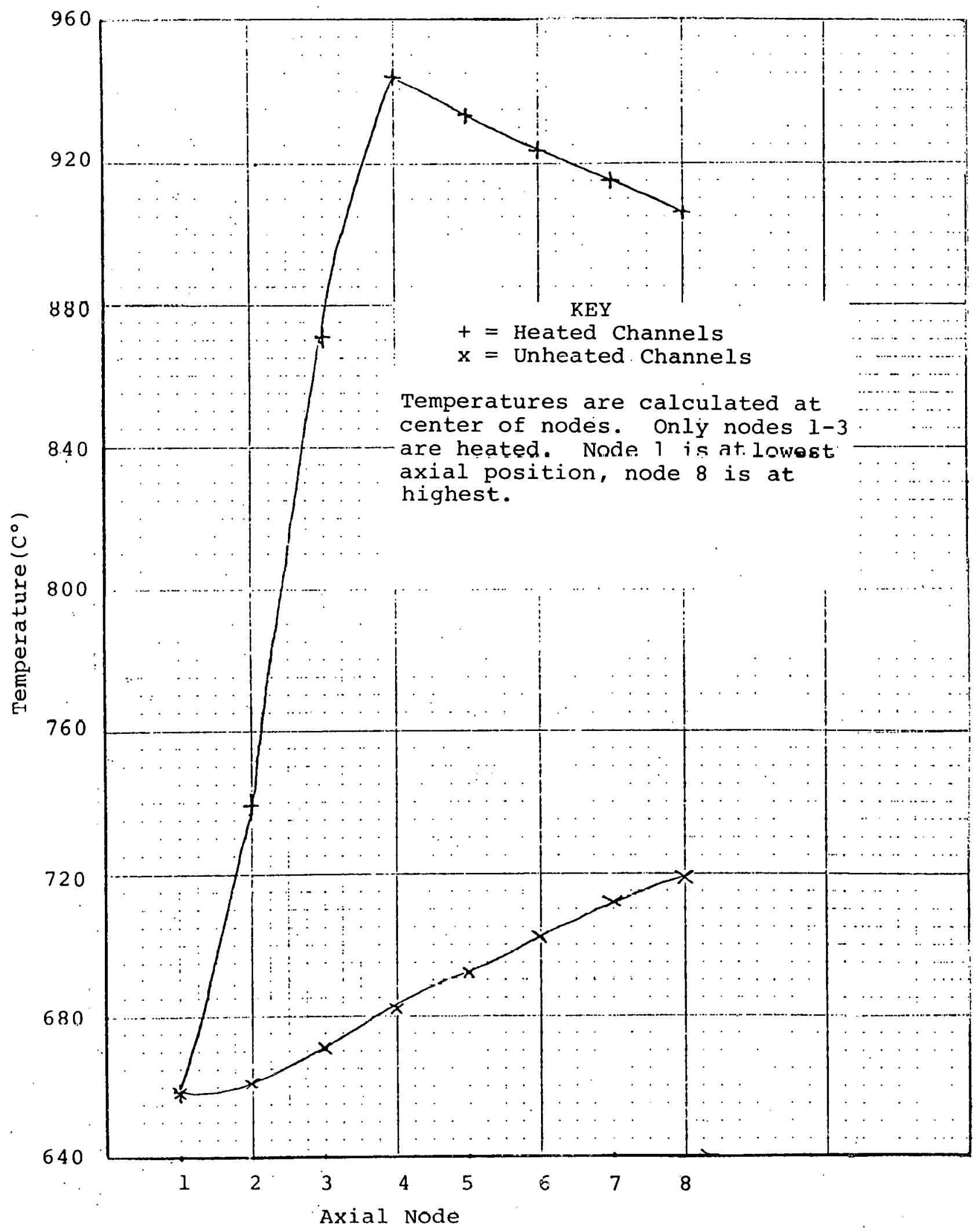

Figure III-2

New Radial Heat Conduction Model - Results of Four Channel iest Case 
The second test case was of an entirely different nature. The axial and transverse velocities were intially set at zero, and the fluid was unheated, but there was a temperature variation between channels. Figure III-3 shows the geometry of the run. Once again, the transverse velocities were kept at zero. Slight axial velocities were introduced by the thermal expansion and contraction in each channel. Because of these small axial velocities, some heat was carried out of the system, so the final equilibrium temperature was about $632.60{ }^{\circ} \mathrm{C}$, instead of the predicted $633.33^{\circ} \mathrm{C}$. The temperature variation with time is plotted for a corner, side, and center channel in Figure III-4. As shown, all channels went towards a single equilibrium temperature as time progressed.

These two test cases show that the radial heat conduction model implemented in THERMIT works satisfactorily: Accuracy could be increased if some correlation were developed to calculate the Nusselt Number, instead of considering it constant, as the code presently. does. 


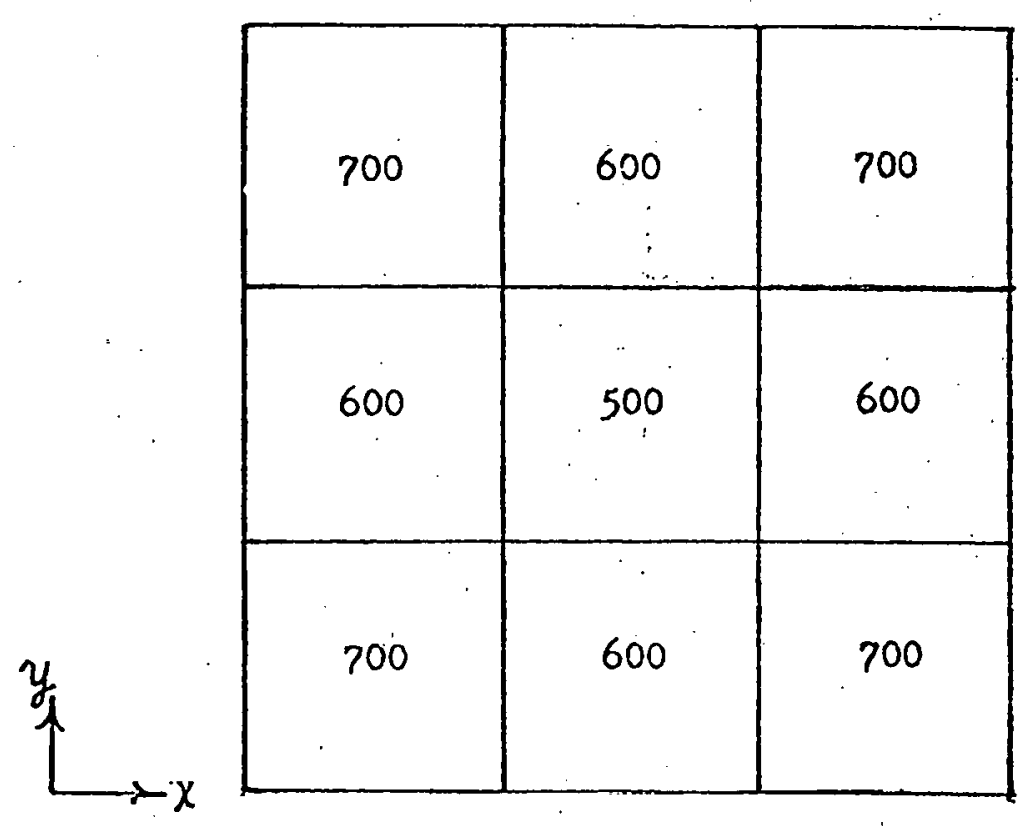

(Numbers indicate initial temperatures in channels in ${ }^{\circ} \mathrm{C}$ )

Figure IIİ-3

New Radial Heat Cunduction Model Geometry for Second Test Case 


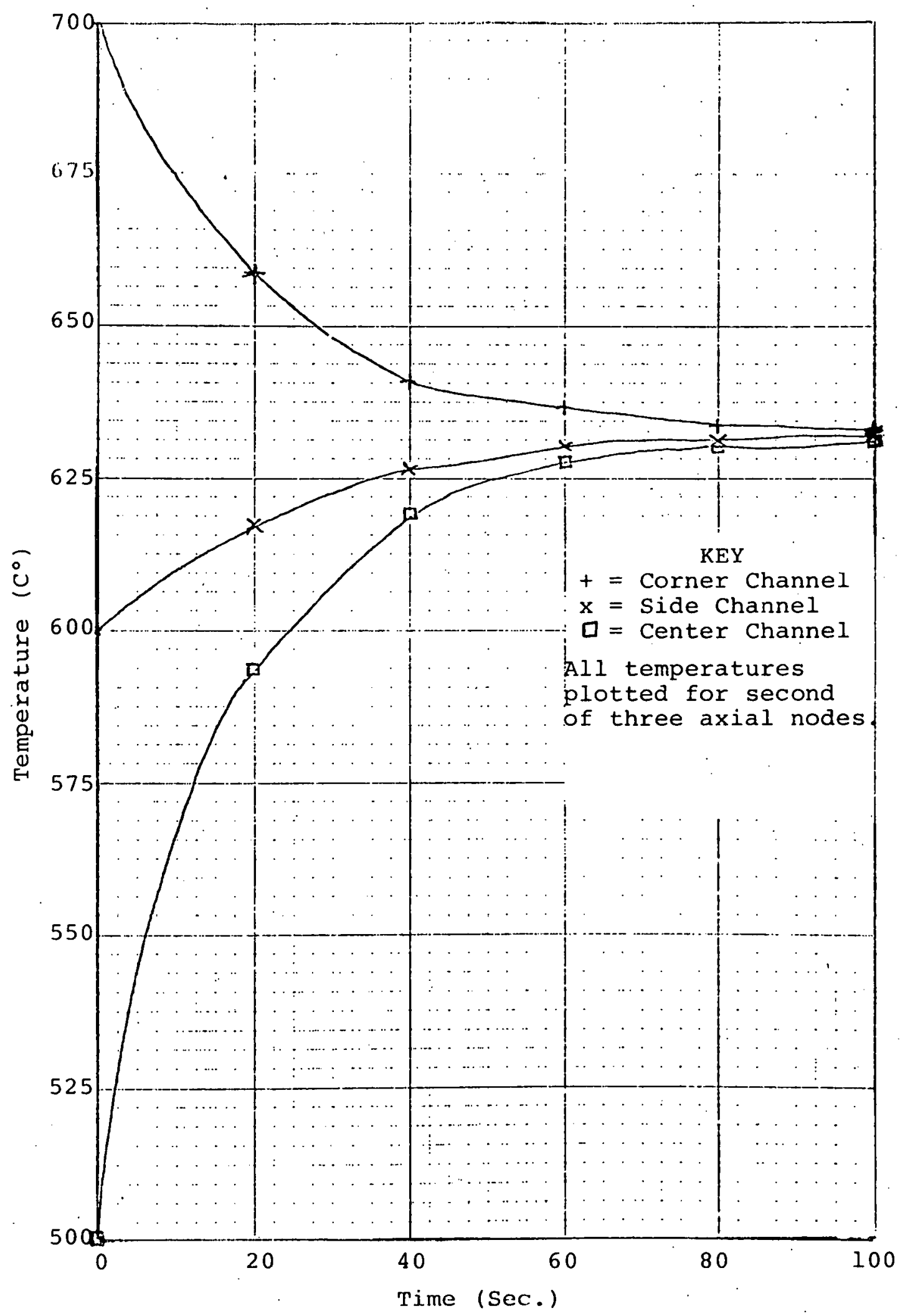

Figure III-4

New Radial Heat Conduction Model Results of Second Case 
E. Code Testing and Application

1. THERMIT Ánalysis of THORS Test $71 \mathrm{H}$ Run 101

THORS Bundle $6 \mathrm{~A}$, Test $71 \mathrm{H}$ Run 101 has been analyzed with the preliminary sodium version of THERMIT. This experiment involved reduction of flow to an electrically heated rod bundle test section designed to simulate part of a liquid metal fast breeder reactor (LMFBR) fuel assembly. The test was characterized by multidimensional two phase flow and time dependent boundary conditions. Results of the test and the analysis with THERMIT are described below:

Test $71 \mathrm{H}$ Run 101 was part of a series of experiments performed at Oak Ridge National Laboratory (ORNL). (Ref. 10). The test section consisted of a triangular array of 19 heater pins housed in a hex can wrapped with insulation to reduce heat loss to the surroundings (see Fig. III-5). Each heater pin consisted of an electrically heated section and a simulated fission gas plenum section. The test section is shown in Fig. III-6. The inlet mass flow rate was ramped down over a period of seven seconds to a final value of one-third the initial steady state value.

Some of the flow variables recorded during the experiment are shown in Fig. III-7. These graphs indicate that boiling and flow reversal occurred several seconds after the bottom of the flow ramp was reached. An inspection of the test section at the end of the experiment revealed that sodium had leaked through the hex can walis and soaked the Marimet insulation. 


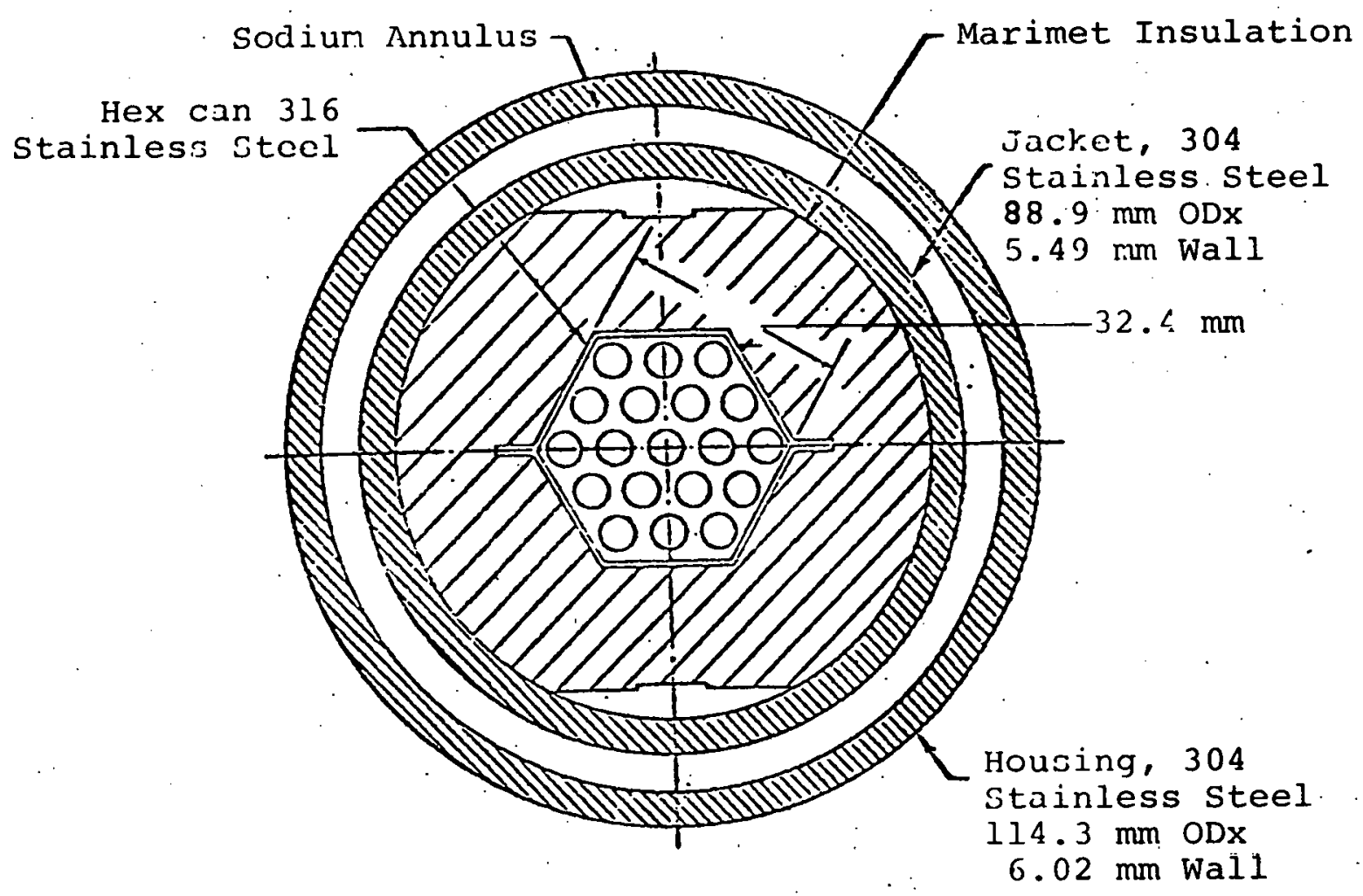

Figure III-5

Cross Section View of THORS Bundle 6A Test Section (ORNL DWg. 78-6760R) 


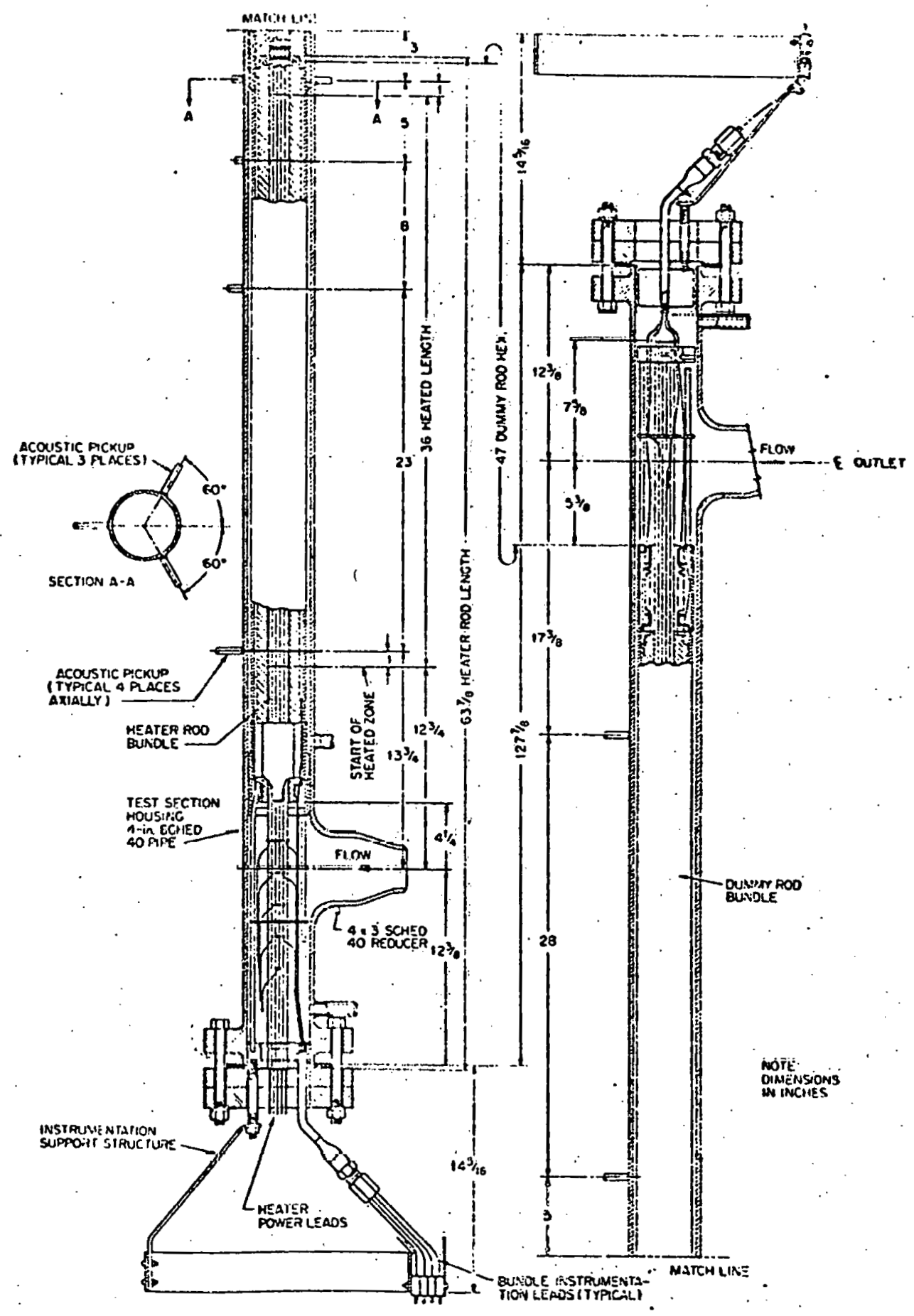

Figure III-6

Axial Dimensions of THORS Bundie 6A Test Section

(ORNL DWg. 74-5.321) 

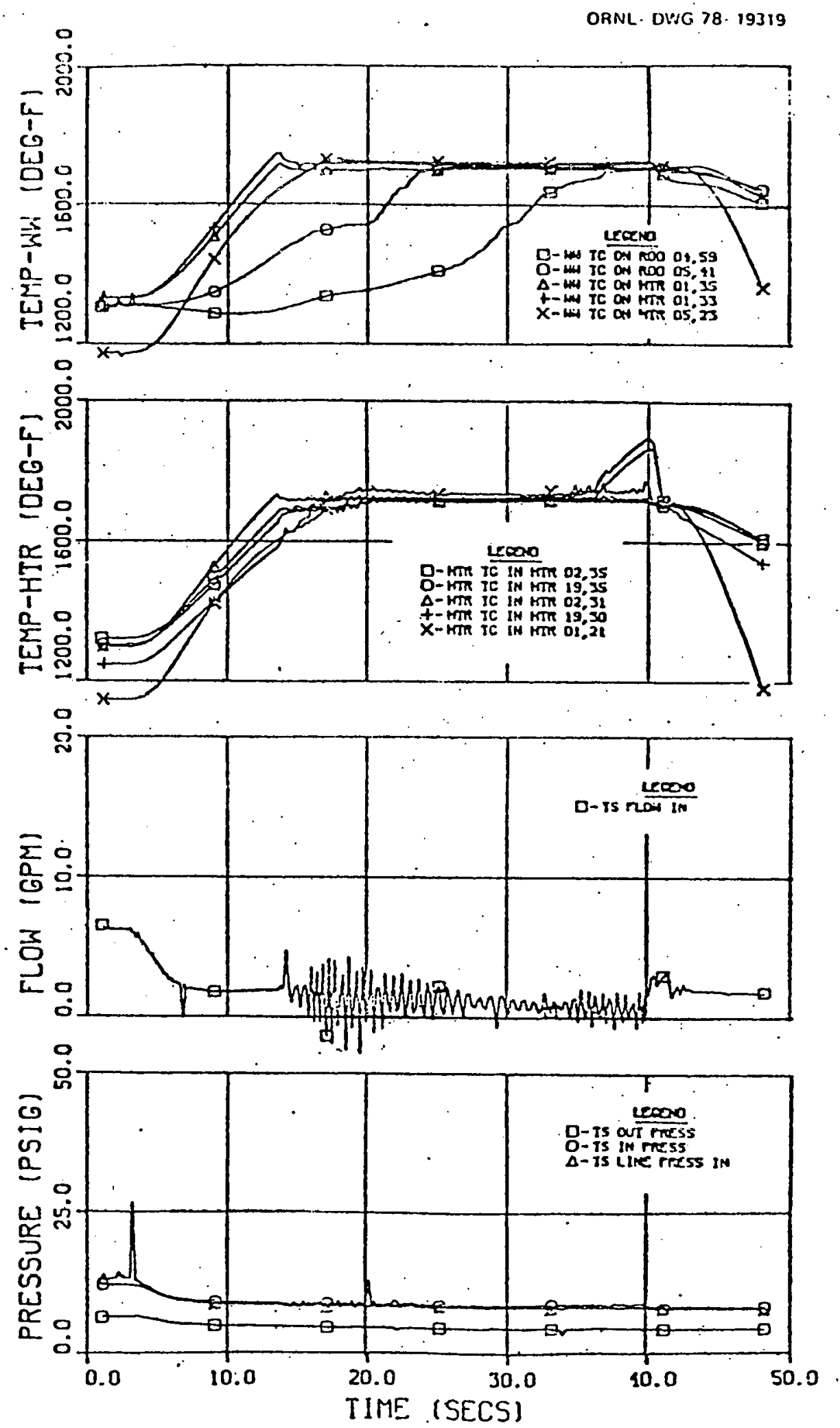

ligure trit-7

Measured l'low Variables from Illlors Burdle $6 n$ Test 71H, Run 101 
This wetting led to a change in the thermal inertia of the hex can structure and is believed to have had a significant effect on the thermal response of the coolant during the transient.

The THERMIT predictions made to date have been primarily intended to verify that the code is correctly predicting first order effects such as axial temperature rise, pressure drop and void progression. With this in mind, the porous body nodalization has been fairly coarse. The fuel assembly was represented as a single channel with eight equal length axial zones. A finer nodalization could have been used to provide greater detail of local conditions, but at the time it was felt that increased computational costs were not warranted. The boundary conditions for the single channel case were taken from the experiment and are shown in Figures III-8 and III-9. In the region where flow oscillations occurred the velocity used was the averaqe velocity.

Initially, the code was run with three different hex can models to determine the model that best represented the heat loss to the sodium soaked hex can. The models were: no heat conduction to hex can structure, heat conduction to hex can structure with Marimet insulation dry, heat conduction to hex can structure with Marimet insulation sodium soaked. Figure III-10 shows the measured temperature six inches downstream of the heated section at a radial location representative of the coolant average temperature. 


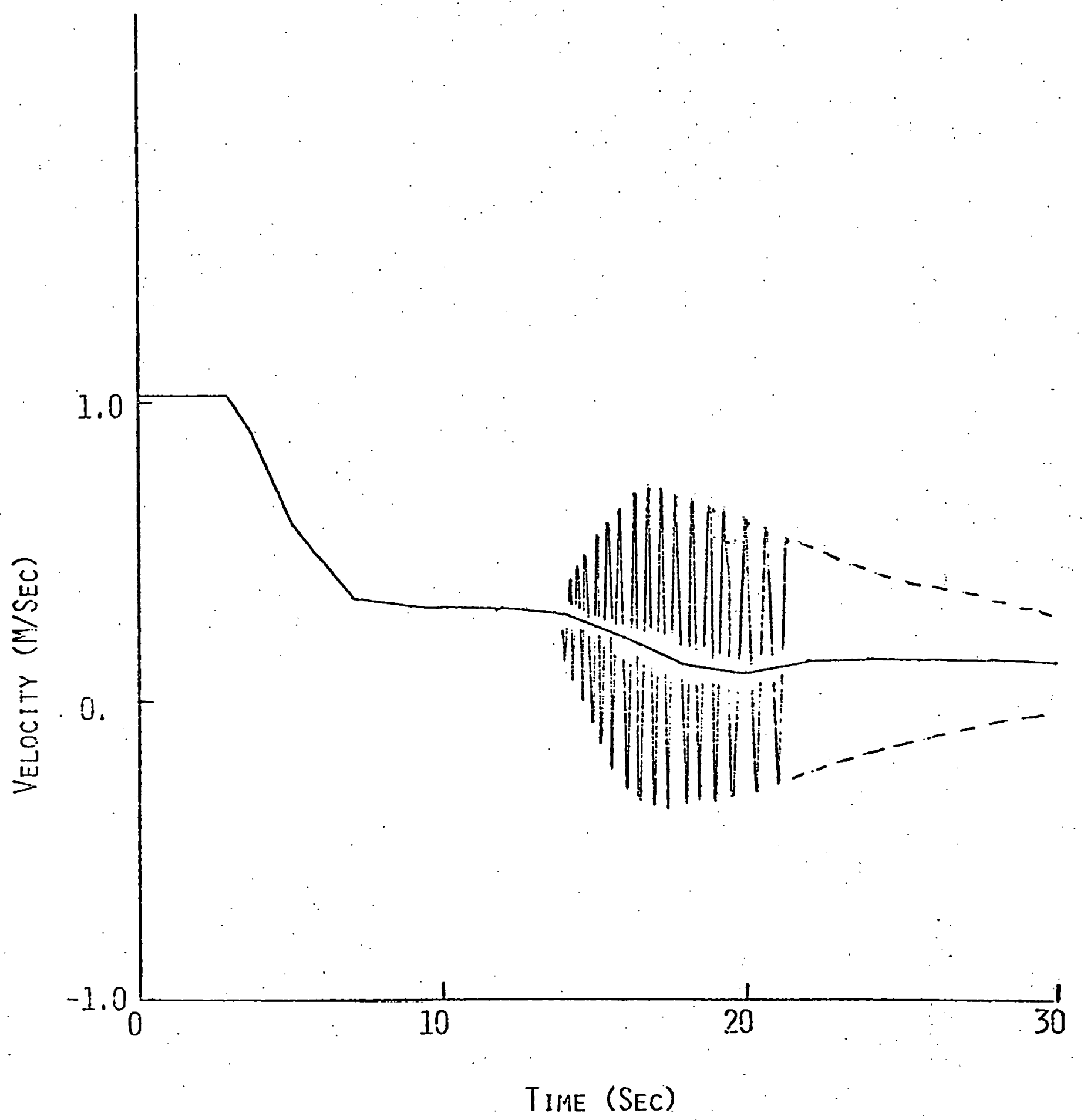

Figure III-8

Bottom Boundary Condition: Inlet Velocity to THORS Bundle 6A, Test $71 \mathrm{H}$, Run 101 
I I I-28

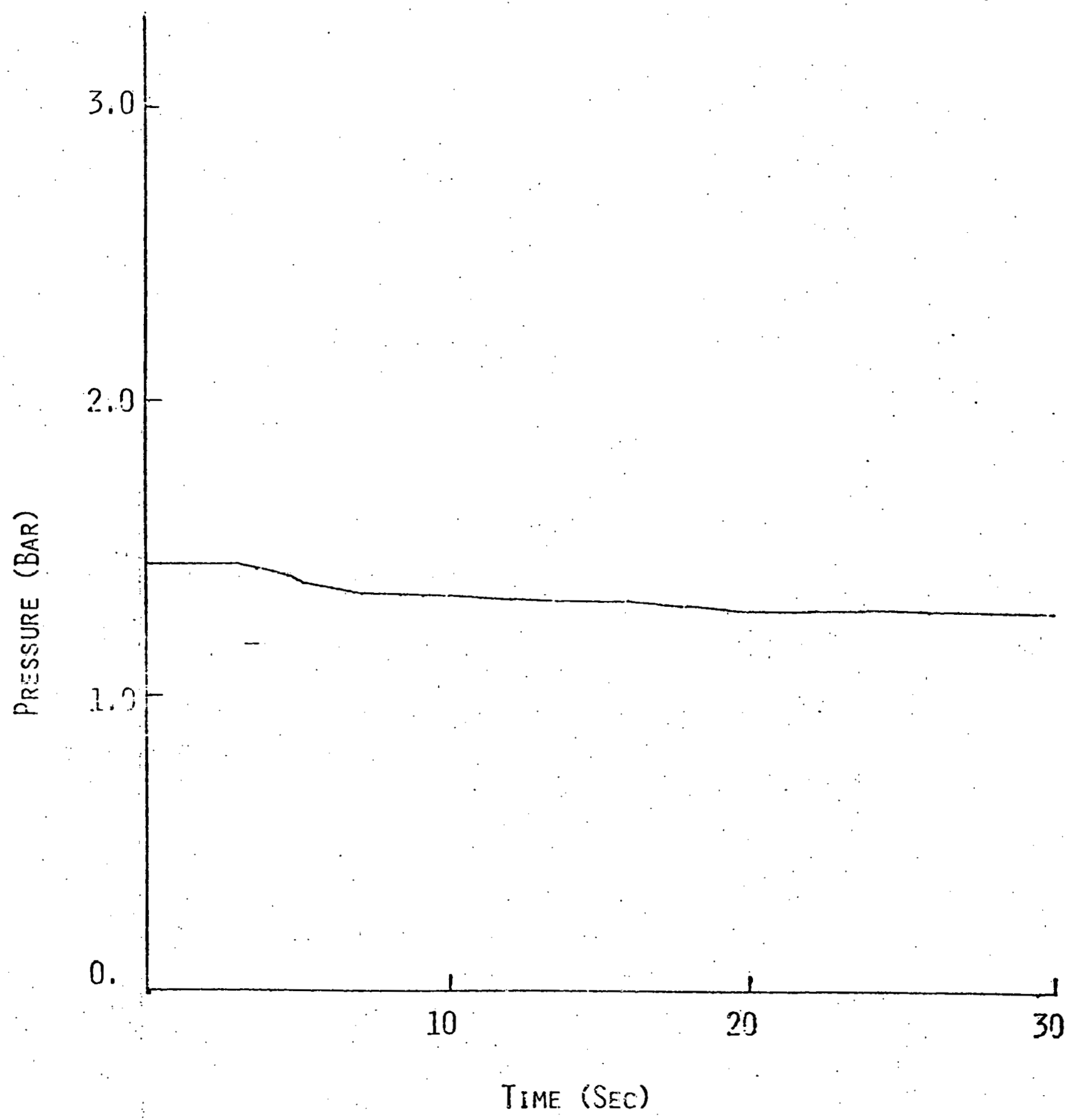

Iigure III-9

Top Boundary Condition: Cutlet Pressure from THORS. Bundle $6 \mathrm{~A}$, Test $7 \mathrm{H}$, Run 101 


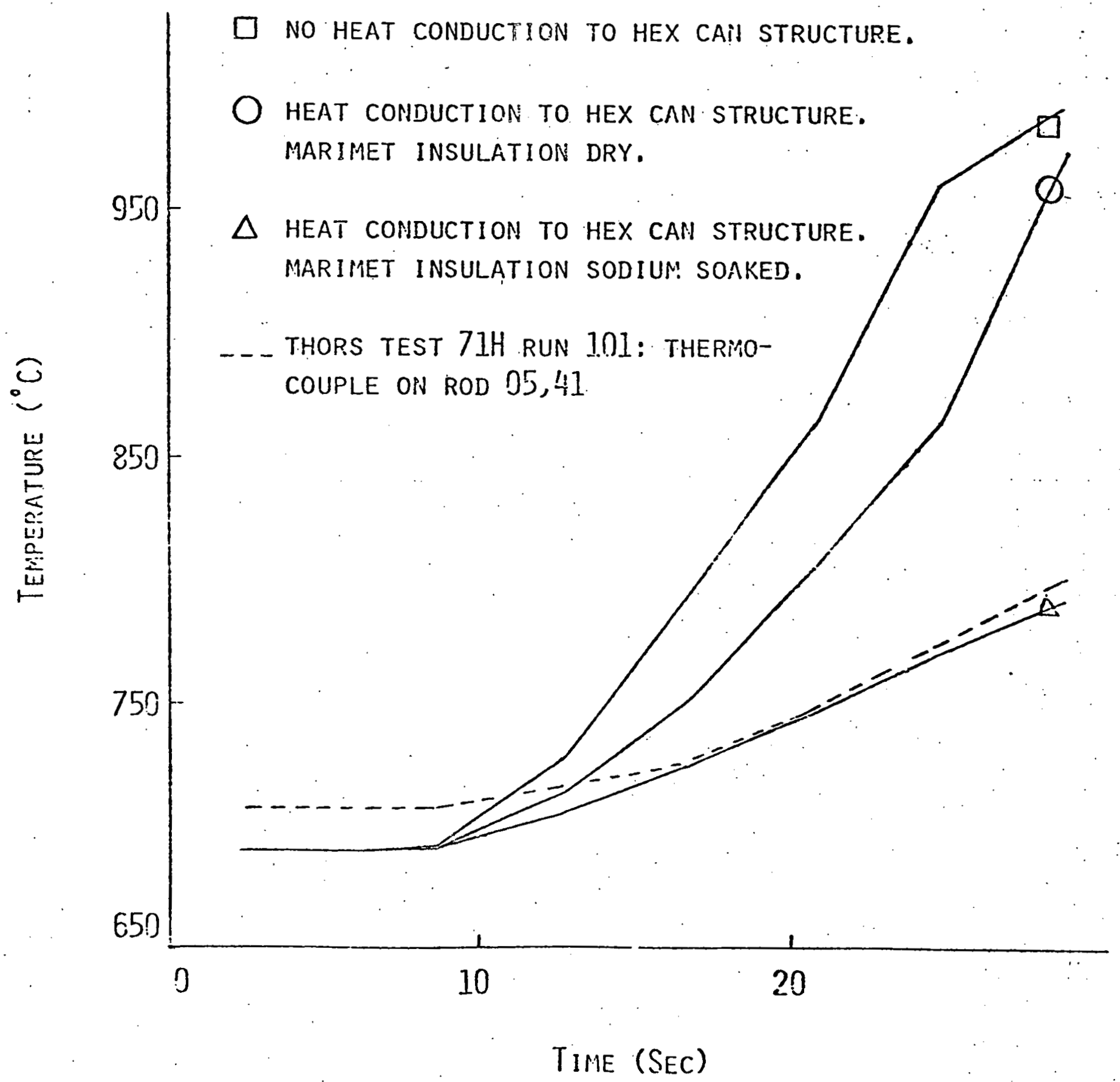

Figure III-10

'lemperature Prediction six Inches Downstream of lleated section outlet for Thors Bundle $6 \mathrm{~A}$, 'lest 7111 Run 101, for Three Different Hex Can Models 
This temperature is compared with the temperature predicted by the code using each of the three hex can models with the fuel assembly represented as a single channel. Figure III-10 shows that the error in the predicted temperature is a minimum for the sodium soaked hex can model. This model was therefore used in the THORS simulation that followed.

The single channel nodalization of the fuel assembly did not provide the spatial detail necessary to predict the time of boiling inception accurately. The value predicted by the code was 2.7 seconds late. Figure III-11 shows the experimental temperature distribution in the subassembly 1.3 seconds after boiling inception. The heat loss to the hex can results in more than $200 \mathrm{~F}$ of subcooling in the periphery of the fuel assembly while conditions in the center are saturated. It follows that a single channel representation would be expected to overpredict the time to boiling initiation, since the average enthalpy is being used to predict boiling instead of local enthalpy. To obtain a more accurate prediction of boiling inception the simulation must be made with a finer radial mesh. In this case the symmetry in the bundle power and geometry requires that only a single quadrant of the subassembly need be represented.

The axial development of the boiling zone is shown in Figure III-12. This figure compares the onset of saturated conditions predicted by the single chanel run of THERMTT to the onset of boiling observed in the experiment. Note that the simulation curve lags the experimental curve in the region 


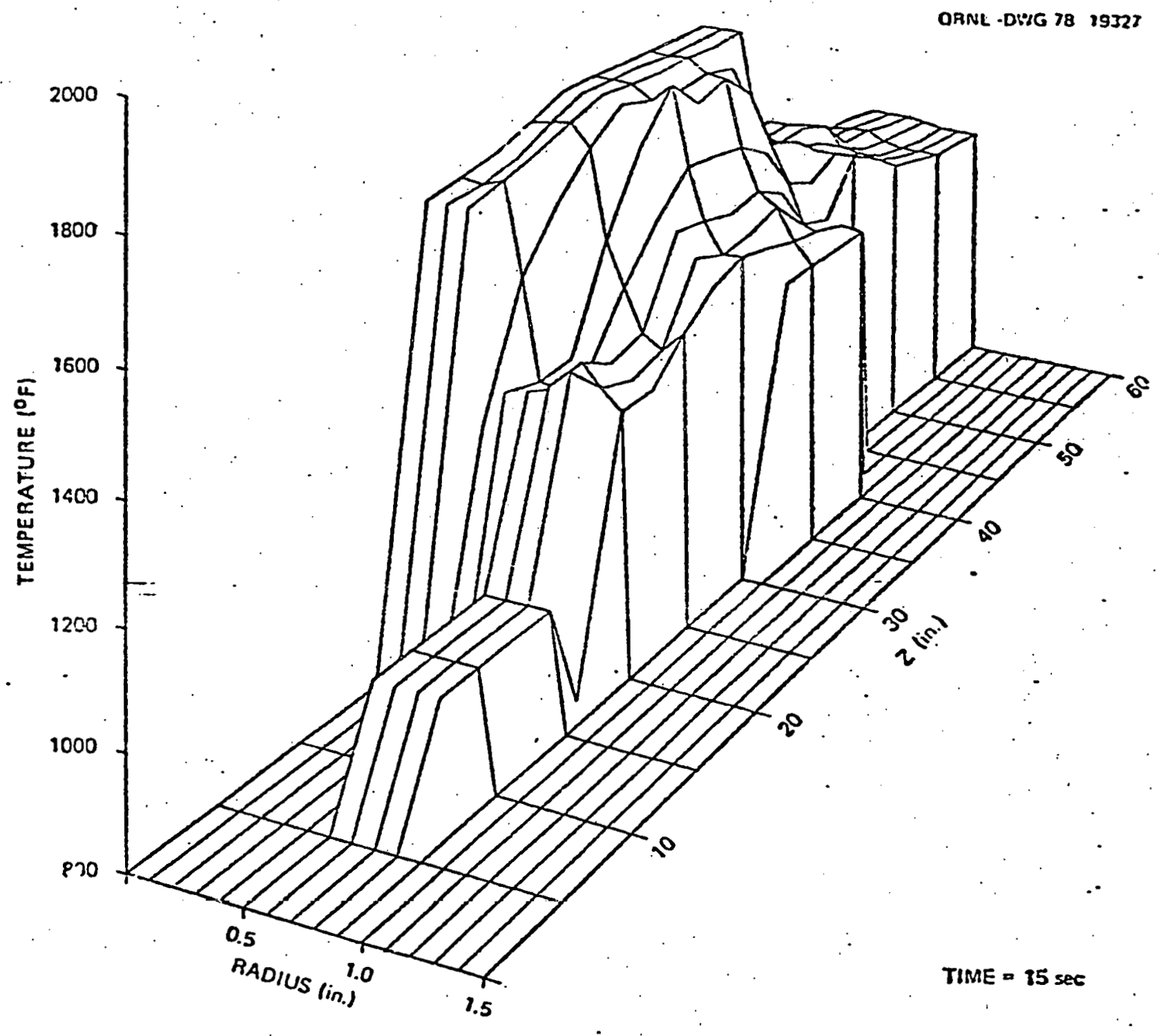

Figure III-1I

Temperature in the Test section as a Function of Axial and Radial Position at 15 Seconds for THORS Bundle 6A, Test 71H, Run 101 


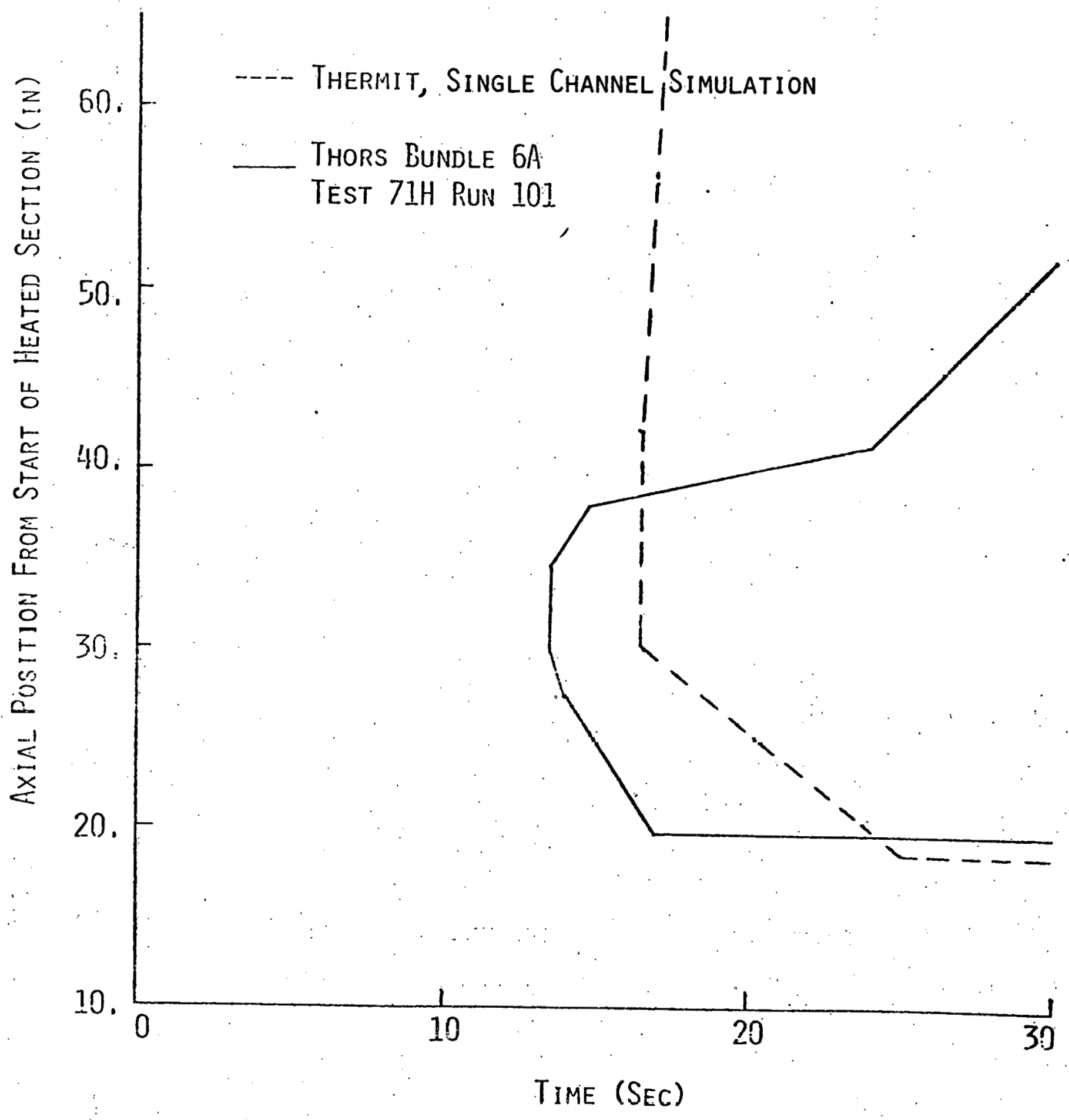

Figure III-12

Comparison of Predicted anà observea Development of Saturation Conditions in Test Section, THORS Bundle 6A, Test $71 \mathrm{H}$, Ruri 101 
20 to 30 inches from the start of the heated section. This discrepancy results from the fact that the single channel nodalization results in the time to boiling being overpredicted, as discussed above. The curves differ downstream of the heated section, for a different reason. Physically, the heat capacity of the fission gas plenum section inhibits the progression of boiling down the subassembly. In the simulation however, the heat capacity of the plenum was assumed to be: zero, causing a more rapid progression of boiling down the assembly than observed in the experiment. The plenum heat capacity was nelgected because the present version of the code does not have the capability of modelling axial variations in fuel pin properties. Therefore, it was decided that the heated section of the fuel pins would be modelled correctly and the heat capacity effects in the plenum nelgected by turning off the heat transfer to this region.* Figure III-13 gives a different view of void progression in the single channel simulation.

When the simulation reached steady state two-phase flow, the axial pressure gradient along the channel was considerably steeper than observed in the experiment. Consequently saturation temperatures predicted by the code were greater than found in the experiment. This effect is responsible for the jump in the simulated temperature seen in Figure III-14. This result suggests the code may be overestimating two phase friction.

* The code has an option for doing this in each axial zone of a fuel pi.n. 


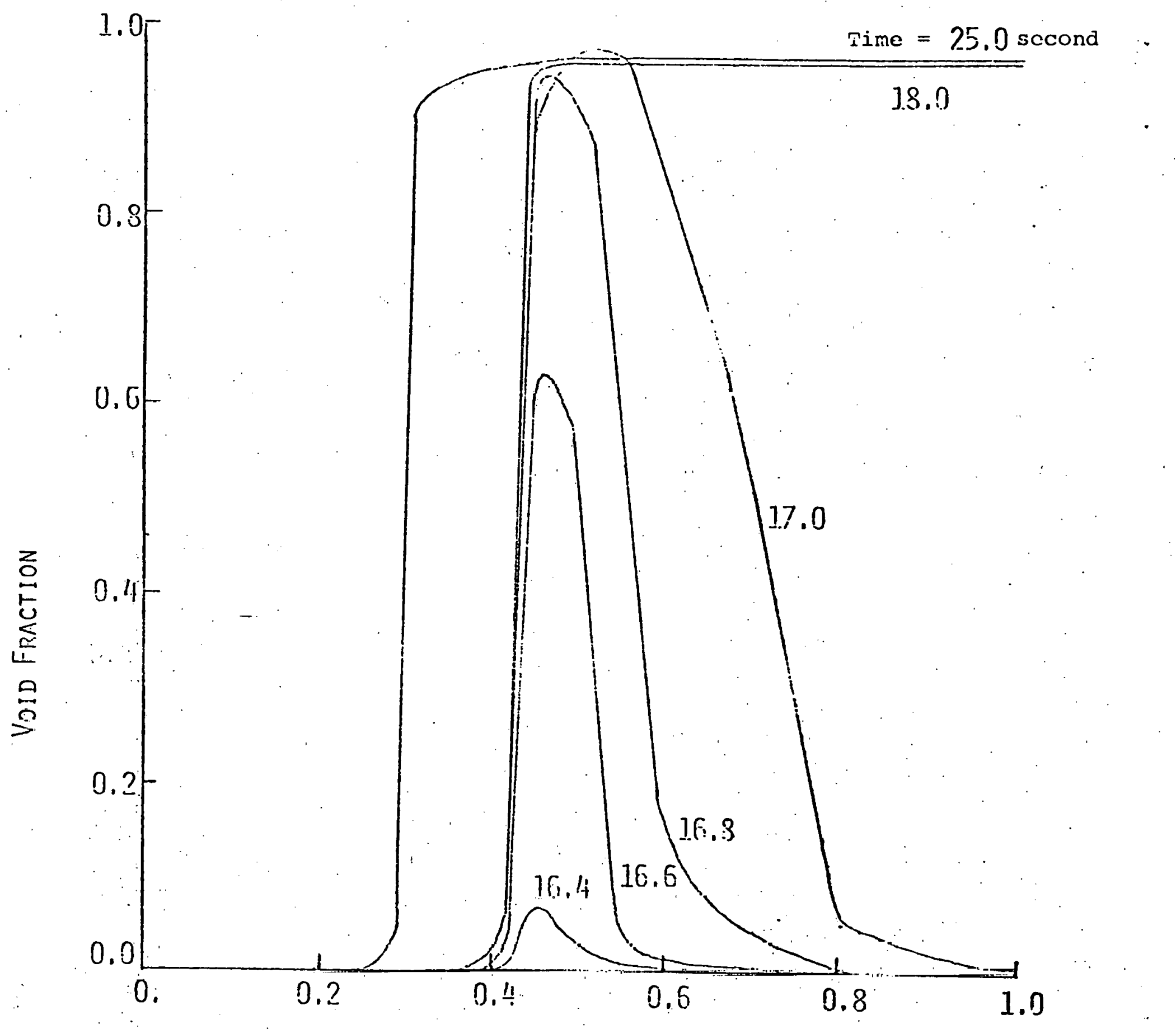

Fraction of Test Section Axial Height

Figure III-13

Growth of Void Fraction in Test Section as Predicted by single Channel Simulation, THORS Bundle 6A, Test 71H, Run 101 


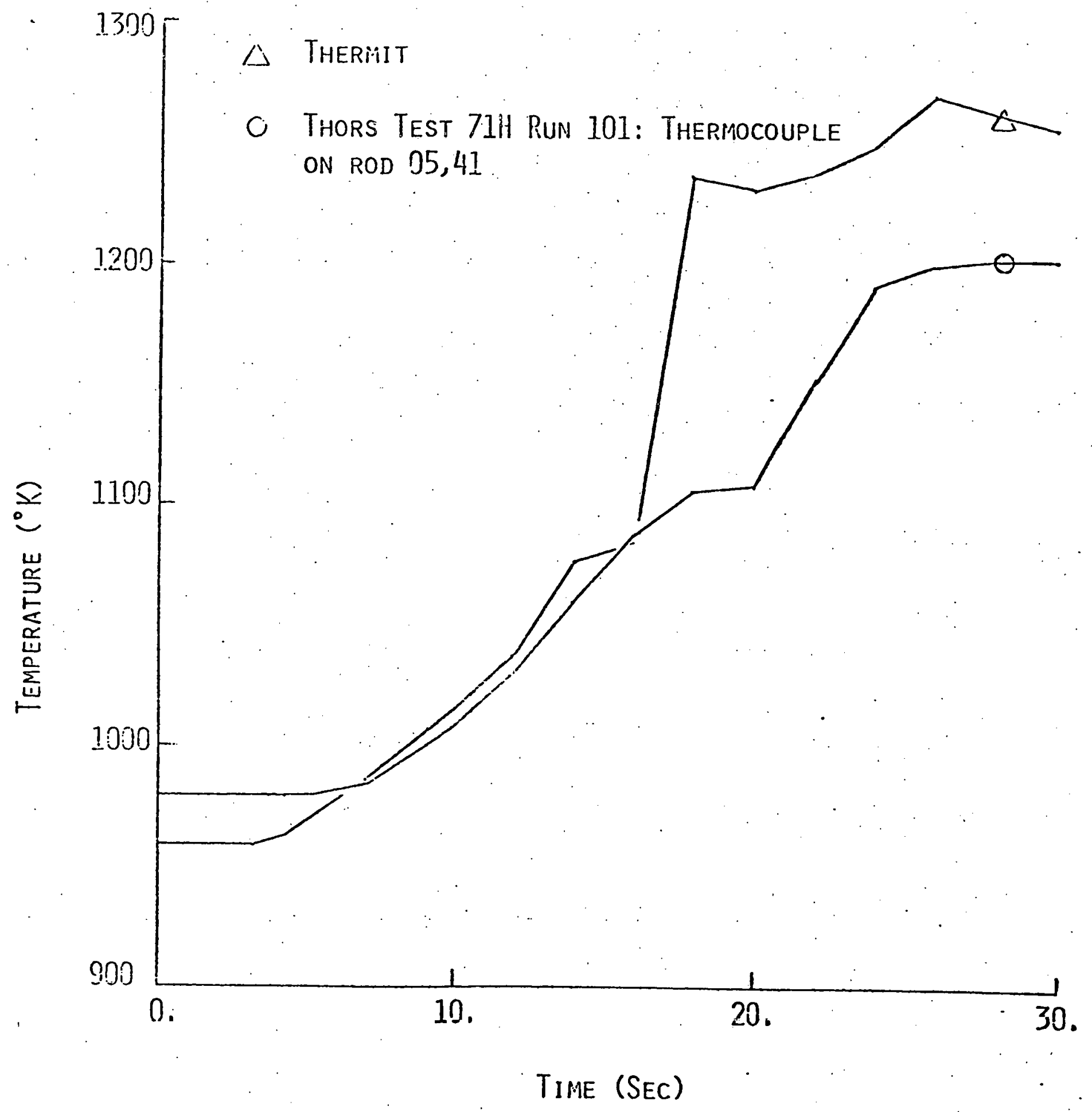

Figure III-14

Temperature Prediction Six Inchos Downstream of lleated section Outlet for 'lllors Bundle $6 \Lambda$, 'lest 7lll, Run 10l. 
2. NATOF-2D Analysis of SLSF-P3A Experiment

As part of the qualification testing of NATOF-2D, the code was used to simulate the SLSF-P3A experiment (Ref. 11). This was an in-pile experiment designed to investigate the early phase of the LOF without scram event. The experiment was conducted using a 37-pin bundle. See Ref. 11 for further details.

The results obtained with NATOF-2D are compared with the experiment in Table III-1 and Figures III-14, 15 and 16. Table III-1 summarizes the significant timing of events. Figure III-14. shows the evolution of temperatures at the top of the heated zone. Figure III-15 shows the axial variation of coolant temperature for different times, and Figure III-16 shows the void maps at three different axial locations.

From these results, it can be seen that the present version of the code predicts the time of boiling inception and flow reversal very well, but somewhat overpredicts the amount of superheat at large values of the void fraction. 


$$
\operatorname{III}-37
$$

\section{Table III-1}

Event sequence Times as Predicted by NATOF-2D

for SLSF-P $3 A$ Experiment

\section{Experimental Data}

Boiling Inception

Boiling at DAS 23 (35.7", interior)

Boiling at DAS 12 (32.7", edge)

Inlet Flow Reversal

$$
8.8
$$$$
8.8
$$

10.0

9.8

10.0

9.8

10.15

9.8 


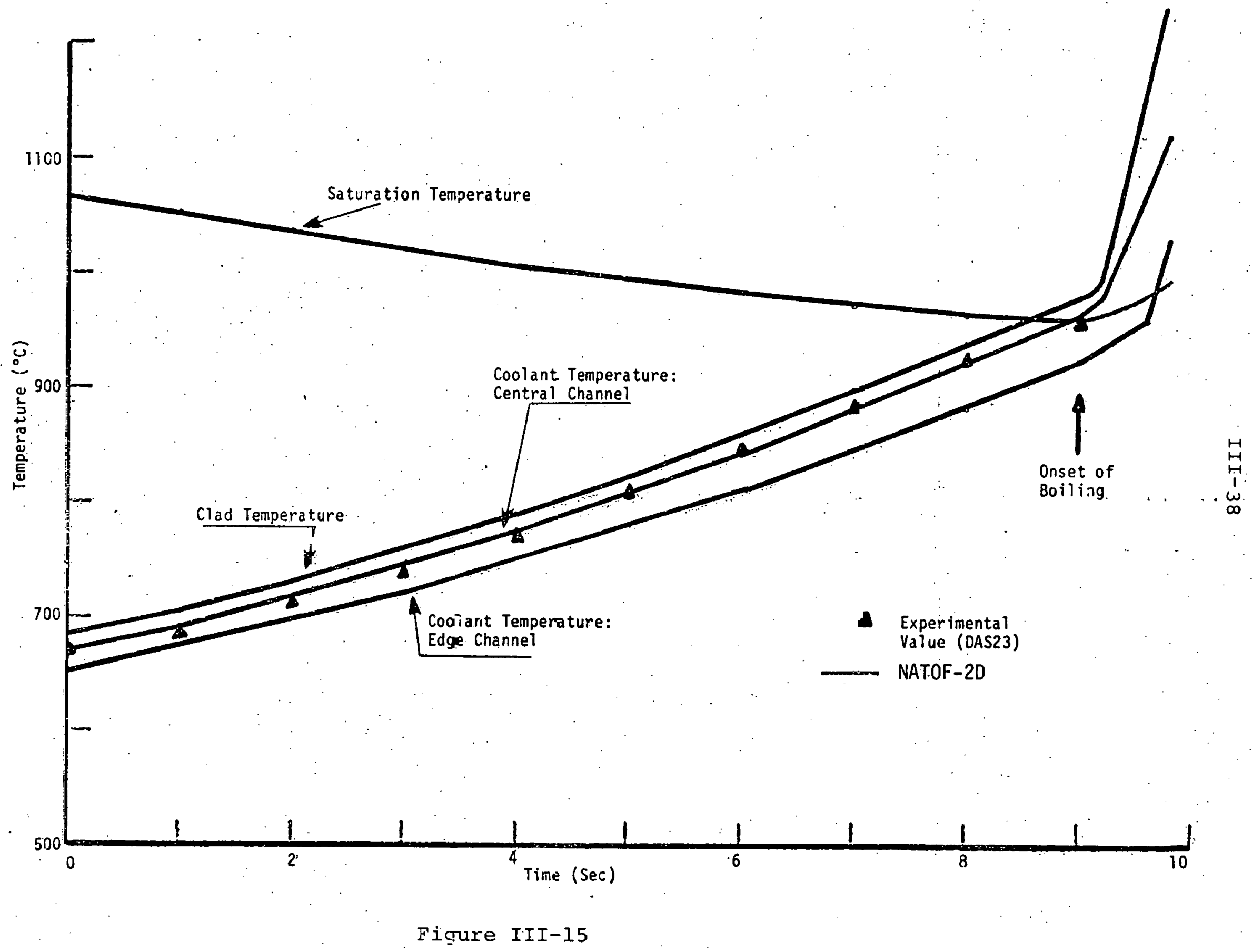

NATOF-2D Preciction of Temperatures at Top of Heated-Zone vs. Time for SLSZ-P3A Experiment 


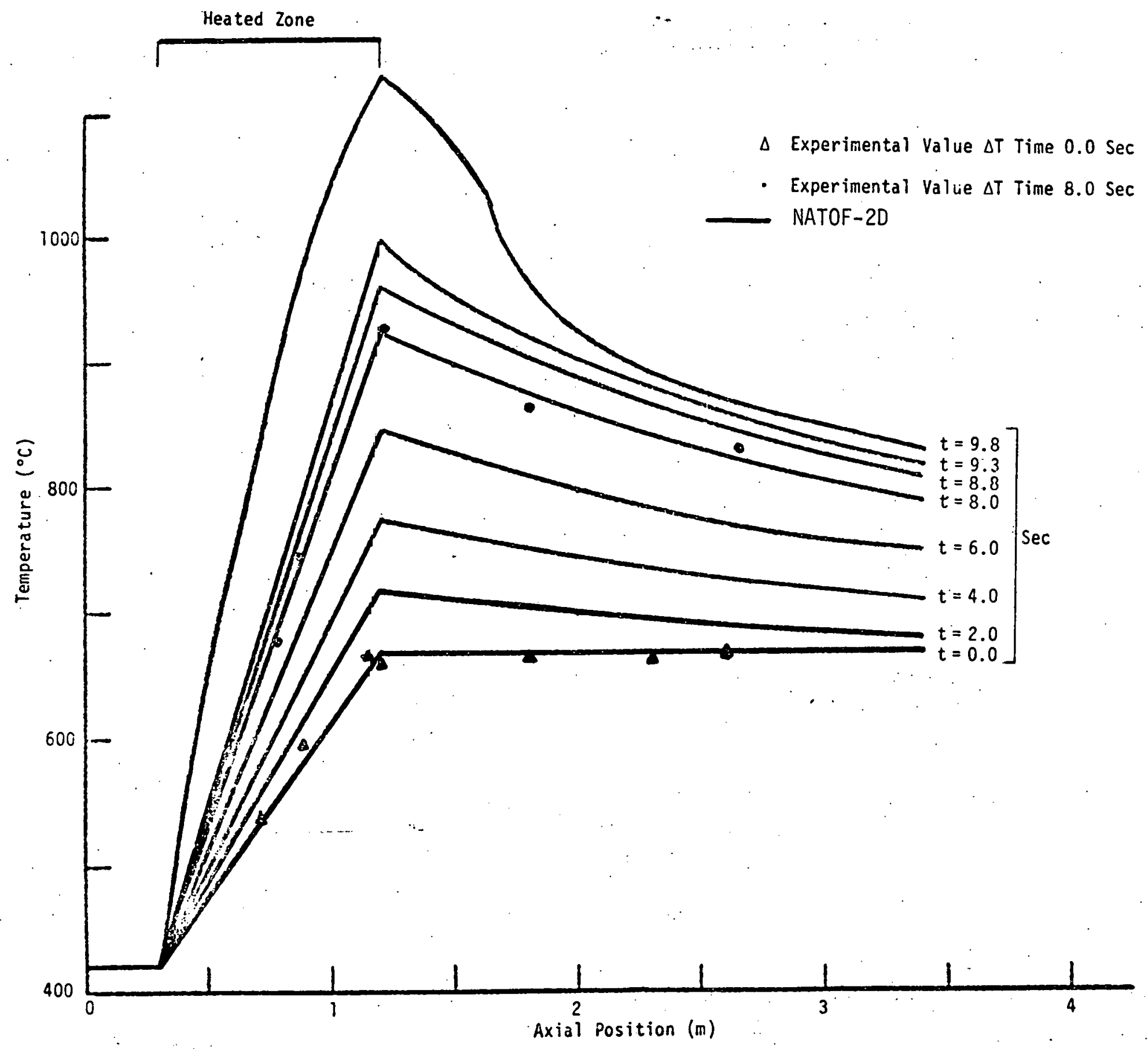

Figure III-16

NATOF-2D Preciction of Axial variation of Coolant Tcmpcrature at Various Times for SLSF-P3A Experiment 

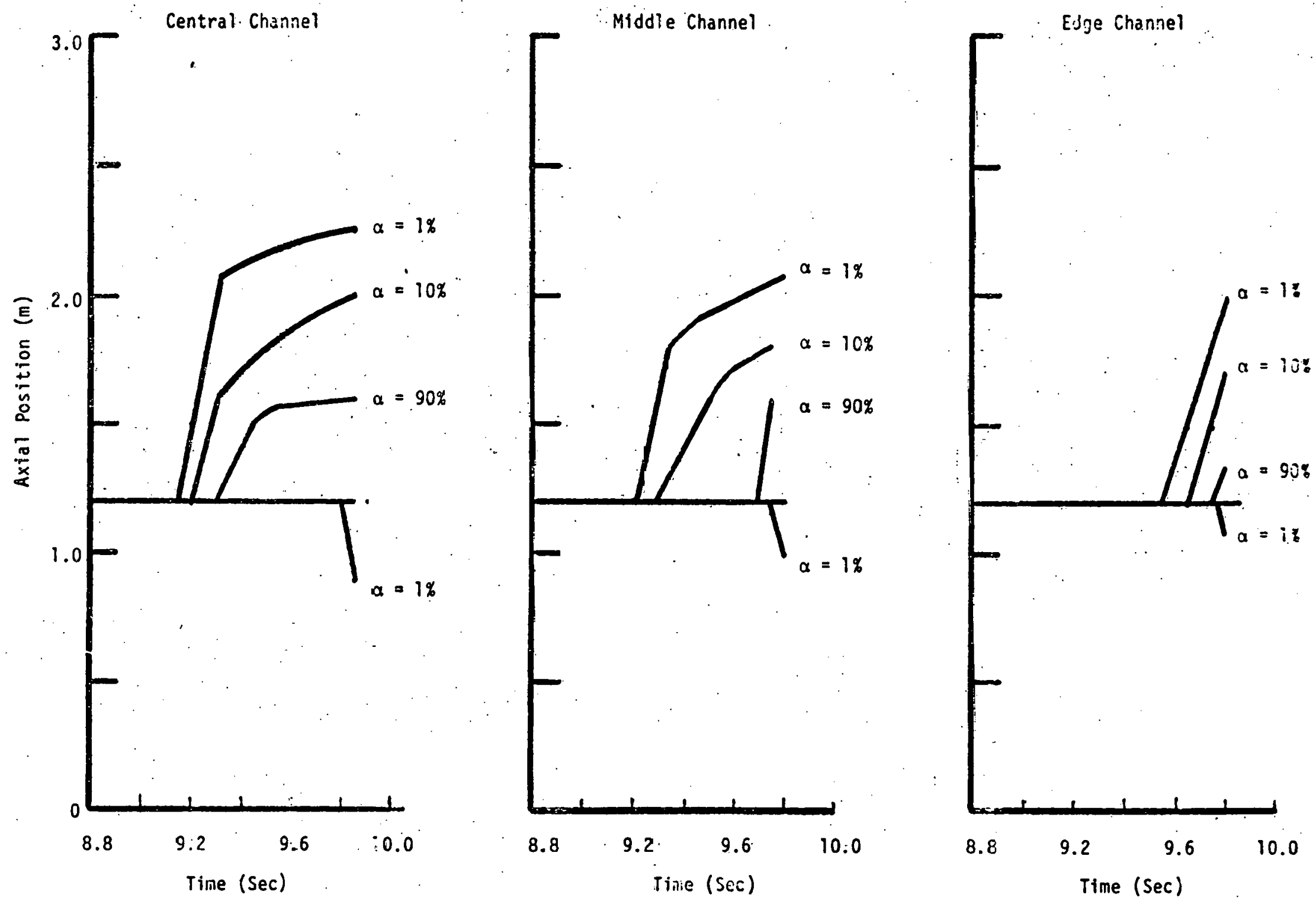

Figure III-17

NATOF-2D Void Predictions vs. Time at

Three Different Axial Positions for SLSF-P3A Experiment 
F. Summary-Present Status and Plans for FY1980

1. Work Completed During FY1979

a. Adaptation of THERMIT

1) Modified code to enable XYZ porous body cell representation of LMFBR hexagonal arrays. (Modified code to accept radially variable heated and wetted equivalent diameters.)

2) Added model to represent THORS type boron nitride heater.

3) Began modifying fuel rod model to incorporate material porperties and gap conductivity correlations appropriate to LMFBR $\left(\mathrm{UO}_{2} / \mathrm{PuO}_{2}-\mathrm{SS}\right)$ fuel rods.

4) Began modifying fuel rod model to allow representation of plenum/blanket regions (axailly varying fuel rod properties).

5) Added model, to represent hex can (including case of sodium-soaked insulation encountered in THORS Bundle 6 Tests).

6) Replaced fluid property correlations for water with correlations appropriate to sodium.

7) Modified code to reduce CPU time required to calculate steady state conditions. (Converted code to double precision and provided option to suppress transverse flow during approach to steady state.).

8) Developed and added input geometry preprocessor to reduce time required to prepare code input.

9) Developed and added bilinear temperature field interpolation scheme (to facilitate comparison of THERMIT results with codes using triangular grid or with thermornuple readings in tests.) 
b. Development of NATOF-2D

1) Developed code structure and numerics to a point comparable to that of THERMIT.

c. Development and Implementation of Constitutive Equations and Models

1) Developed and implemented new, flow regime dependent expressions for $A$, the interfacial area for mass exchange in the equation for $\Gamma$, the phase change rate.

2) Mudiried THERMTil and NA'IU'-2I) to include $\Gamma$ in the z-direction momentum equations.

3) Developed and implemented new correlations for interphase momentum exchange $(K)$, liquid wall friction $\left(F_{w}, l\right)$ and vapor wall friction $(\mathrm{F}, l)$ using experimental results from the KFK experiments in Karlsruhe.

4) Developed and implemented new wall heat transfer correlations for convective two-phase flow in sodium cooled rod bundles.

5) Modified THERMIT and NATOF-2D to include radial heat conduction in the liquid region.

d. Code Testing and Application

1) Used preliminary version of THERMIT to analyze THORS Bundle 6 Test $71 \mathrm{H}$, Run 101.

2) Usen preliminary veroion of NATOF-2D to analyze SLSF-P $3 A$ experiment.

2. Plans for FY1980

a. Adaptation of TIIERMII

1) Complete Subtasks 1.a.3) and 1.a.4). Consider need for incorporating more detailed model.*

*At the November 1979 review meeting, it was agreed that the existing model will be replaced by the HFDL SIEX fuel pin model. 
2) Design and initiate incorporation of output routine which maps and plots axial coolant temperatures and liquid/vapor boundaries, but is not limited to these features.

b. Development of NATOF-2D*

1) Complete development and initial testing of working version of code.

2) Evaluate results of code application and testing vs. THERMIT and decide on further work.

3) Write topical report.

c. Development and Implementation of Constitutive Equations and Models

1) Modify codes to provide user specified superheat capability relative to the internally computed local coolant saturation temperature.

2) Develop and incorporate correlations accounting for the effect of bundle geometry on interphase momentum exchange and wall friction in the transverse direction.

d. Code Testing and Application

1) Test numerical functioning of THERMIT with an appropriate sample problem.

2) Provide user assistance to HEDL regarding options for adding other LMFBR accident modeling features related to the TOP analysis.

3) Assist GE in the application of THERMIT to the interpretation of the LOPI and Boiling window tests from the SLSF-WI experiments.

4) Assist $\mathrm{GE}$ in determining the sensitivity of THERMIT results to assumed values of the constants in the numerical models as applied to SLSF-Wl boiling window test predictions.

* Note that work on these subtasks will. not be funded under the: ly1980 program. However, this work will. be completed by $M$. Granziera as part of his SCD thesis. 


\section{III -44}

5) Evaluate and make recommendations regarding the advantages and/or disadvantages of using THERMIT versus fixed regime codes (such as SOBOIL or SAS) for the analysis of the THORS and Wl tests. 
Appendix A

THORS Heater Pin Physical Properties and Geometry

Region

Inner $\mathrm{BN}$

Heater Ribbon

Outer BN

Stainless steel

Cladding

$\begin{array}{llll}\frac{\mathrm{k}\left(\mathrm{w} / \mathrm{m}^{\circ} \mathrm{K}\right)}{15.060} & \frac{\mathrm{C}_{\mathrm{p}}\left(\mathrm{J} / \mathrm{kg}^{\circ} \mathrm{K}\right)}{1750.08} & \frac{\rho\left(\mathrm{kg} / \mathrm{m}^{3}\right)}{1849.98} \\ 69.240 & 154.91 & 21424.26 \\ 19.041 & \ddots & 1750.08 & 1999.91 . \\ 29.427 & 628.02 & 7977.21\end{array}$

Heater Outer Stainless Ribbon BN Steel Clad

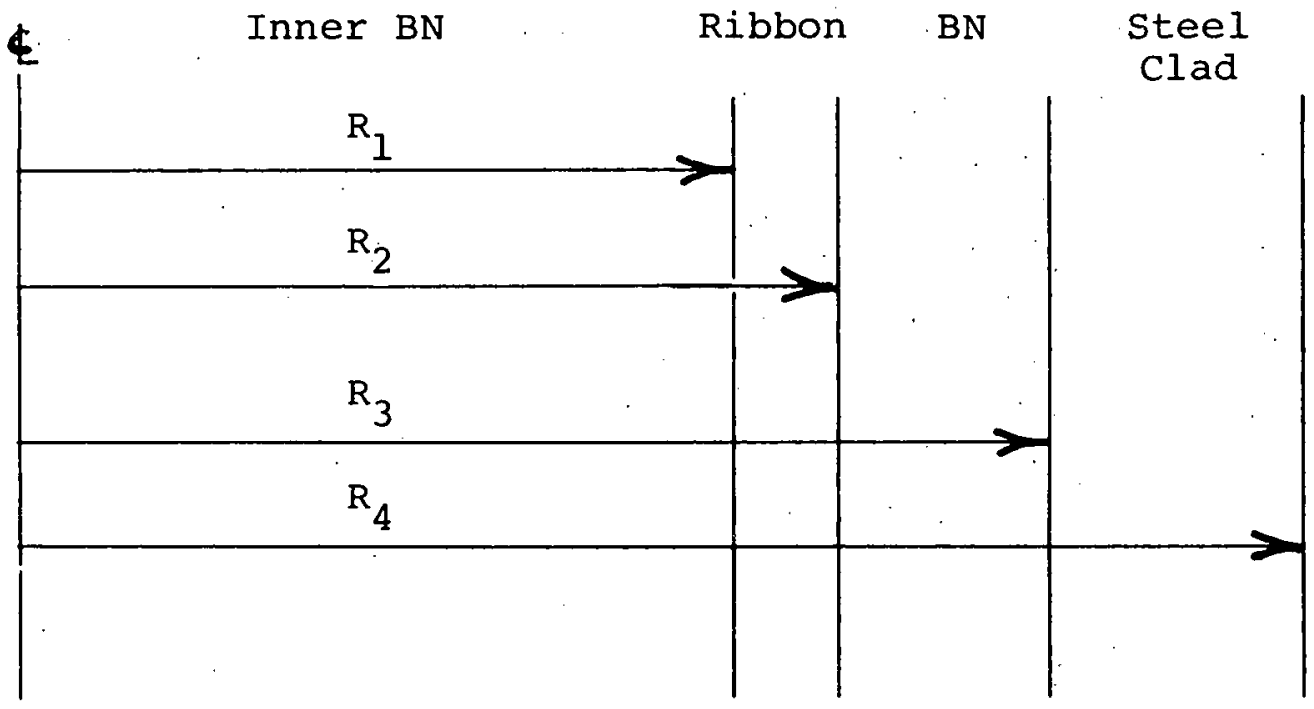

$$
\begin{aligned}
& \mathrm{R}_{1}=8.255 \times 10^{-4} \mathrm{~m} \\
& \mathrm{R}_{2}=1.1684 \times 10^{-3} \mathrm{~m} \\
& \mathrm{R}_{3}=2.54 \times 10^{-3} \mathrm{~m} \\
& \mathrm{R}_{4}=2.921 \times 10^{-3} \mathrm{~m}
\end{aligned}
$$




\section{Appendix B}

Model for Heat Loss to surrounding structure

THERMIT now contains a model which caculates the heat flow between the sodium and surrounding structure. This appendix will describe the model in terms of: 1) the geometry assumed, 2) the boundary conditions applied, 3) the method of solution, and 4) the apportioning of the heat flow among the fluid channels.

\section{B.1. Geometry}

The user sets up the geometrical layout of the structure. The number of radial zones in the structure, the material in each zone, its thickness, and the number of meshes in each zone are all input parameters. (If no radial heat loss is desired the number of zones is set equal to zero.) In addition, the user specifies which of the fluid channels are in contact with the structure, and what the perimeter of contact is, for each channel. For the example shown in Figure B-la, 12 of the 16 . fluid channels are in contact with the structure, which in this case consists of a hex can and surrounding insulation.

In order to assume azimuthal symmetry the code transforms the perimeter of the test section into a circle, keeping the total perimeter constant (see Figure $B-1 b$ ). The sodium in the channels adjacent to the structure is placed in an "imaginary" annulus inside the wall of the structure, with the inner radius of the annulus determined by the total volume of sodium in those channels. The reason for this will be explained in the next section. 
Figure $B-1 a$

Model for lleat Loss to Surrounding Structure - True Geometry

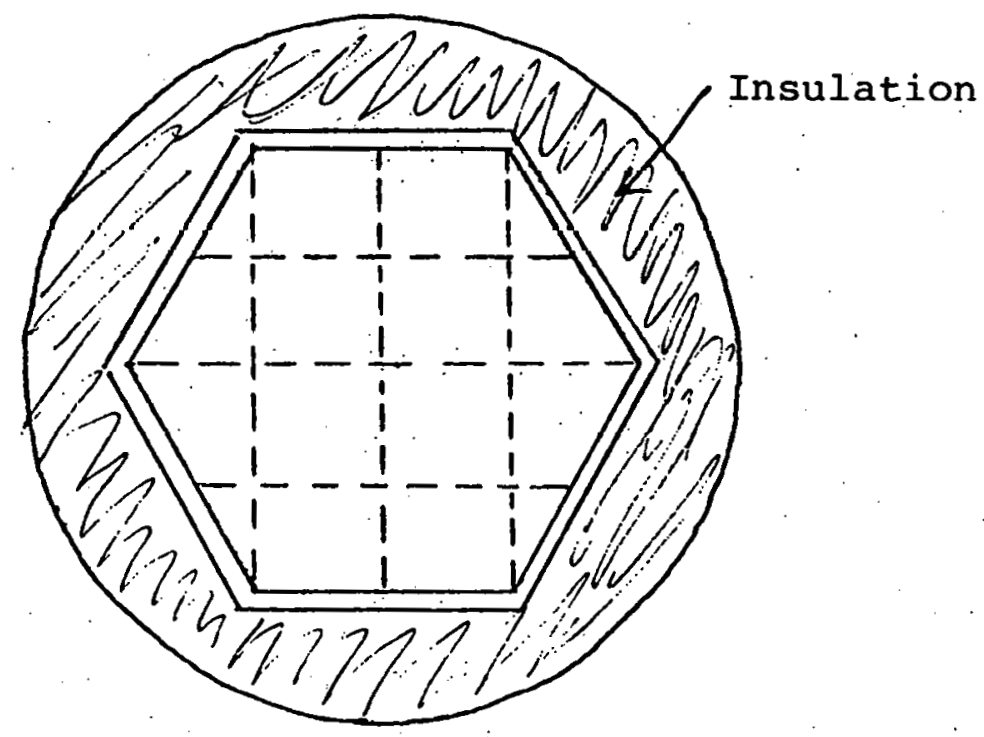

Figure B-1b

Model for Heat Loss to

Surrounding Structure - Assumed Geometry

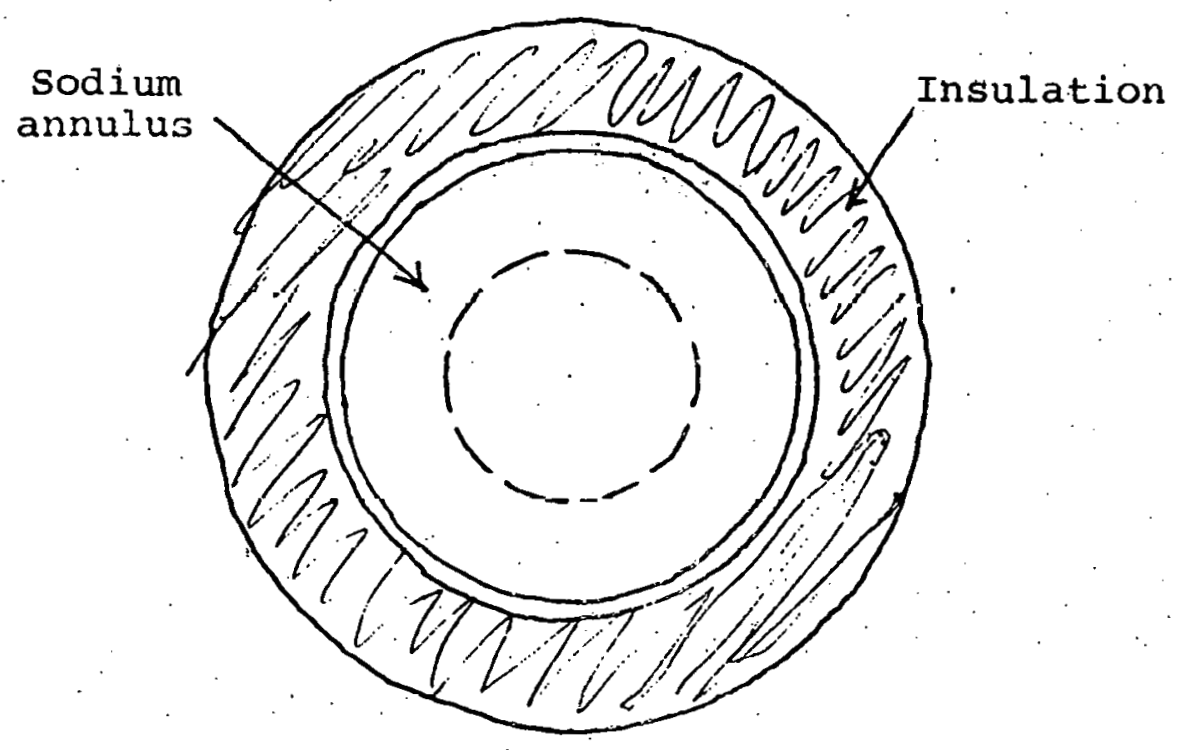




\section{B.2. Boundary Conditions}

In order to solve the conduction equation for the temperature distribution in the structure, the boundary conditions at the inner and outer boundaries are needed. These are provided in the form of a heat transfer coefficient and a temperature.

For the outer boundary the user inputs a constant heat transfer coefficient and a constant temperature outside the structure. Thus the heat flux on the outer boundary will be: $q^{\prime \prime}=h_{\text {out }}\left(T_{\text {out }}-T_{\text {wall, out }}\right)$, where $T_{\text {wall, out }}=$ the temperature at the outer boundary of the structure. If an adiabatic condition at the outer wall is desired, the user should set $\mathrm{h}_{\text {out }}=0.0$.

The boundary conditions at the inner surface of the structure are more complicated because they involve heat transfer between flowing sodium and a stationary structure. First of all, the conditions of the sodium in each of the fluid channels in contact with the structure must be averaged. This is necessary in order to maintain azimuthal symmetry. Therefore, the temperatures and pressures in each of these channels are volumeaveraged to obtain a single temperature and pressure that describes the conditions of the sodium in the channels adjacent to the wall. Second, it is necessary to obtain a heat transfer coefficient for the sodium/wall interface. Obviously, no correlation exists for the actual geometry encountered, and that. is why the sodium is placed in the "imaginary" annulus described in the previous section. O.E. Dwyer (Ref. 1.) developed a 
Nusselt Number correlation for sodium flowing in an annulus, transferring heat through its boundary:

$$
\mathrm{Nu}=\frac{\mathrm{hD}_{\mathrm{e}}}{\mathrm{k}}=\mathrm{A}+\mathrm{C}(\bar{\Psi} \mathrm{Pe})^{\beta},
$$

where

$$
\begin{aligned}
& A=5.54+0.023\left(r_{2} / r_{1}\right) \\
& C=0.0189+0.00316\left(r_{2} / r_{1}\right)+0.0000867\left(r_{2} / r_{1}\right)^{2} \\
& \beta=0.758\left(r_{2} / r_{1}\right)-0.0204 \\
& r_{2}=\text { outer radius of annulus } \\
& r_{1}=\text { inner radius of annulus } \\
& \bar{\Psi} \text { is assumed to be } 1.0 .
\end{aligned}
$$

Using this correlation, a heat transfer coefficient is obtained for each time step. Once again, the heat flux $q^{\prime \prime}=h_{\text {in }}\left(T_{\text {sodium }}-T_{\text {wall, in }}\right)$, where $T_{\text {wall, in }}=$ the temperature at the inner boundary of the structure.

B. 3. Method of Solution

Since there is assumed to be no heat generation in the structure, the heat conduction equation. (for flow in the radial direction only) is:

$$
\rho c_{p} \cdot \frac{\partial T}{\partial t}=\frac{1}{r} \frac{\partial}{\partial r}\left(r k \frac{\partial T}{\partial r}\right)
$$

The finite difference form of this equation is similar to that found in THERMIT for the rod conduction equations, with the heat generation term missing (see Ref. 1). Note that the solution is partially expicit in the boundary conditions : 


$$
\begin{aligned}
& q_{\text {in }}^{(n+1)}=h_{\text {in }}^{(n)}\left(T_{\text {sodium }}^{(n)}-T_{\text {wall,in }}^{(n+i)}\right) \\
& q_{\text {out }}^{(n+1)}=h_{\text {out }}\left(T_{\text {wall,out }}^{(n+1)}-T_{\text {out }}\right)
\end{aligned}
$$

where the superscripts refer to the time step at which the property is evaluated. Tout and $h_{\text {out }}$ are constant. The solution of the matrix formed by these equations is accomplished by the forward elimination - back substitution method.

\section{B.4. Apportioning of Heat Flow}

Once the heat flux into the structure from the sodium annulus ( $q_{\text {in }}^{\prime \prime}$ ) is calculated, the only problem remaining is how to apportion this heat flow among the separate fluid channels. This is done on the basis of the perimeter in contact with the structure. For example, if channel A has a perimeter of contact that is three times that of channel B, then the heat loss (or gain) experienced by channel A will be three times that of channel $B$.

As noled before, only channels in the single phase liquid regime lose a significant portion of heat. Thus, any channel with a void is left out of both the averaging scheme described in Section B.I and the apportioning scheme defined above. 
Appendix C

Sodium Physical Property Correlations*

1. Saturation Temperature $\left({ }^{\circ} \mathrm{K}\right)$

$T_{\text {sat }}=\frac{\mathrm{A}_{1}}{\mathrm{~A}_{2}+\sqrt{\mathrm{A}_{3}+\mathrm{A}_{4} \ln (\mathrm{P})}}$

where:

$A_{1}=6.8354 \times 10^{5}$

$A_{2}=-1.1485 \times 10^{4}$

$A_{3}=1.4267 \times 10^{8}$

$A_{4}=-1.3671 \times 10^{6}$

Range of Validity: $550<\mathrm{T}<1250^{\circ} \mathrm{K}$

Source: Ref. 3

2. Liquid Density $\left(\mathrm{kg} / \mathrm{m}^{3}\right)$

$\rho_{\ell}=A_{5}+A_{6} T+A_{7} T^{2}$

where:

$A_{5}=1.0042 \times 10^{3}$

$A_{6}=-2.139 \times 10^{-1}$

$A_{7}=-1.1046 \times 10^{-5}$

Range of Validity: $550<\mathrm{T}<1250^{\circ} \mathrm{K}$

Source: Ref. 3

3. Vapor Density $\left(\mathrm{kg} / \mathrm{m}^{3}\right)$

$\rho_{v}=P\left(\frac{A_{8}}{T}+A_{9}+A_{10} T+A_{11} T^{2}+A_{12} T^{3}+A_{13} T^{4}\right)$

where:

$$
\begin{aligned}
& A_{8}=4.1444 \times 10^{3} \\
& A_{9}=-7.4461 \\
& A_{10}=1.3768 \times 10^{-2}
\end{aligned}
$$

${ }^{*} T$ is in ${ }^{2} K$ and $P$ is in $M ! a$ in all corrolations given in this Appendix. 


$$
\begin{aligned}
& \wedge_{11}=-1.01334 \times 10^{-1 ;} \\
& A_{12}=3.8903 \times 10^{-9} \\
& A_{13}=-4.922 \times 10^{-13}
\end{aligned}
$$

Range of Validity: $550<\mathrm{T}<1250^{\circ} \mathrm{K}$

Source: Ref. 3

4. Liquid Enthalpy $(\mathrm{J} / \mathrm{kg})$

$$
H_{\ell}=A_{14}+A_{15} T+A_{16} T^{2}+A_{17} T^{3}
$$

where:

$$
\begin{aligned}
& A_{14}=-6.7508 \times 10^{4} \\
& A_{15}=1.6301 \times 10^{3} \\
& A_{16}=-4.1672 \times 10^{-1} \\
& A_{17}=1.5427 \times 10^{-4}
\end{aligned}
$$

Range of Validity: $360<\mathrm{T}<1644^{\circ} \mathrm{K}$ Source: Ref. 4

5. Heat of Vaporization $(\mathrm{J} / \mathrm{kg})$

$$
\lambda=A_{18}+A_{19} T+A_{20} T^{2}+A_{21} T^{3}
$$

where:

$$
\begin{aligned}
& A_{18}=5.3139 \times 10^{6} \\
& A_{19}=-2.0296 \times 10^{3} \\
& A_{20}=1.0625 \\
& A_{21}=3.3163 \times 10^{-4}
\end{aligned}
$$

Range of Validity: $550<\mathrm{T}<1250^{\circ} \mathrm{K}$ Source: Ref. 3

6. Liquid Adiabatic Compressibility $\left(\mathrm{Pa}^{-1}\right)$

$$
B_{S}=A_{22}+\frac{A_{23}}{A_{24}-T}
$$

where:

$$
A_{22}=-5.4415 \times 10^{-11}
$$




$$
\begin{aligned}
& A_{23}=4.7663 \times 10^{-7} \\
& A_{24}=2.5033 \times 10^{3}
\end{aligned}
$$

Range of Validity: $550<\mathrm{T}<1250^{\circ} \mathrm{K}$ Source: Ref. 3

7. Liquid Conductivity $\left(\mathrm{w} / \mathrm{m}^{\circ} \mathrm{K}\right)$

$k_{\ell}=A_{25}+A_{26} T+A_{27} T^{2}+A_{28} T^{3}$

where:

$$
\begin{aligned}
& \mathrm{A}_{25}=1.1045 \times 10^{2} \\
& \mathrm{~A}_{26}=-6.5112 \times 10^{-2} \\
& \mathrm{~A}_{27}=1.543 \times 10^{-5} \\
& \mathrm{~A}_{28}=-2.4617 \times 10^{-9}
\end{aligned}
$$

Range of Validity: $550<\mathrm{T}<1250^{\circ} \mathrm{K}$ Source: Ref. 3

8. Vapor Conductivity $\left(\mathrm{w} / \mathrm{m}^{\circ} \mathrm{K}\right)$

$$
\mathrm{k}_{\mathrm{v}}=\mathrm{A}_{29}+\mathrm{A}_{30} 0_{\mathrm{T}}+\mathrm{A}_{31} \mathrm{~T}_{\mathrm{s}}{ }^{2}
$$

where:

$$
\mathrm{T}_{\mathrm{S}}=1.8 \mathrm{~T}-459.7
$$

and

$$
A_{29}=2.8366 \times 10^{-3}
$$

$A_{30}=6.8830 \times 10^{-5}$

$A_{31}=-1.6783 \times 10^{-8}$

Range of Validity: $360<\mathrm{T}<1644^{\circ} \mathrm{K}$ Source: Ref. 4

9. 1,iquid Viscosity ( $\mathrm{Pa} \mathrm{sec})$

$$
u_{\ell}=A_{32}+\frac{A_{33}}{T}+\frac{A_{34}}{T^{2}}+\frac{A_{35}}{T^{3}}
$$

where:

$$
\begin{aligned}
& A_{32}=3.6522 \times 10^{-5} . \\
& A_{33}=1.6626 \times 10^{-1}
\end{aligned}
$$




$$
\begin{aligned}
& \Lambda_{34}=-4.5688 \times 10^{1} \\
& A_{35}=2.8733 \times 10^{4}
\end{aligned}
$$

Range of Validity: $550<\mathrm{T}<1250^{\circ} \mathrm{K}$ Source: Ref. 3

10. Vapor Viscosity (Pa sec)

$$
\mu_{v}=A_{36}+A_{37} T
$$

where:

$$
\begin{aligned}
& A_{36}=1.261 \times 10^{-3} \\
& \Lambda_{37}=6.085 \times 10^{-9}
\end{aligned}
$$

Range of Validity: $360<\mathrm{T}<1644^{\circ} \mathrm{K}$ Source: Ref. 4

11. Surface Tension (N/m)

$$
\sigma=A_{38}+A_{39}\left(T-A_{40}\right)
$$

where:

$$
\begin{aligned}
& A_{38}=2.067 \times 10^{-1} \\
& A_{39}=-1.0 \times 10^{-4} \\
& A_{40}=2.7314 \times 10^{2}
\end{aligned}
$$

Range of Validity: $360<\mathrm{T}<1644^{\circ} \mathrm{K}$ Source: Ref. 4

12. Vapor Enthalpy

$$
\mathrm{H}_{v}=H_{\ell}+A_{18}+A_{19} T^{T}+A_{20} T^{2}+A_{21} T^{3}
$$

13. Liquid Energy

$$
\mathrm{E}_{\ell}=\mathrm{H}_{\ell}-\frac{\mathrm{p}}{\rho_{\ell}}
$$

14. Vapor Energy

$$
E_{v}=H_{v}-\frac{P}{\rho_{v}}
$$


15. Derivative of Saturation Temperature with Respect to Pressure

$$
\left.\frac{\partial \mathrm{T}_{\text {sat }}}{\partial \mathrm{P}}\right|_{\mathrm{T}}=-\frac{\mathrm{A}_{4} \mathrm{~T}_{\text {sat }}^{3}}{2 \mathrm{~A}_{1} \mathrm{P}\left(\mathrm{A}_{1}-\mathrm{A}_{2} \mathrm{~T}_{\text {sat }}\right)}
$$

16. Derivative of Liquid Density with Respect to Pressure

$$
\left.\frac{\partial \rho_{\ell}}{\partial \mathrm{P}}\right|_{\mathrm{T}}=\rho_{\ell}{ }^{\beta} \mathbf{S}
$$

17. Derivative of Liquid Density with Respect to Temperature

$$
\left.\frac{\partial \rho_{\ell}}{\partial T}\right|_{P}=A_{6}+2 A_{7} T
$$

18. Derivative of Vapor Density with Respećt to Pressure

$$
\left.\frac{\partial \rho \mathrm{V}}{\partial \mathrm{P}}\right|_{\mathrm{T}}=\frac{\rho \mathrm{V}}{\mathrm{P}}
$$

19. Derivative of Vapor Density with Respect to Temperature

$$
\left.\frac{\partial \rho_{V}}{\partial T}\right|_{\mathrm{P}}=P\left[\frac{-\mathrm{A}_{8}}{\mathrm{~T}^{2}}+\mathrm{A}_{10}+2 \mathrm{~A}_{11} \mathrm{~T}_{\mathrm{V}}+3 \mathrm{~A}_{12} \mathrm{~T}^{2}+4 \mathrm{~A}_{13} \mathrm{~T}^{3}\right]
$$

20. Derivative of Liquid Energy with Respect to Temperature

$$
\left.\frac{\partial E_{\ell}}{\partial T}\right|_{P} A_{15}+2 A_{16} T+3 A_{17} T^{2}+\frac{P}{\rho_{\ell}{ }^{2}} \frac{d \rho_{\ell}}{d T}
$$

21. Derivative of Liquid Energy with Respect to Pressure

$$
\left.\frac{\partial E}{\partial P}\right|_{T}=0
$$




$$
\text { III }-56
$$

22. Derivative of Vapor Energy with Respect to Temperature

$$
\begin{aligned}
\left.\frac{\partial E_{v}}{\partial T}\right|_{P} & =A_{15}+A_{19}+2 T\left[A_{16}+A_{20}\right]+3 T^{2}\left[A_{17}+A_{21}\right] \\
& +\frac{p}{\rho_{v}^{2}} \cdot \frac{d_{v}}{d T}
\end{aligned}
$$

23. Derivative of Vapor Energy with Respect to Pressure

$$
\left.\frac{\partial E_{v}}{\partial \mathrm{dP}}\right|_{T .}=0.0
$$




\section{Appendix D}

Old and New Models for the Mass Exchange Coefficient

The correct version of the Nignatulin Model, as described in Reference 7 , is the following:

$$
\begin{aligned}
& \Gamma=\Gamma_{e}+\Gamma_{c} \\
& \Gamma_{e}=\rho_{\ell} A \alpha(1-\alpha) \sqrt{R_{g}} \lambda_{e}\left(\frac{T_{\ell}-T_{s}}{\sqrt{T_{S}}}\right) \text { for } T_{\ell}>T_{S} \\
& =0 \quad \text { for } \mathrm{T}_{\ell} \leq \mathrm{T}_{\mathrm{S}}
\end{aligned}
$$

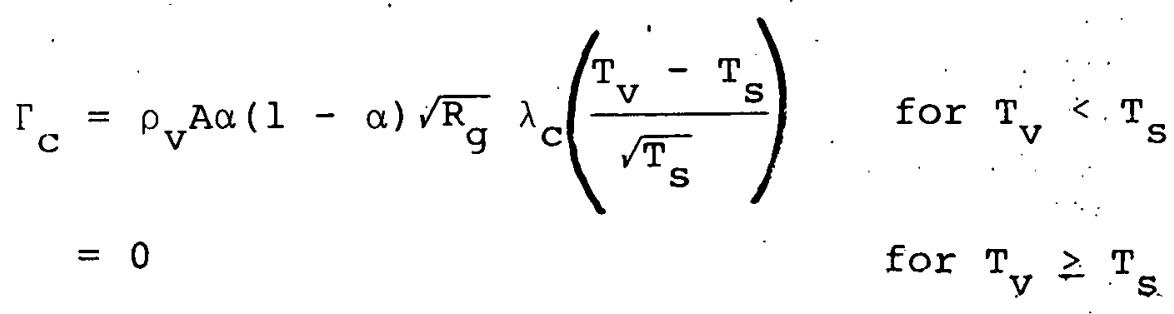

$$
\begin{aligned}
A & =\left(\frac{4 \pi N}{3}\right)^{1 / 3} \alpha^{2 / 3} \quad \text { for } \alpha \leq 0.5 . \\
& =\left(\frac{4 \pi N}{3}\right)^{1 / 3}(1-\alpha)^{2 / 3} \quad \text { for } \alpha>0.5 \\
\lambda_{e} & =\lambda_{C}=0.1, \quad \mathrm{~N}=10^{7} \text { bubbles } / \mathrm{m}^{3}
\end{aligned}
$$

where $\Gamma=$ net mass exchange rate $\left(\mathrm{kg} / \mathrm{m}^{3} \mathrm{scc}\right), \Gamma_{c}=$ evaporation rate, $\Gamma_{C}=$ condensation rate, $A$ is proportional to the interfacial area of mass exchange per unit volume $\left(\mathrm{m}^{-1}\right), \|=$ void 
III- 58

fraction, $R_{g}=$ gas constant for sodium $=361.49 \mathrm{~J} / \mathrm{kg}^{\circ} \mathrm{K}$, and $\lambda_{e}$ and $\lambda_{c}$ are constants which could conceivably vary between 0.01 and 1.0 .

Note that in the previous version of THERMIT' two mistakes were present: $\rho_{v}$ was replaced by $\rho_{\ell}$ in the equation for $\Gamma_{C}$, and the expressions for $A$ were:

$$
A=\left(\frac{41 \mathrm{~N} u}{3}\right)^{2 / 3} \text { if } \alpha \leq 0.5, A=\left[\frac{4 N(1-\alpha)}{3}\right]^{2 / 3} \text { for } \alpha>0.5 \quad(D-5)
$$

Simple dimensional analysis will show that the latter equations are incorrect.

THERMIT now contains a modfied version of the Nigmatulin Model, in which Equations (D-4) are revised so as to incorporate the effects of channel geometry and flow regime. The original Nigmatulin Model assumes a constant number of bubbles per unit volume. This is unrealistic, hecause not only will the number of bubbles change as evaporation increases; but in sodium boiling one finds that the large void fractions encountered dictate annular flow most of the time. The modified version takes these factors into account in developing a methodology for calculating A based on flow regime and channei geometry.

First consider the bubbly flow regime, which is assumed to exist for $\alpha<0.6$ (the reason for choosing this particular number will be given later). Bubbles are assumed to form in the middle of each subchannel, packed on top of each other (see Figure $\mathrm{D}-1$ ). The geometry considered is that of a triangular array of fuel rods, as is normally encountered in sodium-cooled reactors. 


$$
A=\frac{\text { surface area of bubbles }}{\text { volume of fluid }}
$$

Take a volume of height dz. In this volume there are $\mathrm{dz} / 2 \mathrm{r}_{\mathrm{b}}$ bubbles, where $\mathrm{r}_{\mathrm{b}}=$ radius of each bubble. Thus the total surface area of all the bubbles is: $\frac{d z}{2 r_{b}} \times 4 \pi r_{b}{ }^{2}=2 \pi r_{b} d z$.

The volume of the fluid is $A_{x} d z$, where $A_{x}=$ cross-sectional area of the subchannel. Substituting these expressions into (D-5) gives:

$$
A=\frac{2 \pi r_{b} d z}{A_{x} d z}=\frac{2 \pi r_{b}}{A_{x}}
$$

For a triangular array, $A_{x}=\frac{P^{2} \sqrt{3}}{4}-\frac{\pi D^{2}}{8} ;$ thus

$$
A=\frac{16 \pi r_{b}}{2 P^{2} \sqrt{3}-\pi D^{2}}
$$

In order to obtain $A$ as a function of the geometry and void fraction an expression for $r_{b}$ in terms of these parameters is needed. This can be obtained using the following definition of $\alpha$ :

$$
\alpha=\frac{\text { volume of vapor }}{\text { volume of fluid }}=\frac{4 / 3 \pi r_{b}{ }^{3} \mathrm{dz} /\left(2 r_{b}\right)}{\left(\frac{\mathrm{p}^{2} \sqrt{3}}{4}-\frac{\pi D^{2}}{8}\right) \mathrm{dz}}
$$

Solving for $r_{b}$,

$$
r_{b}=\sqrt{\frac{3}{16 \pi}\left(2 P^{2} \sqrt{3}-\pi D^{2}\right) \alpha}
$$



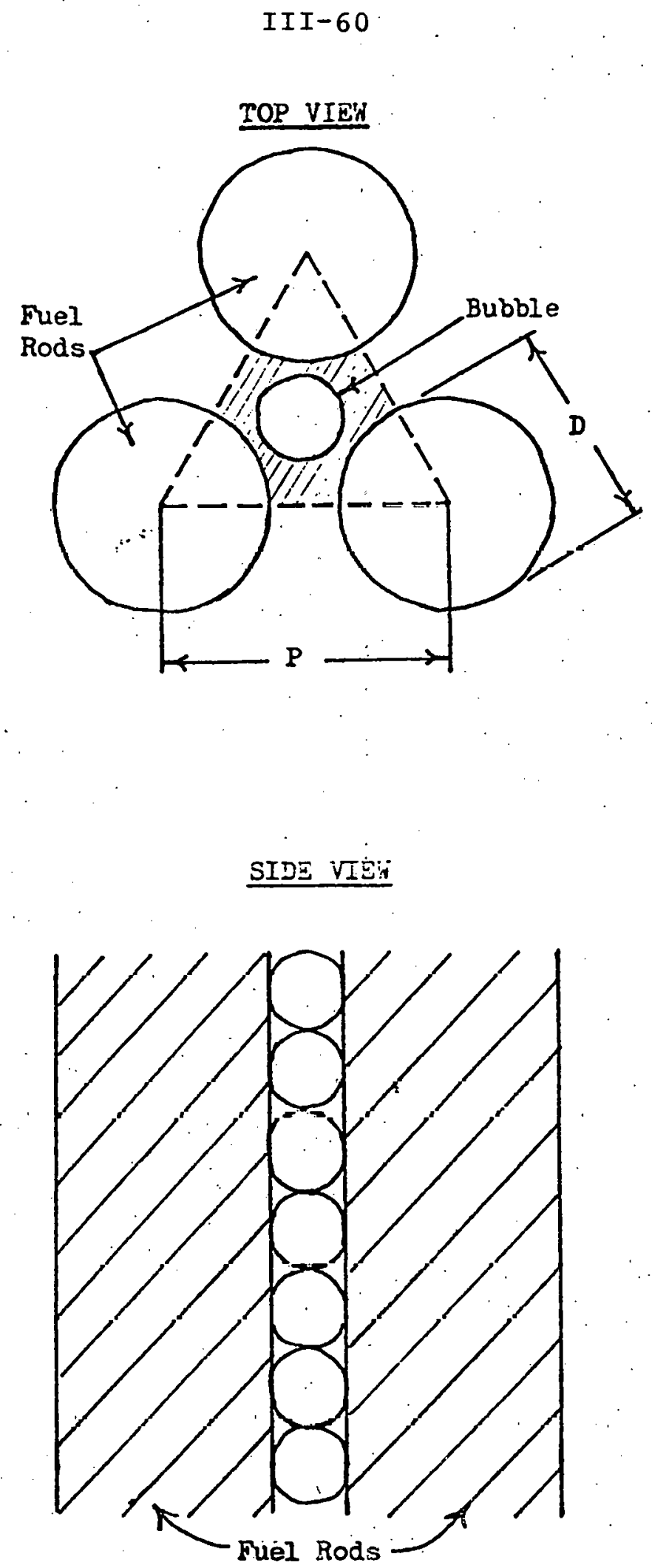

Figure $D-1$

New Model for Mass Exchange Coefficient Assumed Geometry for Bubbly Flow 
Substituting the results of (D-9) into (D-7) then gives

$$
A=\frac{4.0}{D}\left\{\frac{3 \pi \alpha}{2 \sqrt{3}\left(\frac{P}{D}\right)^{2}-\pi}\right\}^{0.5} \quad \text { for } \alpha \leq 0.6
$$

For a void fraction greater than 0.6 and less than a certain dryout value (set at 0.957 , for reasons to be given later), it is assumed that the flow is annular, with the liquid flowing in an annulus around the fuel rods, as shown in Figure D-2. For $r_{a}=$ the outer radius of the liquid annulus,

$$
A=\frac{\frac{1}{2} 2 \pi r a d z}{\left(\frac{P^{2} \sqrt{3}}{4}-\frac{\pi D^{2}}{8}\right) d z}=\frac{8 \pi r a}{2 P^{2} \sqrt{3}-\pi D^{2}}
$$

and

$$
\alpha_{\ell}=1-\alpha=\frac{\frac{1}{2} \pi\left(r_{a}^{2}-(D / 2)^{2}\right) d z}{\left(\frac{P^{2} \sqrt{3}}{4}-\frac{\pi D^{2}}{8}\right) d z}
$$

Solving Equation (D-12) for $r_{a}$,

$$
r_{a}=\sqrt{\frac{(1-\alpha)\left(2 P^{2} \sqrt{3}-\pi D^{2}\right)+\pi D^{2}}{4 \pi}}
$$

Substituting this into equation (D-11) and simplifying gives

$$
A=\frac{4.0 \sqrt{\pi}}{D}\left\{\frac{2 \sqrt{3}\left(\frac{P}{D}\right)^{2}}{\left[2 \sqrt{3}\left(\frac{P}{D}\right)^{2}-\pi\right]^{2}}-\frac{\alpha}{2 \sqrt{3}\left(\frac{P}{D}\right)^{2}-\pi}\right\} 0.5
$$

$$
\text { for } 0.6 \therefore 1.0 .957
$$




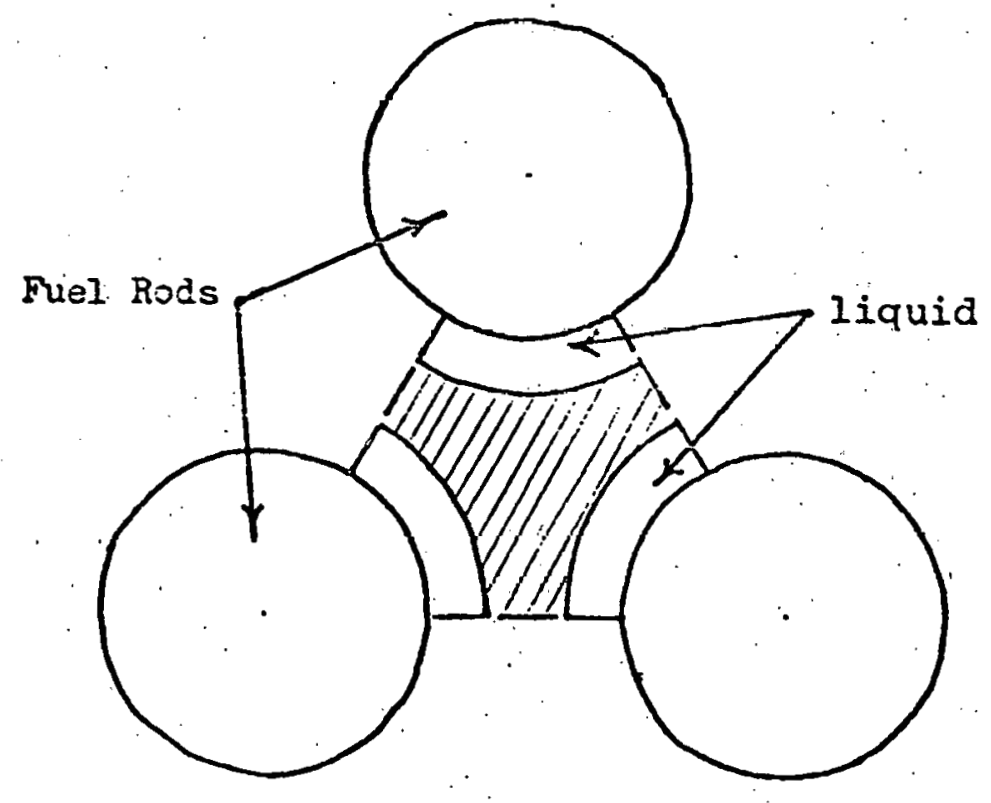

Figure $D-2$

Ännular Flow

New Model for Mass Exchange Coefficient Assumed Geometry for Annular Flow 
A comparison of this expression with Equation (D-10) shows that for common values of the pitch-to-diameter ratio $(1.1-1.3)$ the areas calculated by these formulas are roughly equal for $0.5<\alpha<0.7$. Since the bubbly/slug - annular transition usually occurs in this range, $\alpha=0.6$ was chosen as the transition void fraction. Considering the numerous other uncertainties associated with the Nigmatulin Model for $\Gamma$ (the values of $\lambda_{e}$ and $\lambda_{c^{\prime}}$, for example), the uncertainty introduced by the choice of a transition void fraction is negligible.

Physically one would expect the interfacial area, A, to approach zero as $\alpha \rightarrow 1.0$, but one can see that Equation (D-14) doesn't satisfy this criterion. This is because the derivation of Equation (D-14) assumed that the liquid remains in contact with the wall at all times. In reality there is a void fraction below 1.0 at which some vapor comes in contact with the wall. Experiments done on steady state flow of sodium in a heated tube (Ref. 9) have shown that this dryout void fraction is approximately equal to 0.957. Therefore, for $0.957<\alpha$ the interfacial area should decrease as $\alpha \rightarrow 1.0$. Thus Equation (D-14) is modifiec. to yield:

$$
\left.\begin{array}{rl}
\Lambda= & \frac{4.0 \sqrt{11}}{D}\left\{\begin{array}{c}
2 \sqrt{3}\left(\frac{P}{D}\right)^{2} \\
{\left[2 \sqrt{3}\left(\frac{P}{D}\right)^{2}-11\right]^{2}} \\
\end{array}\right. \\
\left(\frac{1-\alpha}{1-0.957}\right)^{0.5} \quad \text { for } \alpha>0.957
\end{array}\right\}
$$


Equations (D-10), (D-14), and (D-15) represent a continous, flow-regime-dependent methodology for calculating the interfacial area of mass transfer required in the Nigmatulin Model for $\Gamma$. These areas are plotted as a function of $\alpha$ For different $P / D$ ratios in Figure. $D-3$. For comparison the Nigmatulin expression for A [Equations (D-4)], is also plotted. Note that this expression is multiplied by a factor of 3 , because the true interfacial area of mass exchange is three times as large as Equations (D-4). One can see from Figure $D-3$ that as $P / D$ decreases the difference between the Nigmatulin Model and the proposed one increases, especially at large void fractions, which are commonly encountered in sodium boiling. 


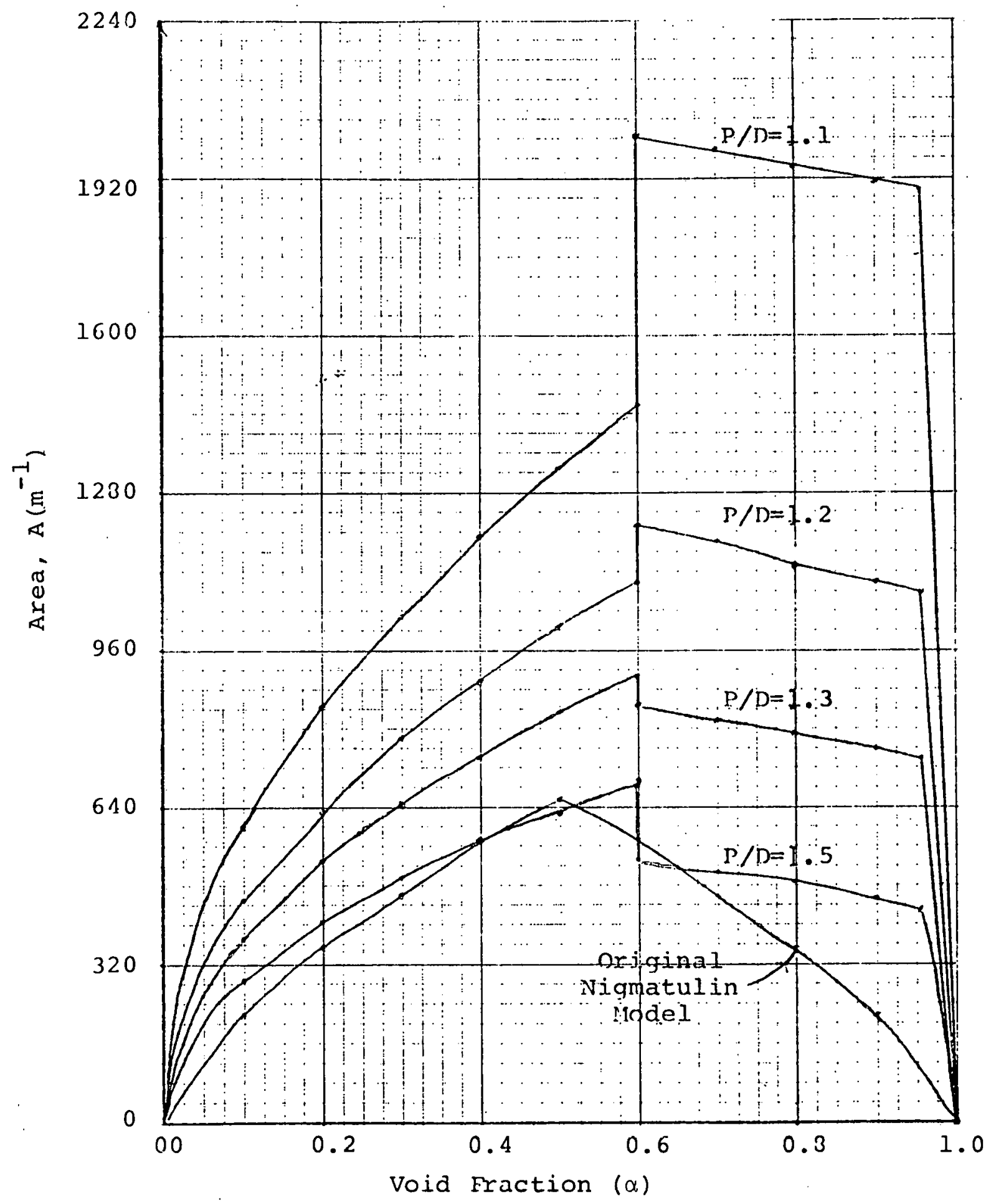

Figure D-3

Compirison of old and New Models for Mases lixchanise coefficient - Tnterfacial Area vs o it for Different values of $1 . / D$ 


\section{Appendix E}

Proposed Correlation for Two Phase

Convective Heat Transfer in LMFBR Rod Bundles

\section{E.1. Introduction}

An adequate heat transfer correlation for convective two phase flow in LMFBR rod bundles is not presently available in the literature. Accordingly, a new correlation has hepn formulated. This correlation assumes a mechanism of micro and macro-convective hëat transfer to boiling liquid metals similar to that proposed by Chen (Ref. 7) for non-metallic liquids. The new correlation has not yet been verified by comparison with experimental data. Reasonable agreement with experiment is anticipated, however, since, in comparisons with experimental results for water and organic fluids, Chen showed an average deviation of $11 \%$, as compared to deviations of $32 \%$ to $43 \%$ for previous correlations (Ref. 7.).

\section{E. 2. Assumptions}

The conditions for validity of the correlation are stable, vertical, axial convective flow of saturated liquid metals with no liquid deficiency. These conditions are, in general, satisfied by convective boiling of liguid metale with net vapor generation in annular or mist-annular two phase flow. The proposed model for convective flow is based on the postulate that there are two mechanisms that contribute to total heat transfer and these mechanisms interact with each other. The macro-convective mechanism is associated with overall flow and the micro-convective mechanism is associated with bubble 
growth in the annular liquid fiim.

\section{E. 3. Derivation}

Using the assumptions of A.2., Chen (Ref. 7.) obtained the following for the micro-convective contribution:

$$
h_{\text {mic }}=0.00122 \frac{k_{L}^{0.79} C_{p_{L}} 0.45 \rho_{L}{ }^{0.49} \Delta \mathrm{P}^{0.75} g_{C}{ }^{0.25} \cdot S}{\sigma 0.5 \mu_{L} 0.29}\left(\frac{\Delta T}{\lambda \rho_{v}}\right) 0.24
$$

where,

$$
S=\left(\frac{\Delta T_{e}}{\Delta T}\right)=0.99
$$

and,

$$
\begin{aligned}
& \mathrm{k}_{\mathrm{L}}=\text { liquid thermal conductivity } \\
& \mathrm{C}_{\mathrm{p}_{\mathrm{L}}}=\text { liquid heat capacity } \\
& \rho_{\mathrm{L}}=\text { liquid density } \\
& \mathrm{g}_{\mathrm{C}}=\text { gravitational constant }(=1 \text { for } \mathrm{SI}) \\
& \sigma=\text { surface tension } \\
& \mu_{\mathrm{L}}=\text { liquid viscosity } \\
& \lambda=\text { heat of vaporization } \\
& \rho_{\mathrm{V}}=\text { vapor density } \\
& \Delta \mathrm{T}_{\mathrm{e}}=\text { effective superheat for bubble growth in annular liquid } \\
& \mathrm{S}=\text { measure of the suppression of bubble growth by presence } \\
& \Delta \mathrm{T}=\text { wall temperature minus saturated liquid temperature } \\
& \Delta \mathrm{P}=\text { pressure at wall minus liquid pressure }
\end{aligned}
$$

Based on Foster - zuber's pool boiling theory (from which Equation (E-1) is derived), Equation (E-1) appears to be applicable for liquid metals as well as ordinary fluids (Ref. 13).

* $S$ may be correlated against an effective two-phase Reynolds number (See Fig. E-1). 


\section{III-68}

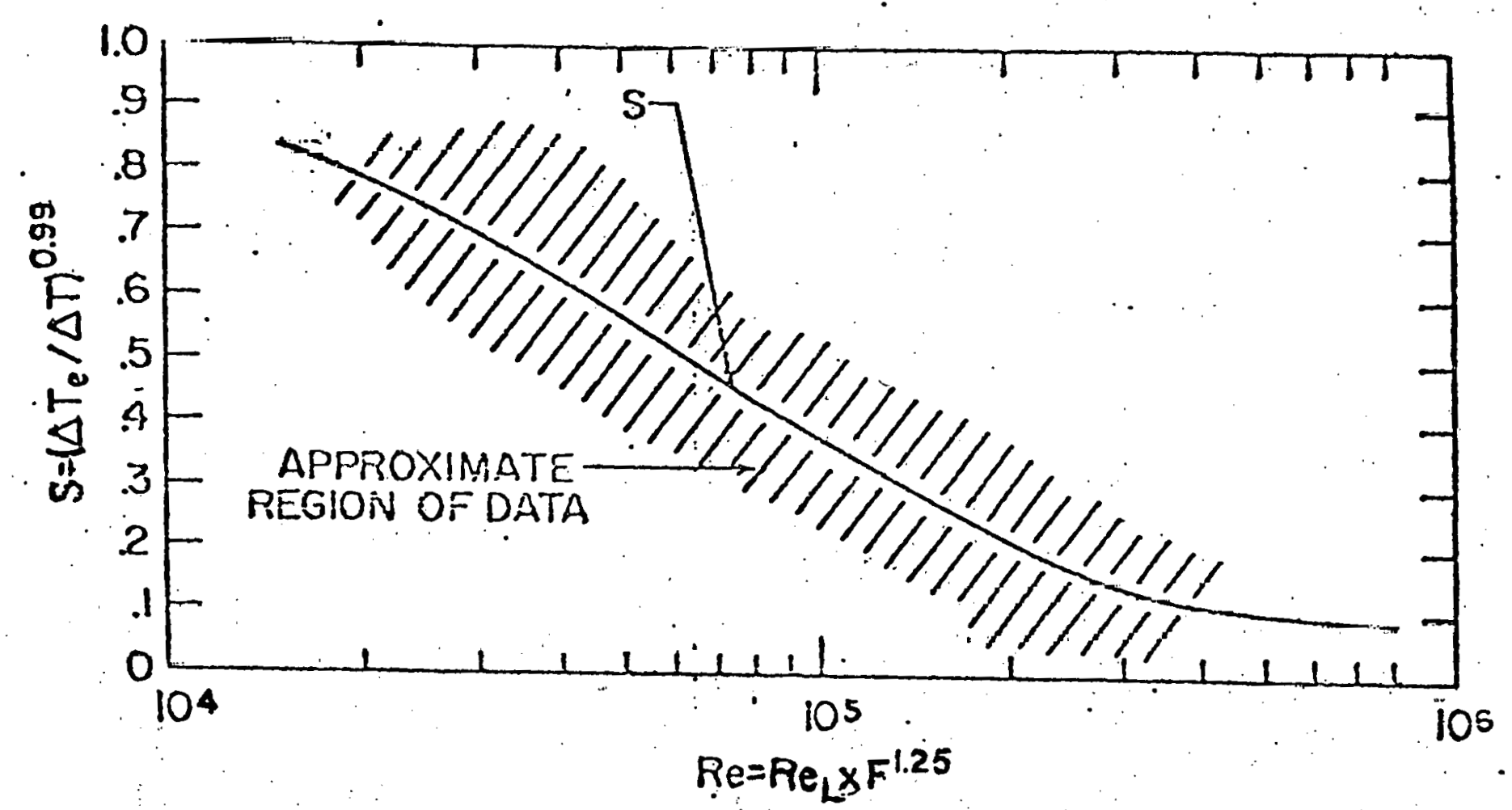

Figure $E-1$

The Suppression Function, $S$, in Equation (E-I) 
Ref. 14 proposed a modified form of the Lyon - Martinelli equation for the macro-convective term. However, a correlation applicable to rod bundles is needed.' Therefore, as recommended in Ref.15, the Schad correlation for single phase liquid was chosen and modified for two phase flow conditions. The modified Schad correlation for macro-convective heat transfer is:

$$
h_{\text {mac }}=R\left[\left(F \operatorname{Re}_{L}{ }^{0.3}\right)\left(\operatorname{Pr}_{L} \beta\right)^{\alpha}\right] \cdot \frac{\delta k_{L}}{D_{H}}
$$

where:

\begin{tabular}{|c|c|c|c|}
\hline & Two Phase & Vapor & Liquid \\
\hline$\delta$ & 1 & $\mathrm{k}_{v} / \mathrm{k}_{\mathrm{L}}$ & 1. \\
\hline $\mathrm{R}$. & $\begin{array}{c}-16.15+24.96(P / D) \\
-8.55(P / D)^{2}\end{array}$ & .023 & $\begin{array}{l}-16.15+24.96(P / D) \\
-8.55(P / D)^{2}\end{array}$ \\
\hline$B$ & 1 & $\mathrm{Pr}_{\mathrm{V}} / \mathrm{Pr} \mathrm{L}_{\mathrm{L}}$ & 1 \\
\hline$\alpha$ & 0.3 & 0.4 & 0.3 \\
\hline$F$ & $\left.\left[\frac{\mathrm{Re}}{\mathrm{Re}_{\mathrm{L}}}\right]\right]^{0.3}$ & $\frac{\operatorname{Re}_{\mathrm{V}} 0.8}{\operatorname{Re}_{\bar{L}} 0.3}$ & $1 \quad$ \\
\hline
\end{tabular}

Equation (E-2) reduces to the conventional Schad equation for single phase heat transfer in the limit of $0 \%$ quality. . In the limit of $100 \%$ quality, Equation $(E-2)$ reduces to the DittusBoelter equation for single phase vapor. In the region of mixed quality, the parameter $F$ takes on values intermediate between the single phase values. The function $F$ may be physically interpreted as a measure of the effectiveness of two phase 
momentum transfer as compared to the corresponding liquid phase momentum transfer. $F$ can be correlated against the Martinelli parameter and the recommended correlation is shown in Figure E-2 (Ref. 7). Thus, total convective boiling heat transfer is given by:

$$
h=h_{\text {mic }}+h_{\text {mac }} .
$$




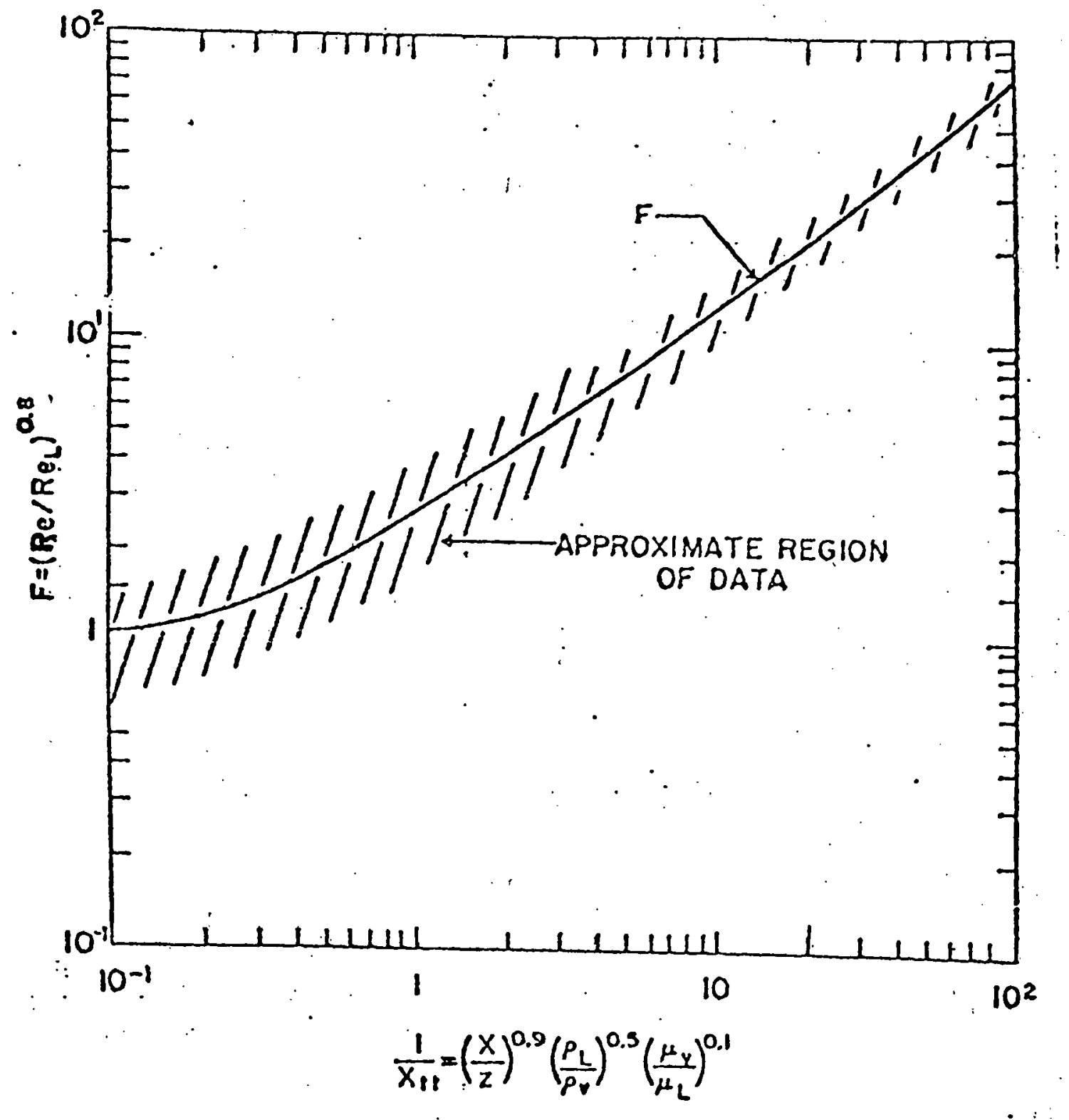

Figure E-2

The Reynolds Number Function, F: in Equation (F-2) 


\section{Appendix $\mathrm{F}$ \\ Details of Radial Heat Conduction Model Added to THERMIT*}

\section{F.1. Introduction}

A radial heat conduction model has been incorporated into THERMIT. This has been done by puttting an additional term in the liquid energy equation in subroutine JACOB, qcnd, which represents the heat flow (per unit volume of sodium) Into the node trom the tour sides. This heat flow is calculated in a new subroutine, @COND, which is called from subroutine NEWTON. The subroutine is called once per time step, and calculates the net heat flow into (or out of) each node. The heat flow through all external faces (i.e. boundary faces) is set equal to zero.

The user has the option of choosing between two different methods of incorporating liquid conduction, or bypassing it altogether. The first option for liquid conduction is fully explicit in nature, and as such, may introduce a time step restriction. The second option is partially implicit, and unconditionaliy stable, so it imposes no time step restriction. The disadvantage of this method is that it doesn't strictly conserve energy at all points. The user may select which of these options to use through the input parameter, rnuss, which is an effective conduction Nusselt Number (to be explained later). If rnuss is set equal to zero the liquid conduction routine is bypassed altogether. If rnuss is greater than zero the partially implicit method is employed, whereas if rnuss is less than zero the fully explicit method is used. Iho following sections contain a description of each of the two liguid conduction options. 


\section{F.2. Explicit Method}

With this method all properties are evaluated at the old time step. As mentioned before, this introduces a time step limitation which may or may not be more limiting than the time step limitation introduced by the axial velocity. The time step limitation for conduction in two dimensions (i.e. neglecting axial conduction) is:

$$
\Delta t<\frac{(\Delta x)^{2}}{4 \alpha} \text {, where } \alpha=\text { thermal diffusivity }=\frac{k}{\rho c_{p}} \text { and }(F-1)
$$

$\Delta \mathrm{x}$ is assumed to be equal to $\Delta \mathrm{y}$.

The heat flow term for each face is calculated by multiplying the temperature difference by an effective conduction heat transfer coefficient. The total heat flow for each node is obtained by summing the heat flows for all four sides. For the configuration of Figure F-1,

$$
\begin{aligned}
\left(Q_{\text {cnd }}\right)^{n+1} & =\frac{A_{1-0} h_{1-0}}{V_{0}}\left(T_{\ell, 1}-T_{\ell, 0}\right), \text { and } \\
\left(Q_{\text {cnd }}\right)_{0}^{n+1} & =\left(Q_{\text {cnd }}\right)_{1-0}^{n+1}+\left(Q_{\text {cnd }}\right) \frac{n+1}{2-0}+\left(Q_{\text {cnd }}\right) \frac{n+1}{3-0} \\
& +\left(Q_{\text {cnd }}\right)_{4-0}^{n+1},
\end{aligned}
$$

where $Q_{c n d}=$ heat flow per unit volume $\left(\mathrm{W} / \mathrm{m}^{3}\right), \mathrm{A}_{1-0}=$ the area of heat transfer (which is assumed equal to momentum transfer) between nodes 1 and $0, V_{0}=$ the volume of sodium in node 0 , and $\mathrm{h}_{1-0}=$ the conduction heat transfer coefficient between nodes 1 and 0 . The superscripts refer to the timestep at which the quantities are evaluated. 


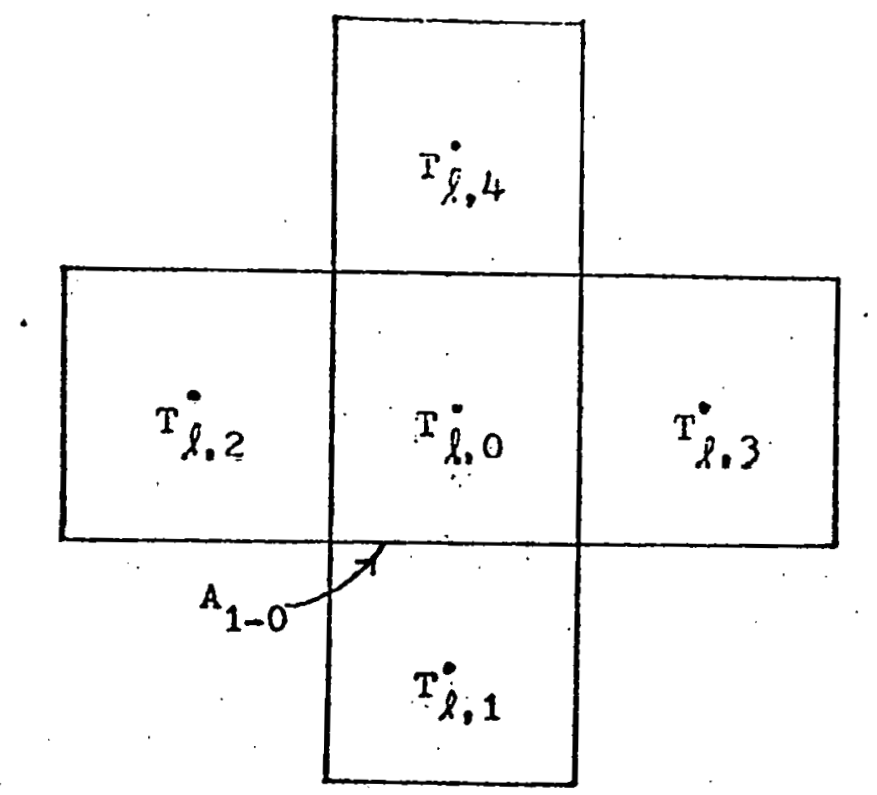

Figure $\mathbf{F - 1}$

New Radial Heat Conduction Model Nodal Configuration Used for Derivation of Equations $(F-2)$ and $(F-3)$

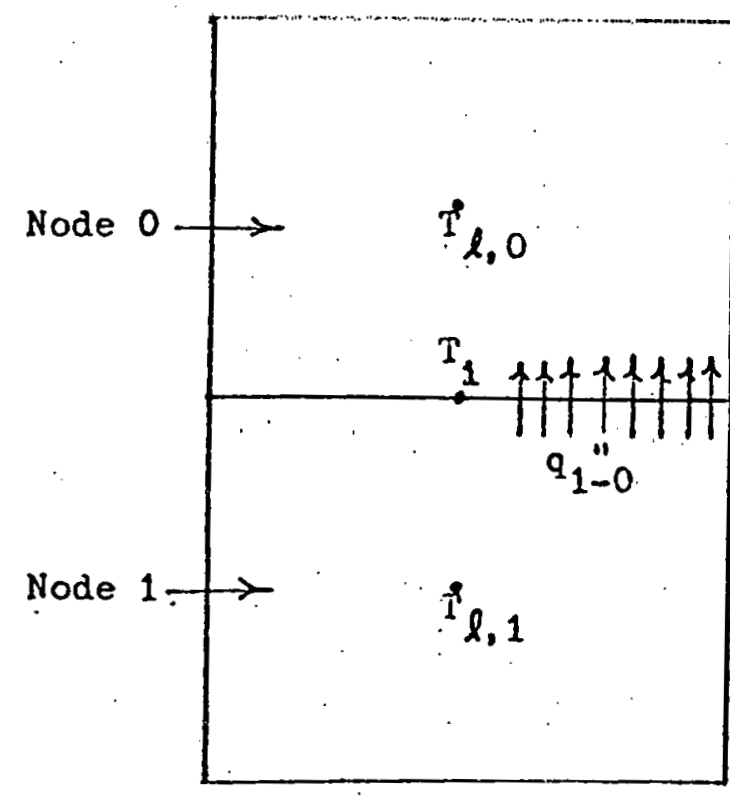

Figure $F-2$

New Radial Heat Conduction Model Nomenclature Used in Derivation of Effective Conduction Heat Transfer Coefficient 
The conduction heat transfer coefficient, $h$, is calculated for each face by calling another new subroutine, HTRAN. This subroutine calculates an $h$ for each of the two nodes and then couples them together to obtain an effective $h$. See Figure F-2.

In the explicit option the user inputs a negative number for the Nusselt number, rnuss. The conduction Nusselt number in each channel is set equal to the absolute value of rnuss. Using the nomenclature of Figure F-2,

$$
\frac{\mathrm{h}_{1} \mathrm{D}_{\mathrm{e}_{1}}}{\mathrm{k}_{1}}=\frac{\mathrm{h}_{0} \mathrm{D}_{\mathrm{e}_{0}}}{\mathrm{k}_{0}}=\mid \text { rnuss } \mid
$$

The number 7.0 is a good number to use for rnuss, because it represents a typical value for the Nusselt number in sodium. If in the future a correlation is developed for calculating the Nusselt number in a geometry like that encountered here, it could be implemented with a minimum of work.

The equivalent diameter, $D_{e}=\frac{4 \times A_{z}}{P_{w}}$, is known from geometry, and the thermal conductivity is known as a function of liquid temperature, so $h_{0}$ and $h_{1}$ can be calculated. The heat flux on the boundary is

$$
\mathrm{q}_{1-0}^{\prime \prime}=\mathrm{h}_{0}\left(\mathrm{~T}_{\mathrm{i}}-\mathrm{T}_{\ell, 0}\right)=\mathrm{h}_{1}\left(\mathrm{~T}_{\ell, 1}-\mathrm{T}_{\mathrm{i}}\right) \text {. }
$$

Therefore,

$$
\mathrm{T}_{1}=\frac{\mathrm{h}_{1} \mathrm{~T}_{\ell, 1}+\mathrm{h}_{0} \mathrm{~T}_{\ell, 0}}{\mathrm{~h}_{1}+\mathrm{h}_{0}}
$$


h-o i.s doringed anch that.

$$
\mathrm{h}_{1-0}=\frac{\mathrm{C}_{1-0}}{\mathrm{~T}_{\ell, 1}-\mathrm{T}_{\ell, 0}}=\frac{\mathrm{h}_{0}\left(\mathrm{~T}_{i}-\mathrm{T}_{\ell, 0}\right)}{\mathrm{T}_{\ell, 1}-\mathrm{T}_{\ell, 0}}
$$

Substituting for $\mathrm{T}_{i}$ in Equation $(F-7)$,

$$
\begin{aligned}
h_{1-0} & =\frac{h_{0}}{T_{0,1}-T_{\ell, n}}\left[\frac{h_{1} \dot{T}_{\ell, 1}+h_{0} T_{\ell, 0}}{h_{1}+h_{0}}\right. \\
& \left.-\frac{T_{\ell, 0}\left(h_{1}+h_{0}\right)}{h_{1}+h_{0}}\right]
\end{aligned}
$$

Simplifying,

$$
\mathrm{h}_{1-0}=\frac{\mathrm{h}_{1} \mathrm{~h}_{0}}{\mathrm{~h}_{1}+\mathrm{h}_{0}} \text {. }
$$

Therefore, it is seen that $h_{1-0}$ is one half of the harmonic mean of the two local heat tranisfer coefficients. This value is returned to the subroutine QCOND, which then calculates the value of $Q_{\text {cnd }}$. This process is repeated for each node.

\section{F.3. Partially Implicit Method}

As stated before, the fully explict method introduces a restriction of the time step. For fairly largc iadial (i.e., $x-y)$ mesh spacing, this restriction is less severe than the convective time step limitation imposed by the fiuid dynamics calculation; and thus the explicit method is quite adequate. However, when the radial mesh spacing is small (on the order of subchannel dimensions), the adequate time step decreases 
significantly. Actually the dimension that dictates the stability criterion is, in our formulation, the "equivalent" diameter, as previously described. In the presence of large amounts of structure, such as in the case of a fuel assembly, this equivalent diameter may be substantially smaller than the mesh spacing. An additional effect leading to a decrease of the time step limit is that due to the enhancement of the actual liquid conductivity by a factor equal to |rnuss|. The combined effect of the aforementioned factors leads in some situations to a time step limitation significantly below that imposed by fluid convection, especially under low flow conditions. To avoid a substantial increase in computing time (and, hence, cost), a different scheme was implemented. Specifically the temperature at the center point of the 5-point difference operation (equivalent to 2-D. Laplacian differential operation) is taken at the new time. The usual linear stability analysis predicts unconditional stability.

In this scheme, the total heat flux to node 0 is given by:

$$
\begin{aligned}
\left(Q_{c n d}\right)_{o}^{n+1} & =\frac{1}{V_{o}} \sum_{t=1}^{i=4} A_{i-\circ} h_{i-\circ}^{n}\left(T_{\ell, i}^{n}-T_{\ell, o}^{n+1}\right) \\
& =q_{c n d}{ }^{n}-h_{c n d}^{n} T_{\ell, o}^{n+1}
\end{aligned}
$$

where the definitions of " $\mathrm{c}$ nd" and "h cnd" are obvious. Thus, an additional quantity is passed to subroutine JACOB, for the liquid energy equation. This quantity $h_{\text {cnd }}$ will affect both the right hand side of the equation, as a source, as well as 
the derivative of the equation with respect to liquid temperature (this derivative is required in the linearization process).

At this point it should be noted that this scheme was chosen and not a fully implicit one, because of the basic restriction of the THERMIT method of solution, namely that implicit cell coupling must appear only via pressure.

The only shortcoming of the scheme is the lack of strict energy conservation. For practical situations, this aspect was not found limiting, mostly because of the rather slow change of temperature in time. 


\section{References}

1. Reed, W.H. and H.B. Stewart, "THERMIT: A Computer Program for Three-Dimensional Thermal-Hydraulic Analysis of Light Water Reactor Cores," Mid-1978 draft of forthcoming EPRI report.

2. Ribando, R.J., personal communication, January 1979.

3. Arconne National Laboratory Reactor Development Program nuarterly Progress Report, ANL-RDP-78, December 1978.

4. Golden, G.H. and J.V. Tokar, "Thermophysical Properties of. Sodium," ANL-7323, August 1967.

5. Chung, T.Y., "Finite Element Analysis in Fluid Dynamics," 1978.

6. Niqmatulin, R.I., "Equations of Hydrodynamics and Compression Shock in Two-Velocity and Two-Temperature Continuum with Phase Transformations," Fluid Dynamics, Vol. 2, No. 5, pp. 20-28, 1968 .

7. Chen, J.C., "A Correlation for Boiling Heat Transfer to Saturated Fluids in Convective Flow," ASME Paper 6.3-HT-34, August 1963.

8. Autruffe, M., "Theoretical Study of Thermohydraulic Phenomena for LMFBR Accident Analysis," M.S. Thesis, Department of Nuclear Engineering, MIT, September 1978.

9. Kaiser, A., Peppler, W. and L. Voross, "Untersuchungen der Stromungsform, des Druckabfalls und des Kritischen Warmeflusses einer Zweiphasenstromung mit Natrium," KFK 2085, Karlsruhe, April 1975.

10. Ribando, R.J., et al., "Sodium Boiling in a Full Length 19-Pin Simulated Fuel Assembly (THORS Bundle 6A), ORNL/TM-6553, January 1979.

11. Thompson, D.H., et al., "SLSF In-Reactor Experiment P3A-Interim Posttest Report," ANL/RAS 77-48, November 1977.

12. O.E. Dwyer, "On the Transfer of Heat to Fluids Flowing Throuqh Pipes, Annuli and Parallel Plates," Nucl. Sci. Enq., 17, 336, 1.963. 
13. Camaels, W.G. and Forster, H.K., "Test of a Heat Transfer Correlation for Boiling Liquid Metals," Jet Propulsion, 27, 1104-1106, October 1957.

14. Chen, J.C., "A Proposed Mechanism and Method of Correlation for Convective Boiling Heat Transfer with Liquid Metals," BNL 7319, August 1963.

15. Tang, Y.S., Coffield, R.D. and R.A. Markley, "Thermal Analysis of Liquid Metal Cooled Fast Breeder Reactors," ANS Monograph, 1978 . 


\section{A. Introduction}

Although the two-fluid (six equations) model in theory provides the utmost in capability and physical consistency, it is in this generality and complexity that its major drawback lies. The presence of the interfacial exchange terms calls for a number of constitutive equations for which current understanding is rather incomplete. A "mixture" (less-thansix equation) model then becomes appealing because:

1) it theoretically needs fewer constitutive equations;

2) the constitutive equations still necessary for closure are believed to be more amenable to interpretation and use of available experimental data; and

3) computationally it may be less expensive.

The objective of this task is to develop a code based on the mixture model approach. Consistent with the recommendation of Section II, this code is being developed by appropriately modifying the two fluid version of the XYZ code, THERMIT. Therefore, much of the work described in section III*, Two Fluid Code Development, is also applicable to this task. Fyl979 work specific to this task is described in sections IV.B through IV.E which follow. A summary and outline of work planned for FY1980 is given in Section IV.F.

* See Sections III.B and IIT.D. 


\section{B. Model Selection}

obviously some generality is lost with a mixture model. However, it is felt that for a certain class of applications such a model could be chosen as to give an entirely adequate capability. An investigation has been started regarding this model selection process, in an attempt to maximize the potential advantages of a mixture model.

First, an overall assessment was made of all the twophase flow models, starting with the generalized three-equation model and going up in refinement and complexity to the "twofluid" (six equation) model. All these models are listed in order of increased number of balance equations and constitutive laws in Table IV-1, adapted from Ref. 1 . Once the general characteristics of these models were well understood, with respect to their relative advantages and disadvantages, the next logical step was to specify those aspects and features that should be considered in connection with sodium boiling simulation. Some of these aspects are:

1) The liquid is superheated at the time of boiling inception;

2) When both phases are present, the liquid is at saturation:

3) Once vapor is formed, an annular flow pattern is establithed, with liquid film on the wall;

4) At very high void fraction, liquid may exist as saturated droplets surrounded by superheated vapor, now in direct contact with the solid wall;

5) Except for the situation described in (4), wall fxiction and heat flux may be considered applicable to liquid only; 
Table IV-1

Two- Phase Flow lloucle (Ref. 1)

\begin{tabular}{|c|c|c|c|c|c|c|}
\hline & \multicolumn{2}{|c|}{ linpo:ed Restrlations } & \multirow{2}{*}{$\begin{array}{c}\text { Remoining } \\
\text { dependent vorloblos }\end{array}$} & \multirow[b]{2}{*}{$\begin{array}{l}\text { Batance equutions } \\
\text { wrltten lit pructico }\end{array}$} & \multicolumn{2}{|c|}{ Constlitutive lows noeded } \\
\hline & Numbier & Nature : Lows for & & & Nurnber & Nature : Laws for \\
\hline$D$ & 3 & ${ }_{\text {(c.g. homogeneous modoll }}^{\Delta w .} \Delta i_{1} \Delta i_{2}$ & $R_{2} p \cdot w_{1}$ & 3 inixturo bulanee Ens & 2 & $\begin{array}{l}\text { Mixluste wall frictiout } \\
\text { Mixlure wall heat flux }\end{array}$ \\
\hline C3 & \multirow{3}{*}{2} & $\underset{\text { (c.g. dilfusion models) }}{\Delta w} i_{2}$ (or $\Delta i_{1}$ ) & $R_{2} p$ & $\begin{array}{c}3 \text { mixture bulanco Eqs } \\
+\quad 1 \text { pliase Ualancu Eq. (mass) }\end{array}$ & 3 & $\begin{array}{l}\text { Mixture wall friction } \\
\text { Mixlure woll heal flux } \\
\text { Muss interaction term }\end{array}$ \\
\hline $\mathrm{C} 2$ & & .10 & & $\begin{aligned} & 3 \text { mixture balance Eqs } \\
+ & 1 \text { phoso balonce Eq. (energy) }\end{aligned}$ & 4 & $\begin{array}{l}\text { Mixture woll frictlon } \\
\text { Wall heat flux for each phaso } \\
\text { Enctuy inturaction term }\end{array}$ \\
\hline $\mathrm{C1}$ & & $\underset{\text { (o.g. thermal oqullibrium) }}{\Delta i_{1} \quad \Delta i_{2}}$ & $R_{2} p w_{1} w_{2}$ & $\begin{aligned} & 3 \text { mixture balancu Eqs } \\
+ & 1 \text { phase bilance Eq. (momentum) }\end{aligned}$ & 4 & $\begin{array}{l}\text { Wall friction lor ejcli pliase } \\
\text { Mixturu wall heat flux } \\
\text { Momentum Interaction term }\end{array}$ \\
\hline 33 & \multirow{3}{*}{1} & $\Delta w$ & $R_{2} p w_{1} \Delta i_{1} \Delta i_{2}$ & 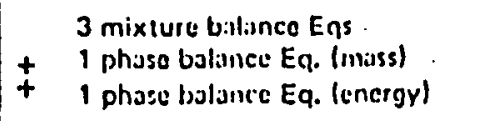 & 5 & $\begin{array}{l}\text { Mixture wall friclion } \\
\text { Wall letat flux for tilch phase } \\
\text { Mass, eneroy interat:tlon terms }\end{array}$ \\
\hline 82 & & \multirow{2}{*}{$\Delta i_{2}\left(\right.$ or $\left.\Delta i_{1}\right)$} & \multirow{2}{*}{$\mid \begin{array}{llll}R_{2} & p & w_{1} & w v_{2} \\
\Delta i_{1} & \left.\text { (or } \Delta i_{2}\right)\end{array}$} & $\begin{aligned} & 3 \text { mixture balitnce Ens } \\
+ & 1 \text { pliase bulisnci Eq. (nwss) } \\
+ & 1 \text { phase bulance Eq. (momentum) }\end{aligned}$ & 5 & $\begin{array}{l}\text { Wall fiction lor eakth phase } \\
\text { Mixiutu wall hejt llux } \\
\text { Mass, inomentum interictlon terms }\end{array}$ \\
\hline$B 1$ & & & & $\begin{aligned} & 3 \text { mixture balance Eqs } \\
+\quad & 1 \text { phase balance Eq. (mnmentum) } \\
+\quad & 1 \text { phose ballance Eq. (energy) }\end{aligned}$ & 6 & $\begin{array}{l}\text { Wall friction lor cach pilitie } \\
\text { Wall heat flux for edach phase } \\
\text { Momentunt, encrgy interaction terms }\end{array}$ \\
\hline$A$ & 0 & . & $R_{2} p w_{1} w_{2} \Delta i_{1} \Delta i_{2}$ & $\begin{array}{l}3 \text { mixture bolance Eqs } \\
+\quad 3 \text { phase balance Eqs } \\
\text { (or } 6 \text { phose bilance Eqs) }\end{array}$ & 7 & $\begin{array}{l}\text { Wall friction } \mid \text { for eoch phose } \\
\text { Wall hest flux } \mid \text {. } \\
\text { Mass. momentum, energy intersetion } \\
\text { eorms }\end{array}$ \\
\hline
\end{tabular}

where : $\begin{aligned} & R_{2} \text { - void area fraction } \\ & i \quad \text { - phase enthalpy } \\ & \underset{w}{p} \text { - pressure } \\ & \quad \text { - phase velocity }\end{aligned}$


6) When the disruption of the liquid film begins, direct contact between vapor and wall should be accounted for via a wall contact fraction.

With these features in mind, four models out of the initial eight were selected for further investigation, regarding the required consitutive laws and restrictions. A comparison of these models is shown in Table IV-2. Based on this analysis, it has been decided to pursue a generalized three-equation model, allowing for relative motion between phases through the introduction of relative velocity. Thermal equilibrium will be assumed, except for the liquid superheat preceeding the inception of boiling. A major part of future work will be devoted to the development and implementation of a general and consistent multidimensional representation of relative velocity. If at some point in the future it appears desirable to include the vapor superheat, the three-equation model can be easily extended to a four-equation model through the addition of a separate continuity equation for the vapor phase. Of course, this would entail the specification of the vapor generation rate, $\Gamma$. 


$$
\text { IV }-5
$$

Table IV-2

Two-Phase Flow Model Comparison

\begin{tabular}{|c|c|c|c|c|}
\hline \multirow[b]{2}{*}{$\begin{array}{c}\text { Constitutive laws } \\
\text { and restrictions }\end{array}$} & \multicolumn{4}{|c|}{ Number of balance equations } \\
\hline & $\begin{array}{l}6 \\
(A) \\
\end{array}$ & $\begin{array}{c}5 \\
(B-2) \\
\end{array}$ & $\begin{array}{c}4 \\
(c-3) \\
\end{array}$ & $\begin{array}{c}3 \\
(D) \\
\end{array}$ \\
\hline Wall friction (liquid) & $\sqrt{ }^{1}$ & $\sqrt{ }^{1}$ & - & - \\
\hline Wall friction (mixture) & - & - & $v^{2}$ & $V^{2}$ \\
\hline Heat flux (liquid) & $r$ & - & - & - \\
\hline Heat flux (mixture) & - & $\sqrt{ }$ & $\checkmark$ & $\checkmark$ \\
\hline Mass exchange & $\checkmark$ & $\sqrt{ }$ & $\checkmark$ & - \\
\hline Momentum exchange & $\checkmark$ & 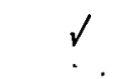 & - & - \\
\hline Energy exchange & $\checkmark$ & - & - & - \\
\hline Relative velocity & - & - & $\sqrt{ }^{2}$ & $\sqrt{ }^{2}$ \\
\hline Liquid superheat & - & $\checkmark$ & $\checkmark$ & $\checkmark$ \\
\hline Vapor superheat & - & - & - & $\checkmark$ \\
\hline
\end{tabular}

Notes:

1 - one-dimensional form.

2 - three dimensional form 


\section{Model Formulation}

Whenever a reduced (i.e., less than six) set of conservation equations is employed in describing the two-phase flow, the closure of the chosen formulation is effected through additional restrictions on the evolution of the dependent variables (Ref. I). Regarding phase velocities, such a restriction is customarily expressed by a correlation for either slip ratio $\left(\mathrm{S}=\mathrm{V}_{\mathrm{v}} / \mathrm{V}_{\ell}\right)$ or slip velocity $\left(\mathrm{V}_{\mathrm{r}}=\mathrm{V}_{\mathrm{v}}-\mathrm{V}_{\ell}\right)$. Closely related to the second approach is the drift velocity of the vapor with respect to mixture center-of-mass (or alternatively, centerof-volume) velocity.

One of the ground rules for the first stage of the mixture model development has been to use the two-fluid code THERMIT with a minimum of modifications for testing of various "lessthan-six equation" models. Consequently, an attempt was made to obtain a relationship between the interfacial momentum transfer coefficient (appearing in the phasic momentum equations of. the two-fluid model) and the slip ratio.

It rapidly became obvious that such an approach would be impractical, the reason being that even for one-dimensional. flows, the interfacial momentum transfer coefficienț, $k$, exhibits a very complex functional dependence with respect to slip, namely:

$$
K=f\left(S, \frac{\partial S}{\partial t}, \frac{\partial S}{\partial z}, v_{\ell}, \frac{\partial p}{\partial z}, \alpha, \rho_{v}, \rho_{\ell}, \ldots\right)
$$

A different approach was then taken, whereby the two phasic momentum equations will be replaced by a mixture momentum equa- 
tion (for the center-of-mass velocity) plus a relationship between phase velocities. The necessary formulation was developed for two forms of this relationship:

\section{a) Slip Ratio}

For three-dimensional applications, we define a slip ratio matrix such that

$$
\vec{V}_{V}=[S] \vec{V}_{\ell}
$$

and assume only "parallel" slip, that is, the matrix [S] is diagonal:

$$
[S]=\left[\begin{array}{ccc}
s_{x} & & 0 \\
& s_{y} & \\
0 & & s_{z}
\end{array}\right]
$$

From the Equation $(I V-2)$ and the definition of centerof-mass velocity:

$$
v_{m}=\frac{\left|\alpha \rho_{v} \vec{v}_{v}+(1-\alpha) \rho_{\ell} \vec{v}_{\ell}\right|}{\rho_{m}}
$$

where

$$
\rho_{\mathrm{m}}=\alpha \rho_{\mathrm{v}}+(1-\alpha) \rho_{\ell},
$$

one can obtain relationships expressing the phase $\mathrm{k}$ ( $\mathrm{v}$ or $\ell$ ) velocity in terms of the mixture velocity:

$$
\dot{v}_{k}=\left[c_{k}\right] \vec{v}_{m}
$$

where $\left[C_{k}\right]$ is again a diagonal matrix. For example, the coefficient lor the vapor velocity in the $z$ direction is: 


$$
\text { IV }-8
$$

$$
c_{z \ell}=\frac{S_{z} \rho_{m}}{\alpha \rho_{v} S_{z}+(1-\alpha) \rho_{\ell}}
$$

Using the Equation $(I V-6)$ a mixture momentum equation is then obtained in a form directly amenable to the numerical solution employed in THERMIT.

b) Slip Velogity

The slip velocity is defined as

$$
\overrightarrow{\mathrm{v}}_{\mathrm{r}}=\overrightarrow{\mathrm{v}}_{\mathrm{v}}-\overrightarrow{\mathrm{v}}_{\ell}
$$

Then, from Equations $(I V-4)$ and (IV-8), one can write:

$$
\overrightarrow{\mathrm{v}}_{\mathrm{v}}=\overrightarrow{\mathrm{v}}_{\mathrm{m}}+\frac{(1-\alpha) \rho_{\ell}}{\rho_{\mathrm{m}}} \overrightarrow{\mathrm{v}}_{r}
$$

and,

$$
\vec{v}_{\ell}=\vec{v}_{m}-\frac{\alpha \rho_{v}}{\rho_{m}} \vec{v}_{r}
$$

Using Equations $(I V-9)$ and $(I V-10)$, another mixture momentum equation is then obtained, again in a form readily adaptable to THERMIT's numerical techniciue. It may be mentioned that the mixture momentum equations resulting from these two treatments [(a) and (b) 1 differ only in the convective terms.

During FY1980, both approaches will be implemented, in fact converting the THERMIT two-phase, six equation model to a fiveequation model. [ 2 continuity, 1 momentum (mixture) and 2 energy equations]. After having modified the code in this manner, a wide variety of correlations for slip ratio and slip velocity can then be tested against experimental data. In carrying out these 
tests the code will be forced to run as a generalized three equation model by assuming sufficiently large values of the interfacial mass and energy exchange coefficients. Subsequently, the code can then be converted to a generalized three equation model and the appropriate correlations for slip ratio or slip velocity provided.

In addition, the question of well-posedness will be examined. It is well known (Refs. 2\&3) that the commonly. used unequal velocity models are ill-posed under some conditions. That is, the characteristics of the system of equations become in some situations complex, thus destroying the hyperbolic. (initial value) character of the equations. Thus, a careful investigation leading to an improved understanding of the problem is imperative if the model is to be placed on firm grounds. 
D. Code Testing and Application

1. Selection of Test Problem

A French steady state boiling experiment was chosen as an initial test case, given the avialability of not only the experimental results, but also calculational verification (Ref. 4). In addition, the 19-pin bundle used in the experiments utilized wire wrap spacers of uniform diameter, which greatly facilitates bundle representation, as well as the single-phase calibration against codes in the ENERGY family (Refs. 5,6 ).

The assembly layout is presented in Figure IV-1, along with some key geometrical parameters. The $x-y$ grid shown comprises 25 cells (dashed lines). While obviously not the only possible representation, this geometry was deemed adequate for obtaining a sufficiently detailed picture of the key flow quantities (i.e., temperature field, cross-flow distribution, etc.).

At this level of detail, the distinction betwecn "subchannel" and "porous body" approaches requires some clarification. Indeed, it seems that the two approaches converge, the basic difference remaining the choice of subchannels, which in turn affects the definition and determiniation of the relevant parameters, such as transverse pressure drop, turbulent mixing, etc. The essential potential advantage of the porous body approach resides in the fact that parameters just mentioned may be defined in a more general manner, greatly facilitating variations in the amount of detail in the rod bundle representation:

In this example case, only a fraction of the heated zone has been represented; specifically, the region of solution ex- 
All dimensions in $\mathrm{mm}$ :
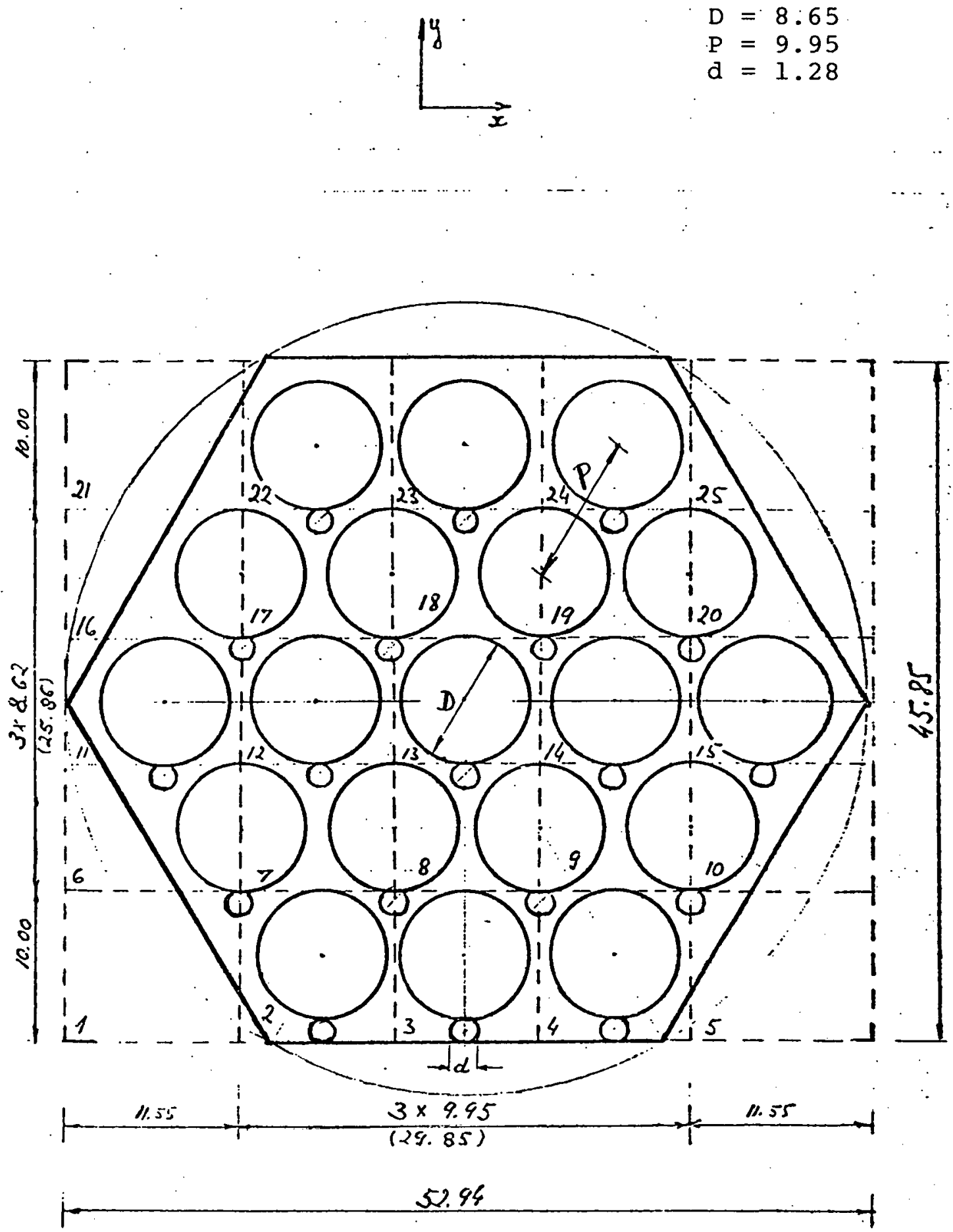

$$
\begin{aligned}
& D=8.65 \\
& P=9.95 \\
& d=1.28
\end{aligned}
$$

$\vec{x}$ 
tends over a length equal to the wire spacer lead. This length is divided into six equal axial intervals, each thus covering $60^{\circ}$ of the wire spacer sweep around a pin. The presence of the wire spacer is accounted for so far by specifying only the actual flow areas and fluid volumes at each axial level. The objective of this extremely detailed representation was to check whether a swirl flow can be induced. The small variations in flow areas and fluid volumes proved to be insufficient for generating a swirling motion along the can. This indicates the need for a more detailed representation of the wire spacer, with flow resistances along and across the wire projected onto the cartesian coordinate directions, thus obtaining the proper pressure field "biasing".

The correct simulation of the swirl effect is important in as far as providing the means for a significant enhancement of energy transfer over and above that due to eddy diffusivity. Currently, only a simple conduction mudel is used, in which lho heat flow between two fluid cells is given by:

$$
\mathrm{q}_{1,2}=\mathrm{A}_{1,2^{\mathrm{h}} 1,2}\left(\mathrm{~T}_{1}-\mathrm{T}_{2}\right)
$$

where,

$$
\mathrm{h}_{1,2}=2 \frac{\frac{\mathrm{k}_{1}}{\mathrm{~d}_{1}} \cdot \frac{\mathrm{k}_{2}}{\mathrm{~d}_{2}}}{\frac{\mathrm{k}_{1}}{\mathrm{~d}_{1}}+\frac{\mathrm{k}_{2}}{\mathrm{~d}_{2}}}
$$

The notations can be easily understood by reference to the following figure: 


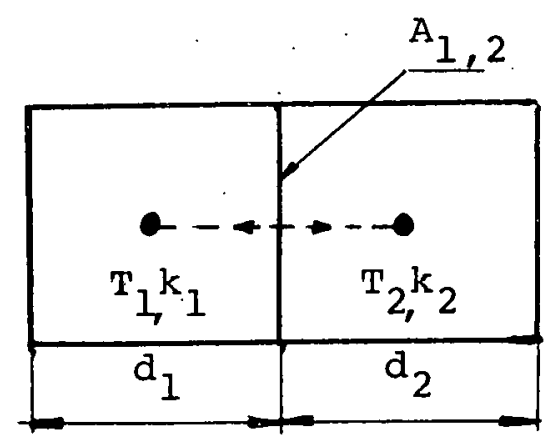

For a calculational check, a radially center-peaked but axially uniform power shape was selected. The exit fluid temperature distribution with and without liquid conduction is presented in Figures IV-2 and IV-3, respectively. As expected, the liquid conduction reduces the radial temperature gradients. In both calculations the hexagonal can was assumed an adiabatic boundary.

\section{Results}

Attempts to run simulations of the entire test section (modeled with 20 axial levels, covering both the heated and unheated zones, and with $25 \mathrm{x}-\mathrm{y}$ cells) proved unsuccessful. The attempted calculations, especially at low flow rates, took an impractically long time, with no assurance of convergence. An investigation of the problem indicates that a remedy is possible within the current numerical method and overall code framework. Details of this investigation are discussed in Section IV.E which follows. 

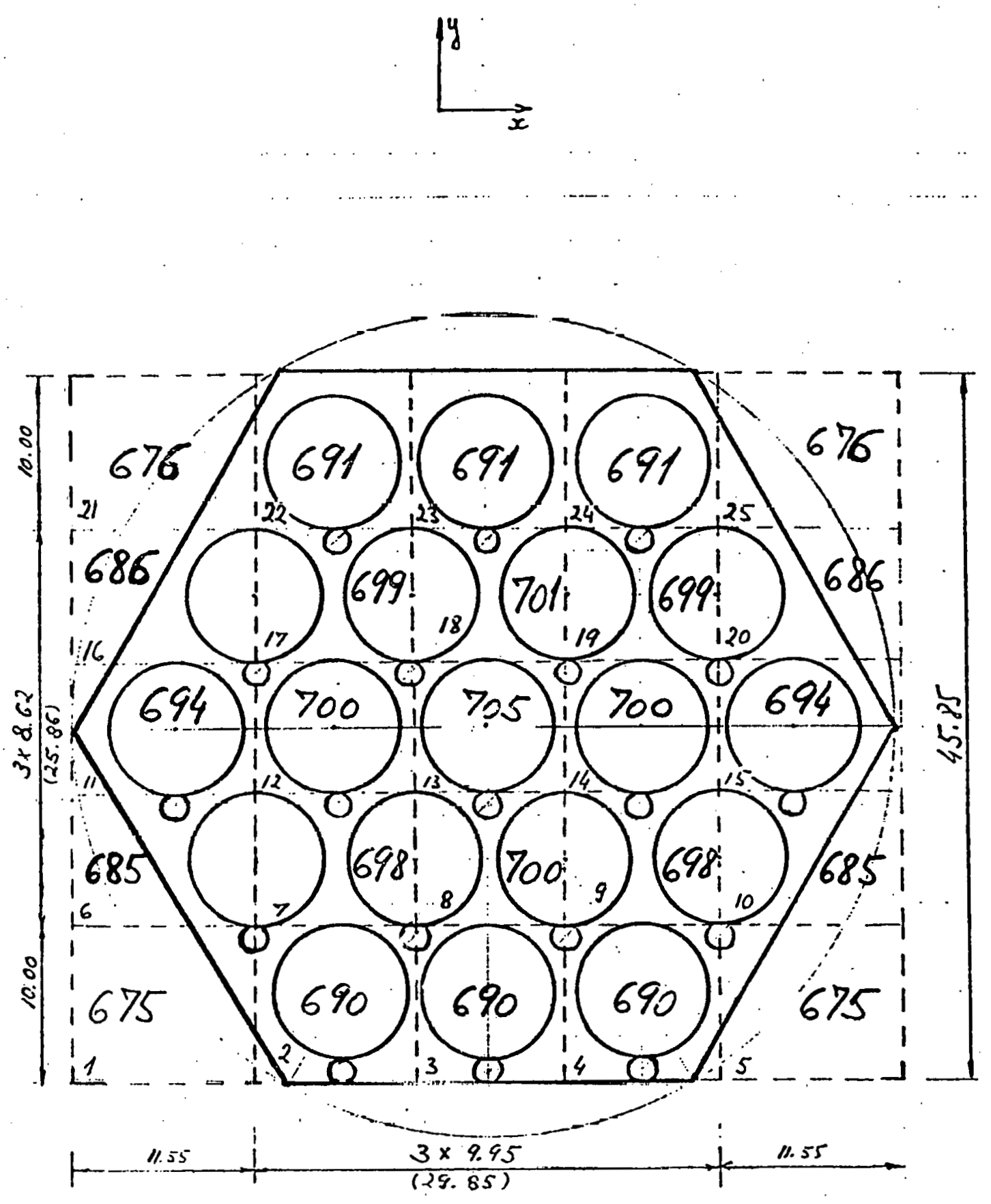

5.94

Figure IV-2

Predicted Exit Temperature Distribution with Lj.quid Conduction and without Wire Wrap Model, French Steady state Boiling Experiment 

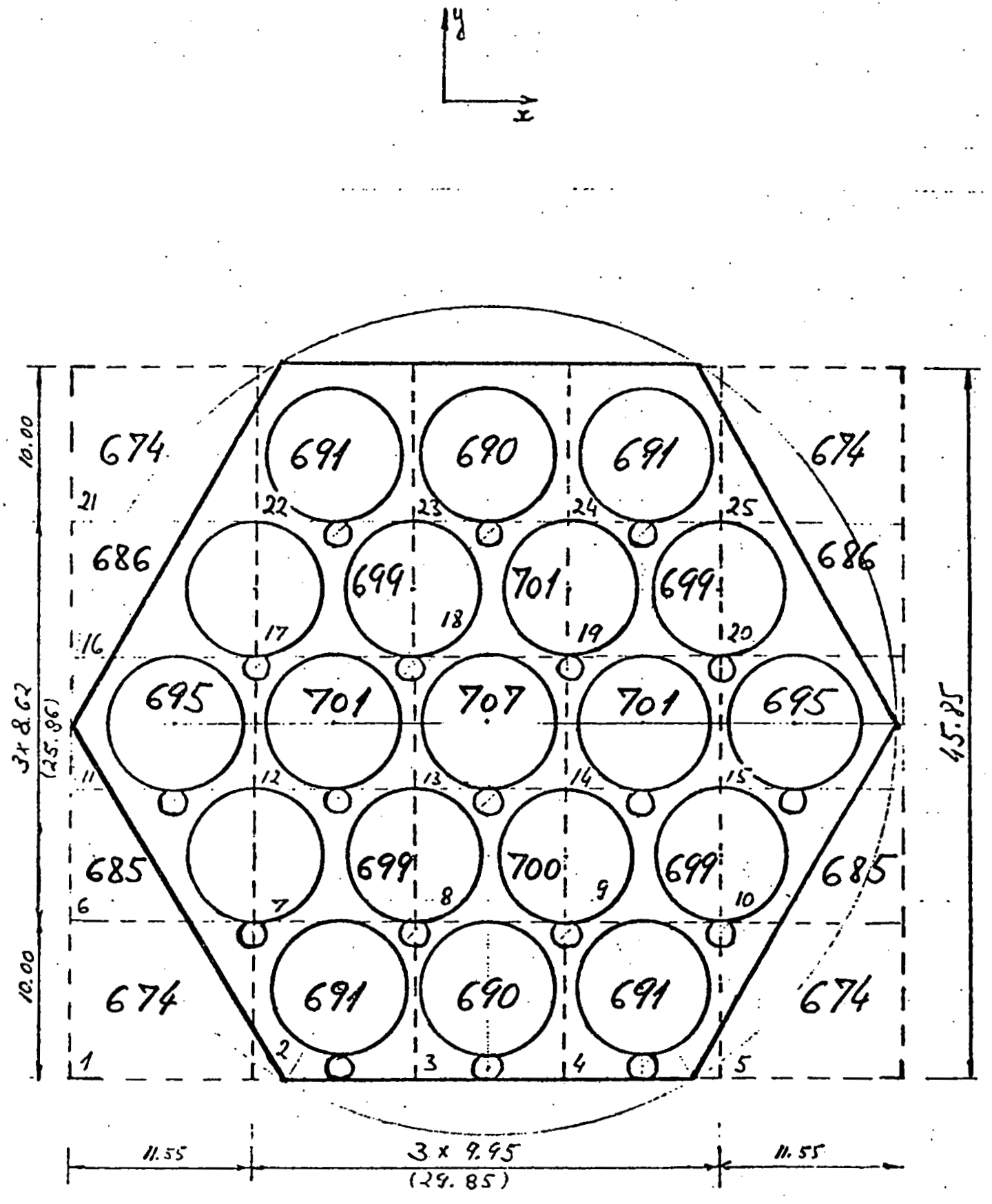

53.44

Figure IV-3

Predicted Exit Temperature Distribution without Liquid Conduction and without Wire Wrap Model, French steady state Boiling lixperiment 
E. Investigation of Numerical Method.

As montioned in scction IV.D, attempts to run simulations of the French 19-pin bundle experiment were unsuccessful. Specifically, for a detailed geometrical representation entailing the use of "small". (i.e., subchannel-size $X-Y$ cells) in singlephase liquid flows (i.e., virtually incompressible fluid), the rate of convergence of the pressure field proved to be exceedingly slow. Continuation of calculations with apparently far-fromconverged solution for the pressure (from which all other dependent variables, i.e., density, internal energy, etc are then inferred) then led to significant residuals in the mass and energy conservation equations which soon contaminated the overall solution. Some effort was devoted therefore to trying to understand the origin of this rather disturbing behavior. The results of this investigation are presented in the following paragraphs.

A typical momentum equation, in difference form (as used in THERMIT numerical method) appears as:

$$
\frac{v^{n+1}-v^{n}}{\Delta t}+\left(v \frac{\partial v}{\partial x}\right)^{n}+\frac{1}{\rho^{m}} \frac{p^{n+1}-p_{-} n+1}{\Delta x}=k_{V}^{n+1}
$$

where " $n$ " stands tor the time counter, and the (+) and (-) subscripts used for pressure refer to the two cells adjacent to the face on which the velocity $\mathrm{v}$ is defined. $\mathrm{K}$ is an equivalent resistance coefficient defined such that $\mathrm{K}_{\mathrm{V}}$ represent the total resistance (due to form and viscous drag) per unit mass of fluid. Comparing this term with the usual expression 
for losses, i.e., $\mathrm{fv}^{2}$, with $\mathrm{f}$ being a function of Reynolds number, roughness, etc., it follows immediately that $\mathrm{K}=\mathrm{fv}$. For example, if a Blasius-type formula is used for $f$ (i.e:, $f \sim 1 / \mathrm{v}^{0.25}$ ), then $\mathrm{K} \sim \mathrm{v}^{0.75}$.

From the momentum equation an expression relating the new velocity $\mathrm{v}^{\mathrm{n}+1}$ to the pressure diferential can be obtained by re-arrangement:

$$
v^{n+1}=\frac{1}{\rho^{n}}\left(\frac{\Delta t}{\Delta x}\right) \frac{1}{(1+k \Delta t)}\left(p_{+}^{n+1}+p_{-}^{n+1}\right)+\cdots
$$

Now a typical convective term, for a quantity $\phi$, in the mass or energy conservation equation is differenced as (after mul-. tiplying through by $\Delta t$ )

$$
\frac{\partial \phi v}{\partial \mathbf{x}} \rightarrow\left(\frac{\Delta t}{\Delta x}\right) \phi^{n} v^{n+1}
$$

Substituting the expression for $\mathrm{v}^{\mathrm{n}+1}$ into such a convective term shows that the pressure coefficient in the resulting equation is proportional to

$$
\left(\frac{\Delta t}{\Delta x}\right)^{2} \frac{1}{(1+K \Delta t)}
$$

Analyzing this last expression enables one to draw the following conclusions:

1) For a given $\Delta t$, the pressure coefficient varies as $1 / \Delta x^{2}$; thus a small mesh spacing in one direction will lead to larger pressure coefficient (i.e.. 
tighter coupling) compared to a direction in which a relatively coarser mesh is used;

2) For a low velocity, $K$ decreases and as a result, a further increase in the pressure coefficient occurs.

Since typically the axial mesh spacing is significantly coarser than the transverse spacing and because (unless 2 blockage exists or develops axially) the axial velocity is much larger than the lateral one, one sees inmediately lhat the pressure coupling will be much stronger in the radial direction. Since our solution of the pressure field is direct in the axial direction but iterative in going laterally from one subchannel to another, the convergence will be very slow. This aspect. is inherent to this method of solution when the matrix is marginally diagonally dominant to begin with.

This situation is not easily remedied. Because of the size of the matrix for a typical problem, a direct solution is practicaliy out of the question. We also feel that gtandard acceleration techniques, such as overrelaxation, may not be effective enough, due to the extreme character of the problem. After an intensive investigation as to potential courses of action, we have found a technique that we feel has the best chances of success. This is the method of fractional bleps (or operator splitting (Ref. 7). Essentially, the multidimensional finite-difference operator is "split" into two or three one-dimensional operators, applied sequentially. Since, for every one-dimensional operator the resulting matrix is tridiagonal (or block-tridiagonal), a direct solution can be 
used, thus circumventing the difficulty of marginal diagonal dominance. Moreover, this method opens up the possibility of devising a scheme with a higher degree of implicitness in order to further reduce computational time. 
F. Surnmary-Present Status and Plans for FY1980

1. Work Completed During FY1979

a. Model Selection

1) Completed assessment of advantages and disadvantages of various two-phase flow models, startiny with the gencralized threc equation model and yoing up in refinement and complexity to the six equation (two fluid) model.

2) Selected generalized three-equation model as basis for further work.

b. Model Formulation and Coding

1) Formulated mixture momentum equations for unequal velocity (< 6 equation) model using two different ways to represent the relationship between phase velocities (slip ratio and slip velocity).

c. Code Testing and Application

1) Attempted unsuccessfully to run HEM simulation of French steady state boiling test using'two fluid version of THERMIT*.

d. Investigation of Numerical Method

1) Began investigation of numerical method used in THERMIT to determine reason for difficulty encountered in Subtask C.I).

2. Plans for FY1980**

a. Model Selection

Completed

*By assuming sufficiently large values of the interfacial exchange coefficient.

* Note that this task will not be funded under the FY1980 program. However, some of this work closely relates to or is applicable to development of the two fluid version of THERMIT. In any event, work on the mixture model version of THERMIT will be completed by A. Schor as part of his SCD thesis. 
b. Model liormulation and coding

1) Conversion of THERMIT to five equation model [ 2 continuity, 1 momentum (mixture) and 2 energy equations using both of the approaches formulated in subtask 1.b.1).

2) Implementation of correlations for slip ratio or slip velocity selected from the results of subtask 2.c. (below).

3) Implementation of any further model or code modifications declded upur as a result of Subtasks 2.c or 2.d (below).

4) Conversion of THERMIT to a generalized three equation model.

c. Code Testing and Application

1) Rerun test case attempted in subtask 1.c.1) or select and run new test case [following completion of Subtasks 2.d (below)].

2) Use 5 equation version of THERMIT [from Subtask 2.b.1)] to test a wide variety of correlations for slip ratio and slip velocity against experimental data. * select: correlations to use in THERMIT.

3) Select and run cases for testing and application of generalized three equation version of THERMIT [from Subtask 2.b.4)] .

d. Investigation of Numerical Method

1) Complete investigation of difficulty encountered with HEM simulation of French steady state boiling test [Ref. Subtask 1.c.1)]. Decide upon and implement necessary modifications to THERMIT or other action. 
2) Examine the question of well-posedness of unequal velocity model. Decision on need for further investigation of this question. 


\section{References}

1. Boure; J.A., "Mathematical Modeling and the Two-Phase Constitutive Equations", European Two-Phase Flow Group Meeting, Haifa, Israel, June 1-5, 1975.

2. Ramshaw, J.D. and J.A. Trapp, "Characteristics, stability, and Short-Wavelength Pheonomena in Two-Phase Flow Equation Systems", Nucl. Science and Eng., 66 (1978).

3. Lyczkowski, R.W. et al., "Characteristics and Stability Analyses of Transient One-Dimensional, Two-Phase Flow Equations and Their Finite Difference Approximations", ASME paper 75-WA/HT-23.

4. Basque, G., Graud, D. and B. Menart, "Theoretical Analysis. and Experimental Evidence of Three Types of Thermohydraulic Incoherency in Undisturbed Cluster Geometry", IAEA Specialists' Meeting on Thermodynamics of Fast Breeder Reactor Fuel SubAssemblies, Karlsruhe, February 1979.

5. Khan, E., Rohsenow, W., Sonin, A., and N. Todreas, "A Porous Body Model for Predicting Temperature Distributions in Wire-Wrapped Fuel and Blanket Assemblies of a LMFBR", COO-2245-16TR, MIT (March 1975).

6. Todrcas, N. and S.F. VTang, "Input Parameters to the ENERGY Codes," Coo-2245-17TR (Ref. 1), MIT, January 1979.

7. Yanenko, N.N., "The Method of Fractional Steps," Springer Verlag, 1971. 


\section{DEVELOPMENT OF A MODEL TO PREDICT FLOW OSCILLATIONS IN LOW-FLOW SODIUM BOILING}

\section{A. Introduction}

This study was conceived as an attempt to model and simulate LMFBR sodium boiling behavior under low flow low power conditions. Results from the Thermal-Hydraulic outof-Reactor Safety Facility (THORS) at Oak Ridge Laboratory have indicated that stable boiling may be expected under LOPI-type conditions (Ref. 1); current models do not predict this behavior. In addition, oscillations in flow rate were noted during the THORS experiments, which may have contributed to the delay in reaching dryout.

Water was chosen as the working fluid for a series of experiments. The experiments, combined with an analytical program, comprised the project, which had as its objectives:

1. Development of a simple one-dimensional model for flow oscillations under low-power, low-flow conditions.

2. Performance of a series of experiments to test the model and to demonstrate the suitability of water as a simulant for liquid sodium.

3. Establishment of a set of criteria for comparison of water to sodium.

4. Comparison of water data to sodium data with the

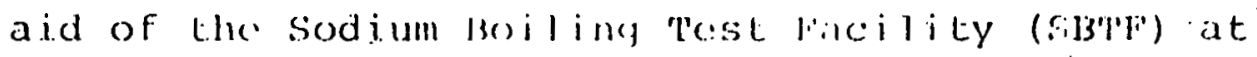
ORNL .

Work wich has becil completed durine IYy 1979 is described in section V.B through V.F which follow. A summary and outline of work planned for FY1980 is given in section V.G. 


\section{B. Model Formulation}

A simple, one-dimensional model has been developed which is conceived as an independent module to be inserted into a large systems code. The model consists of two parts. The first is a hydrodynamic model which describes bubble growth. The second is a thermal model which describes vapor generation. Tuyellier, the two parts arc solved to determine the vapor generation and bubble growth rate as a function of tame. Each of the model parts and the solution procedure are described in the following subsections.

\section{Hydrodynamic Model}

The hydrodynamic model has been developed with a system dynamics approach, both for ease of programming, and also because the form of the equations allows easy insight into the effect of loop hydraulics on the flow behavior. As shown in Figure V-l, the bubble is considered to be at constant pressure. The upper plenum is open to the atmosphere, pruvidisy a common "ground" pressure. The loop is then treated as an electrical circuit, with pressures analogous to voltages, and volumetric flow rates analogous to current. The part of the "circuit" marked " 1 " extends from the bottom of the bubble, through the lower plenum, up through the bypass leg and over to the upper plenum. Regardless of the number of bypass loops present, they can be lumped into one equivalent leg by a "parallel resistance" analogy. The inertances of these loops (analogous to inductance) are treated similarly. The part of the circuit marked "2" extends from the top of the bubble. to the upper plenum. The equations for these two legs are: 


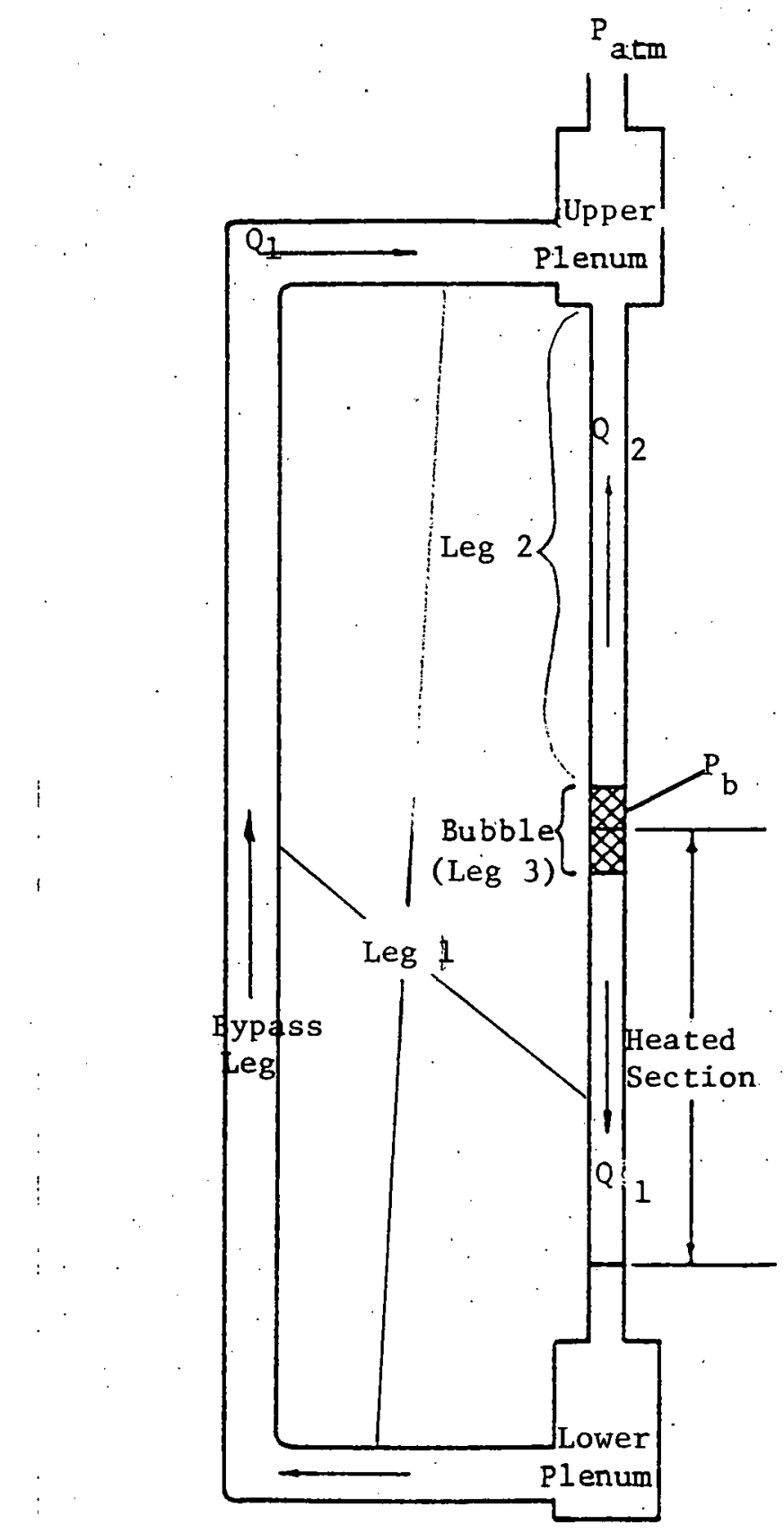

Figure $V-I$

Schematic of Loop Used in Development of Model to pradict plow Oscillations in InOW Flow Sodium Boiling 


$$
P_{b}^{*}-P_{a t m}=R_{1} Q_{1}+I_{1} \frac{d Q_{1}}{d t}
$$

and

$$
\mathrm{P}_{\mathrm{b}^{*}}{ }^{*}-\mathrm{P}_{\mathrm{atm}}=\mathrm{R}_{2} \mathrm{Q}_{2}+\mathrm{I}_{2} \frac{\mathrm{dQ}}{\mathrm{dt}}
$$

These are simply the momentum equations for incompressible flow cast in the circuit form. Here the pressure $P_{b}^{\star}$ has been redilned hy the hydrostatic pressure drop in each leg for ease of handling. The resistances are of the form:

$$
R=2 f \frac{L}{D} \frac{\rho Q}{A}
$$

and the inertances are of the form:

$$
I \cdot=\frac{p L}{A}
$$

which correspond to the friction and accelesaliun eimponent 3 of the pressure drop when multiplied by $Q$ and $\frac{d Q}{d t}$, respectively. Note that the resistance term is dependent on $Q$, the volumetric flow rate, through both the term $Q$ directly and the friction factor, $f$, indirectly, since $f$ is a function of the Reynolds number, $\frac{\rho Q D}{A \mu}$.

The third equation in the hydrodynamic model takes into account the compressibility of the vapor volume. The electrical analog to this is a capacitor. Similar to the current of a capacitor, then, the flow of a compressibility capacitance is defined:

$$
Q_{3}=c \frac{d P_{b}}{d t}
$$


where $C$, the capacitance is defined as $V / B$, the volume of the bubble divided by the bulk modulus of the vapor. The bulk modulus, though, is defined as $\rho \frac{d P}{d \rho}$. The equation has therefore, been cast in the form.

$$
Q_{3}=\frac{v_{g}}{\rho_{g}} \frac{d \rho_{g}}{d t} .
$$

again for ease of handling, since $\beta$ is empirical and this form involves properties only.

The sum of the flow rates, $Q_{1}+Q_{2}+Q_{3}$ is defined as the source flow, $Q_{S}$. Thus,

$$
Q_{s}=Q_{1}+Q_{2}+Q_{3}
$$

and this is equal to the net volumetric vapor generation.

2. Thermal Model

The derivation of the thermal model is arawn from the First Law of Thermodynamics, which states, for a system

$$
\delta Q-\delta W=\delta U
$$

where $Q$ here is the heat input to the system, $W$ is the work done by the system, and $U$ is the internal energy of the bystem. The enthalpy of a system is defined as

$$
\mathrm{H}=\mathrm{U}+\mathrm{PV}
$$

Substituting this into the First Law yields

$$
\delta Q-\delta W=\delta(H-P V)=\delta H-P \delta V-V \delta P
$$


The work term in the expression is actually pressure work done on the environment, so that $W=P \delta V$. This substitution gives

$$
\mathrm{dQ}+\mathrm{VdP}=\delta \mathrm{H}
$$

or, casting the equation in differential form,

$$
\frac{d Q}{d t}+v \frac{d P}{d t}=\frac{d H}{d t}
$$

If the system in question is defined as the bubble and enough fluid surrounding it so that there is no appreciable mass change with time, the system enthalpy change can be written

$$
\frac{d H}{d t}=\frac{d}{d t}\left(m_{\ell} h_{\ell}\right)+\frac{d}{d t}\left(m_{g} h_{g}\right)
$$

or

$$
\frac{d H}{d t}=m_{\ell} \frac{d h_{l}}{d t}+h_{\ell} \frac{d m_{\ell}}{d t}+m_{g} \frac{d h_{g}}{d t}+h_{g} \frac{d m_{g}}{d t}
$$

since $\frac{d m}{d t}$ sys $=0$, then $\frac{d m_{l}}{d t}=-\frac{d m_{v}}{d t}$, and

$$
\frac{d H}{d t}=\left(h_{g}-h_{\ell}\right) \frac{d m_{g}}{d t}+m_{\ell} \frac{d h_{\ell}}{d t}+m_{g} \frac{d h_{g}}{d t}
$$

or

$$
\frac{d H}{d t}=h_{f g} \frac{d \prime \prime g}{d t}+m_{g} \frac{d h_{g}}{d t}+m_{\ell} \frac{d h_{\ell}}{d t}
$$

The last two terms on the right hand side of Equation (V-16) are changes in the sensible heat of the system. These terms are negligible when compared to the first term, due to the large value of the latent heat vaporization, $h_{\mathrm{fg}}$. Thus, 


$$
\frac{d H}{d t} \approx h_{f g} \frac{d m}{d t}
$$

and Eqn. $(\mathrm{V}-12)$ can be written

$$
\frac{d Q}{d t}+v_{g} \frac{d P}{d t}=h_{f g} \frac{d m_{g}}{d t}
$$

Since $m_{g}=\rho_{g} v_{g}, \frac{d m_{g}}{d t}=\rho_{g} \frac{d v_{g}}{d t}+v_{g} \frac{d \rho_{g}}{d t}$. Rearranging terms then gives:

$$
\frac{d v_{g}}{d t}+\frac{v_{g}}{\rho_{g}} \frac{d \rho_{g}}{d t}=\frac{\frac{d Q}{d t}+v_{g} \frac{d P}{d t}}{P_{g} h_{f g}}
$$

It should be noted that

$$
\frac{v_{g}}{\rho_{g}} \frac{d \rho_{g}}{d t}=Q_{3}
$$

in the hydrodynamic model, and

$$
\frac{d V_{g}}{d t}=Q_{1}+Q_{2}
$$

from that model. Thus, the right hand side of the above equation represents the source flow, $Q_{1}+Q_{2}+Q_{3}$, and it can be written:

$$
Q_{S}=\frac{\frac{d Q}{d t}+v_{g} \frac{d P}{d t}}{\int_{g}{ }^{h g}}
$$

\section{Solution Procedure}

A solution for $Q_{1}, Q_{2}$ and $Q_{3}$ requires that the source flow calculated from the hydrodynamic model (Fqns. V-1, V-2, $\mathrm{V}-6$ and $\mathrm{V}-7)$ be equal to that calculated from the thermal 


$$
\mathrm{V}-8
$$

model (Eqn. V-22). This is accomplished by quessing the pressure in the vapor bubble and solving the equations iteratively until the pressure guess produces agreement between the two parts of the model. A computer code has been written to perform the solution. Results of preliminary testing of the model, to determine whether it will perform satisfactorily, are discussed in Section V.D. 


\section{Experimental Apparatus}

A water test loop has been designed and constructed to provide data which can be used in formulating and testing the analytical model described in section V.B. This loop is an upgraded version of the loop used previously at MIT for the natural circulation flow boiling experiments reported in Ref. 2 .

The loop is shown in Figure $\mathrm{V}-2$. The heater rod is driven by a 7-kw DC generator, which provides a uniform heat flux along the tube. The upper and lower unheated zones, simulating the axial blanket and fission gas plenum found in current LMFBR designs, are made of Pyrex tubing, to faciliate visual observation of flow behavior during the experiments. The loop is valved to provide several operating modes, including natural circulation, pumped flow with bypass, and pumped flow without bypass. An orifice flange has been installed as indicated to allow the varying of resistance in the pipe, thereby changing the flow rates from test to test. The diameter of the heater and glass tubes, 0.152 inches, was chosen as being a standard size very close to the nominal hydraulic diameter of an FTR subchannel. Lengths of the sections were chosen to correspond closely to an FTR assembly. A full comparison of the properties and parameters of the loop with LMFBR designs may be found in Ref. 2 .

The remainder of the loop is constructed of 1 inch ID stainless steel pipe, with the exception of the plena, which are 8 inches in diameter. These values were chosen to re- 


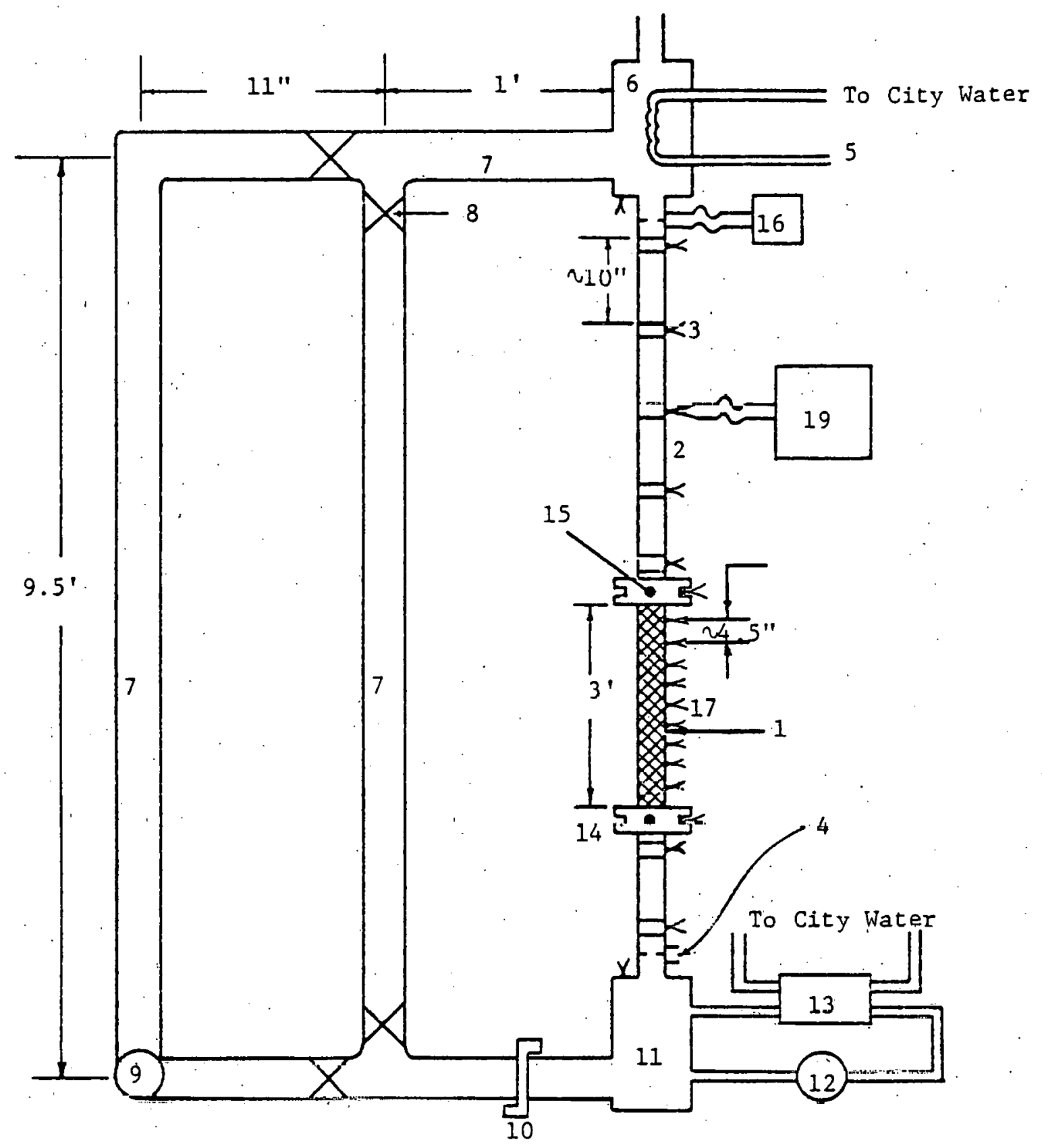

Note: Numbers refer to Table $\mathrm{V}-1$ on following page

Figure $\mathrm{V}-2$

Schematic of Water Test Loop Used to

Simulate Low Flow Sodium Boiling 
Table V-l

Component Number

1

2

3

4

5

6

7

8

9

10

11

12

13

14

15

16

17

18

19

\section{Function}

Heater Tube - $0.25^{\prime \prime}$ OD

Pyrex Tubing - $6 \mathrm{~mm}$ OD

Swagelok Tee for Thermocouple Insertion

Orifice for $\Delta \mathrm{P}$ Transducer Cooling/Heating Coil for Plenum Upper Plenum - 8"I.D. $x$ 8" ht. Stainless Steel Bypass Pipe I" T.D.

Ball Valve for Flow Control.

Pump

Orifice Flange

Lower Plenum 8" I.D. $x$ 8" ht.

Heat Exchange Loop Pump

Heat Exchanger

Connection to $7 \mathrm{kw}$ DC Generator

Insulator and Tyco Pressure Transducer

Validyne $\Delta \mathrm{P}$ Cell across Orifice Thermocouple on outside of Heater Tube

Thermocouple Inserted into Swagelok Tee

Data Acquisition System 
duce any hydraulic effects the rest of the loop might have. on the "primary" section. The plena have heat exchange capability, the lower by direct fluid replacement, and the upper by a copper cooling coil. This temperature control provides an analog to the temperature profile in an LMFBR.

The data acquisition system needed to perform experiments has been received and installed. The software for this system has not been received, however, and so experimentation has not yet begun. In this interim, thermocouples have been installed into fittings in the Pyrex sections for the determination of the temperature-time behavior of the unheated sections of the loop. Thermocouples will be tied onto the outside of the heater tube when experimentation begins. In addition, calibration of the guage and differential pressure transducers, to be installed at the heater inlet and outlet, and across the orifices indicated in the drawing, respectively, has been completed. These instruments will provide a measure of the flow rate, regardless of direction, during the tests. With this quantitative information, plus qualitative observation of the bubble growth and collapse patterns, sufficient data should be gathered to allow comparison with analytical predictions.

Tnstallation of the software is expected to be finished before the end of October 1979, with experimentation planned to commence shortly thereafter. 


\section{Preliminary Analytical Results}

Several computer simulations have been performed in order to test in a general way whether the model is performing in a way that is at least qualitatively similar to experimental observations. Results to date are very promising, but more computer runs are planned, as well as some minor modifications to. the code.

In order to run the code, values for the diameters and lengths of loop components must be input. There is also the capability to input additional flow reistances (e.g. elbows, orifices, tees, etc.). The code has been improved so that a temperature profile in the unheated part of the "primary" side of the loop may be input. The nodal lengths and temperatures of each node in this scheme are input to the code. This scheme allows a realistic simulation of the conditions that actually exist during a transient, since nodal average temperatures are recalculated at each time step. When the bubble is growing, hot fluid is pushed into cooler nodes, raising the temperatures in cooler areas. The temperature is also increased because of condensation heat transfer to the liquid film on the walls. When the bubble begins to collapse, however, cool liquid from above is pulled down to reduce the temperature of lower nodes: When a simulation begins, the lowermost node is set to saturation to allow the bubble to grow. When the bubble collapse reduces the temperature in the lower nodes below saturation, net condensation may exceed net evaporation, and the bubble may collapse completely. In order to allow the simulation to continue, a 
routine has been added to reset the lowermost nodal temperature to saturation and effectively restart the transient with a new temperature profile.

The capability now exists for running simulations with sodium properties, as well as for producing computer-generated plots of flow rate, pressure, and bubble length versus time. Using the code in its current form, several of the computer generated plots described above have been obtained. Some examples are shown in Figures $\mathrm{V}-3$ through $\mathrm{V}-5$. The conditions during each run - fluid, temperature profile, and condensation heat transfer coefficicnt - are indicated on Fig. V-3. on the basis of results such as these, it is clear from a qualitative standpoint, that the code is predicting what is being seen. Quantitatively, the oscillation frequency in sodium is close to that seen in SLSF and THORS experiments, although the test section geometries differ somewhat from the water Test Loop. In addition, some rough experimental temperature measurements have been made, using a digital thermometer, at the interfalte of the heater and upper unheated zone. While the measurements were very crude and likely to be inaccurate in an absolute sense, the trends seem in these observations - that a rising temperature during bubble growth followed by a temperature drop during bubble collapse - lave been reproduced by computer simulations. In addition, rough measurement of oscillation frequency during visual observation testing agree very closely to those predicted by the code.

Purther and morc accurate comparison of experimental measurements to computer prodiction is stalled until the berinning of fully instrumented experimentation. 


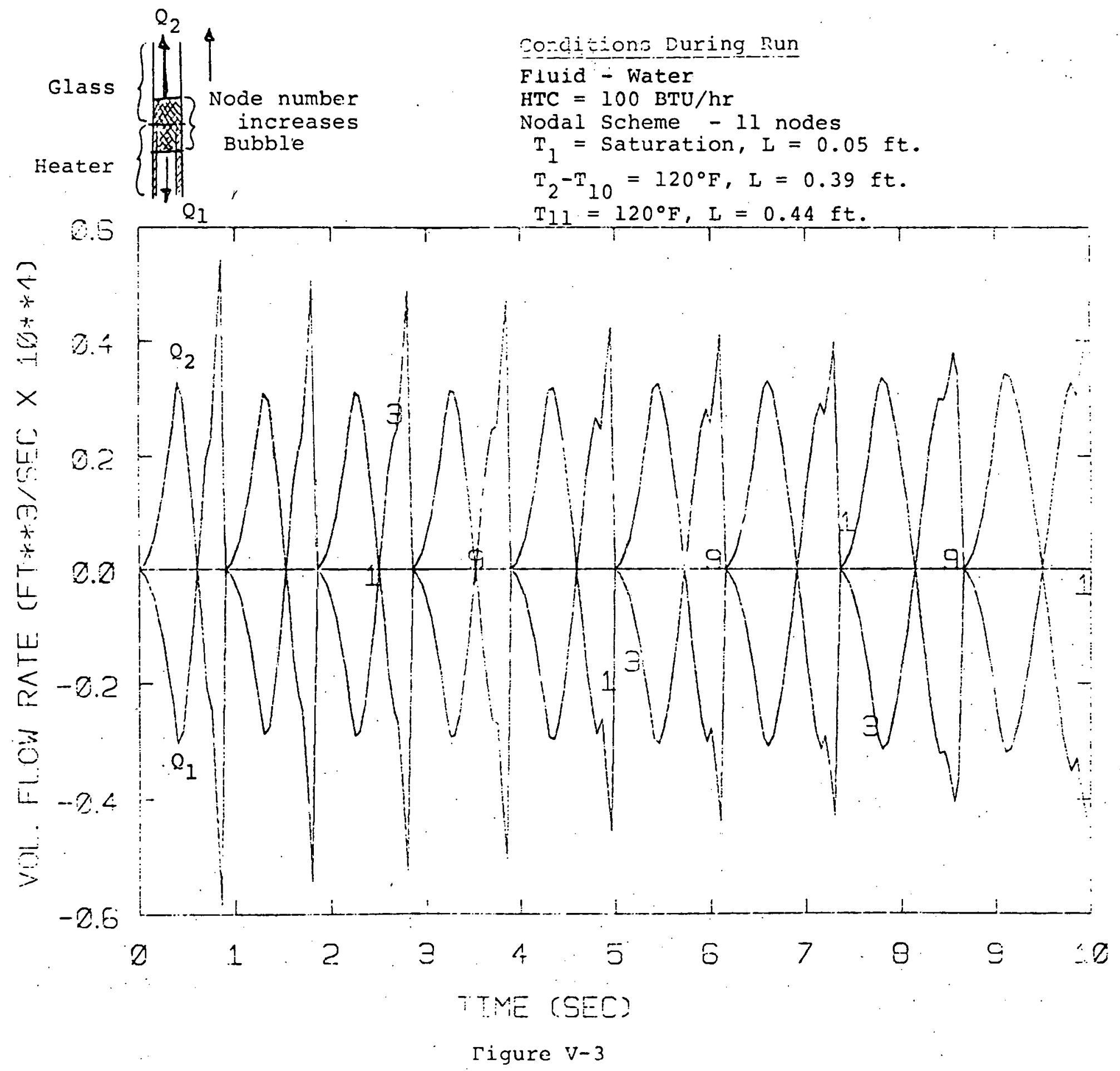




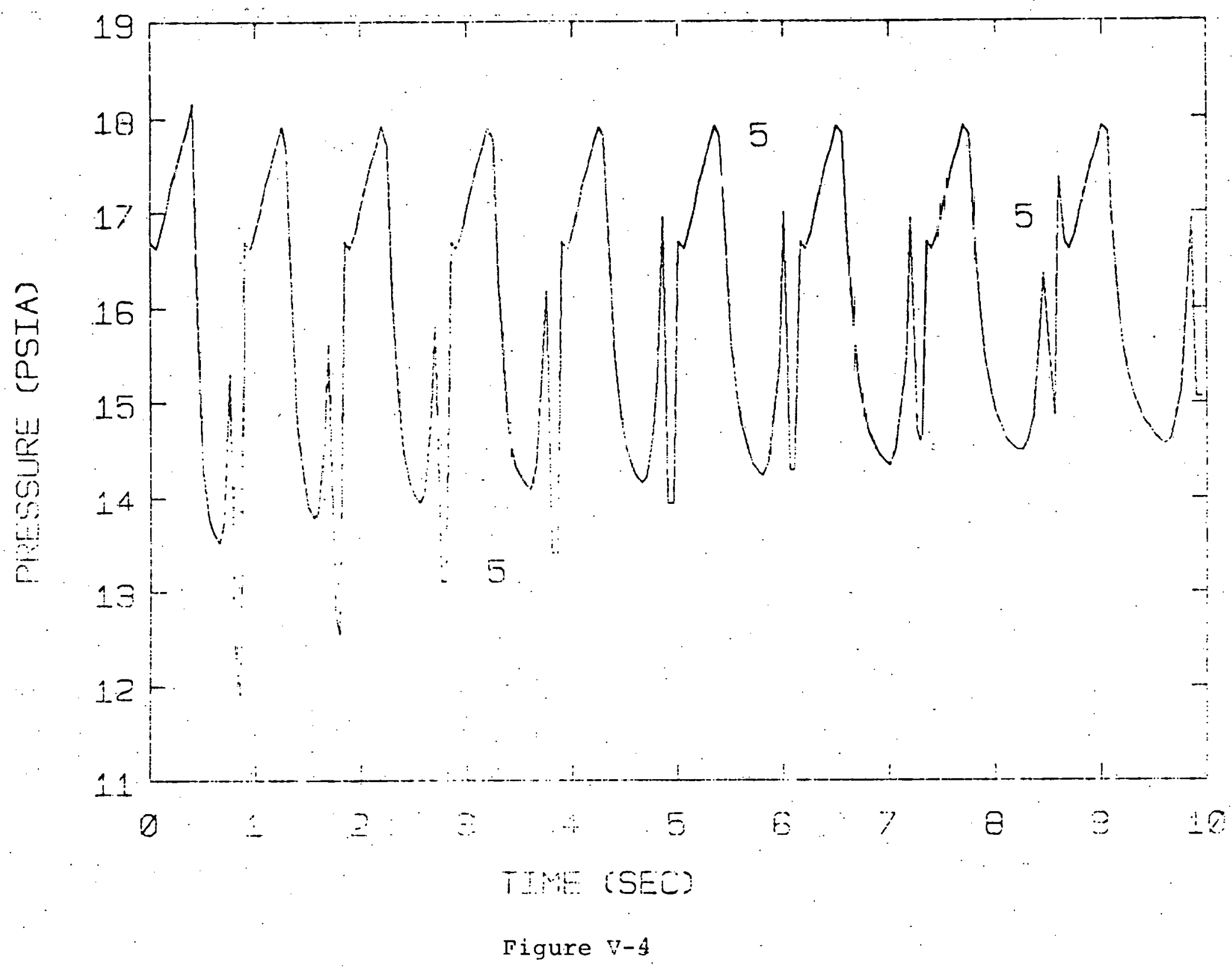




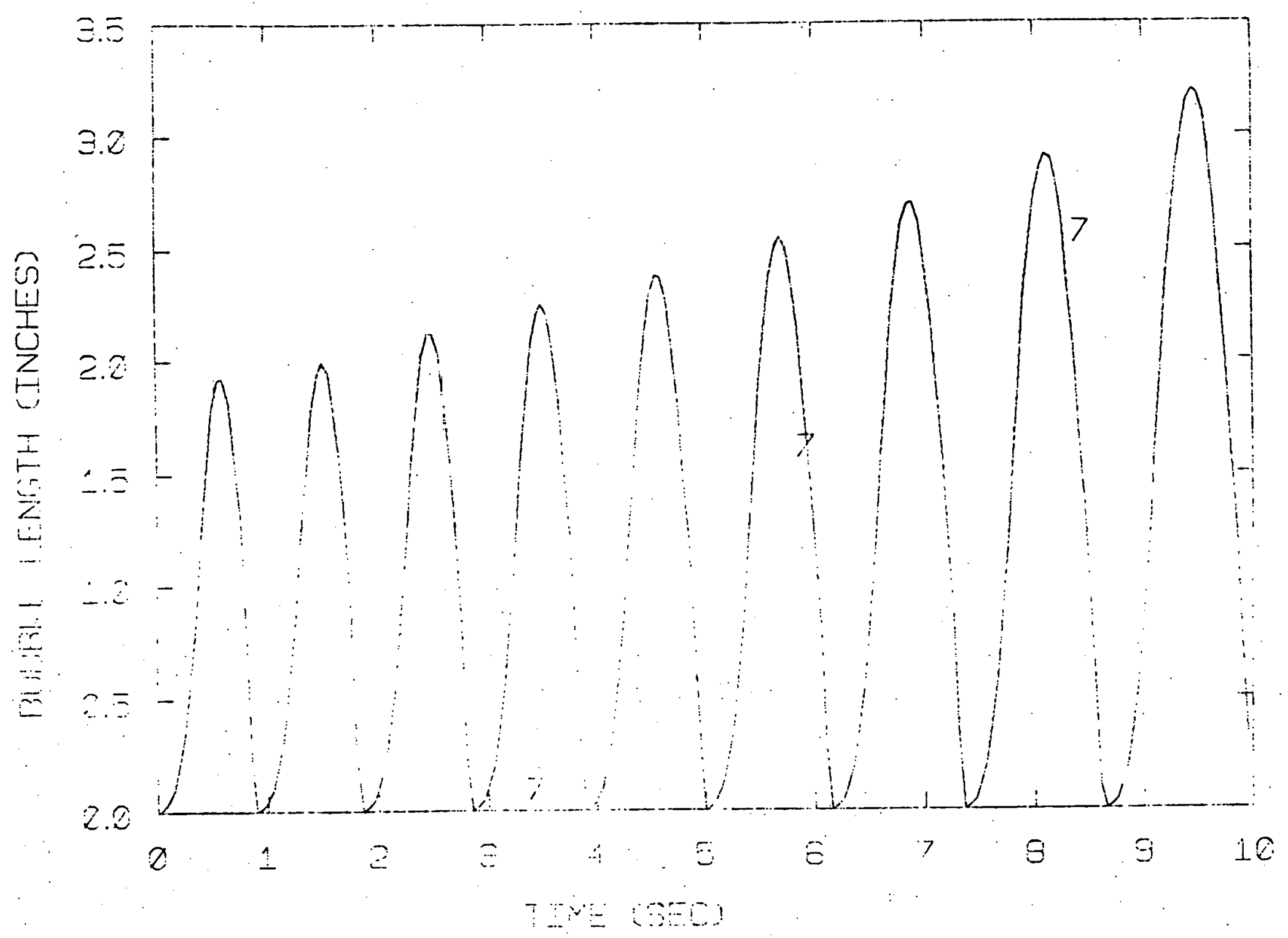

Figuro $V-5$ 
E. Preliminary Experimental Results

Until the loop is fully instrumented and the data acquisition system is in place with operative software, quantitative gathering of detailed and accurate data is impossible. However, several preliminary tests have been performed in order to check. out operation of the loop and see whether the gross phenomena were similar to those observed in liquid sodium tests. The results, in detail, of these "visual observation" tests have been previously reported and will not be repeated here. In summary, though, several points can be made:

1. Flow oscillations can be produced which are qualitatively similar to those observed in sodium experiments involving both natural and forced circulation flow (Refs. 3 and 4).

2. The behavior of the loop is very dependent on the conditions chosen for the test; that is, bypass flow rate, natural or forced convection, power to the heater, and method of introduing boiling (e.g. flow reduction, pump stoppage, power increase). Results appear to be reproducible, given the same experimental procedures.

3. Both analytically and experimentally, one of the key factors in the flow behavior is the temperature profile in the unheated zone. It is expected that accurate measurement of this parameter will yield significant insight into why the flow behaves differently in different experiments. The temperature of the unheated zone and how it changes with time may indeed be the most important single factor in modellling liquid sodium with water.

One further test using a digital thermometer to measure fluid temperature at a single point in the unheated zone was also performed, and is described in the previous section. A more quantitative description of loop behavior will be forthcoming upon the commencement of fully instrumented experimentation. 


$$
V-19
$$

F. Comparison of Sodium and Water Experimental Results

A set of criteria has been developed to compare water and sodium test data. These criteria derive from the non-dimensionalization of the governing equations for the hydrodynamic and thermal models.

Without going through a detailed derivation of these criteria; they are:
1) $\frac{\rho V D}{\mu}$ (Reynoids number),
2) $\frac{\rho_{f}}{\rho_{g}}$ (density ratio),

and

3) $\frac{q_{\text {net }}}{\rho_{g}{ }^{2} \text { ref }^{h g}}$ (product of the Jakob and stanton numbers).

This last number is essentially a normalized power-to-flow ratio, which also is a modified way to calculate the volumetric vapor flow rutc:

These criteria have been applied to some of the computer results generated using water and sodium properties, and appear to provide a good basis for the comparison of these simulations: 
G. Summary - Present Status and Plans for FY1980

1. Work Completed During FY1979.

a. Setup and Calibration of Experimental Apparatus

1) Acquisition of instrumentation needed to modify existing loop.*

2) Completion of calibrations and preliminary testing.

b. Lixperimental Work

Deferred to fry1980 due to delay in receiving the data acquisition system.

c. Analytical Work

1) Formulation of simple one-dimensional model.

2) Coding and preliminary testing of model.

2. Plans for FY1980

a. Setup and Calibration of Experimental Apparatus Completed during FY1979.

b. Experimental Work

1) Perform experiments with water test loop.

2) Follow SBTF experiments (if these experiments are resumed during FY1980).

c. Analytical Work

1) Analyze experimental data using model developed during FY1979.

2) Compare analytical model and water test loop results with data from SBTF (if appropriate data becomes available during FY1980). Develop criteria for use in future comparisons. of sodium and water test results.

3) Develop recommendations concerning expansion of: analytical. model to multi-dimensional form and/or incorporation into large systems colo.

*Watcr test loop designed and built with help of FY1978 funding from $G E$. 


\section{References}

1. Ribando, R.J., et.al.,"Sodium Boiling in a Full Length 19-Pin Simulated Fuel Assembly (THORS Bundle 6A)," ORNL/ RM-6553, Oak Ridge National Laboratory, January 1979.

2. Hinkle, W.D., "Water Tests for Determining Post-Voiding Behavior in the LMFBR," MIT-EL 76-005, June 1976.

3. Garrison, P.W., "Sodium Boiling Test Facility (SBTF) Phase I Test Plan," Final Draft, February 1978.

4. Ribando, K.J., et. al., "Sudiuni Boiling in a Full Longth 19-Pin Simulated Fuel Assembly (THORS Bundle 6A), ORNL/ TM-6553, Janúary $19 \% \dot{9}$. 


\section{PROGRAM COORDINATION}

A. Introduction

During FYl979 an effort has been made to coordinate this program with other DOE programs and activities concerned with sodium boiling R\&D: The objectives of this effort are: (I) to assure maximum use is made of data and information available from related programs and (2) to facilitate eventual acquisition and use of the codes being developed by the appropriate DOE contractors and laboratories. Section VI.B provides an outline of FY1979 meetings and reports aimed at accomplishing these objectives. Section VI.C outlines plans for FYI980.

B. FY1979 Coordination Activities

1. Project Meetings and Reports

a. Meetings

1) $12 / 14 / 78$ meeting at MIT with $A$. Shih of GE and R. Ribando of ORNL.

[This meeting also included discussion of: (a) related work at GE and ORNL and (b) possibilities and logistics of ORNL and GE participation in MIT program.]

2) $2 / 8 / 79$ meeting in Germantown, Md. with

A. Millunzi of DOE.

3) $3 / 15 \& 16 / 79$ meeting at MIT with R. Ribando of ORNL.

4) 4/20/79 meeting at MIT with J. Hanson of HEDL.

5) $4 / 1 \& 2 / 79$ meeting at MIT with $A$. Shih of GE and R. Ribando of ORNL.

[At this meeting, a preliminary working version of THERMIT was provided to GE and ORNL and a working version of the GE code, SOBOIL, was provided to MIT.] 
6) 5/17\&18/79 meeting at MIT [Ref. Item 2.a.3) below] .

7) $7 / 24 \& 25 / 79$ meeting at MIT with A. Shih of GE, R. Masterson of HEDL and G. Klein or ORNL.

[At this meeting an updated version of THERMIT was provided to GE, HEDL and ORNL.]

b. Reports

1) 12/12/78 memo from W. Hinkle to J. Hanson, A. Millunzi and P. Tschamper providing further details concerning approach and scopc and outlining progress through $11 / 30 / 78$.

2) Preliminary draft of interim report describing results of FY1979 work.

2. Other Activities

a. Behavior of Sodium (BONA) Working Group Meetings

1) $9 / 1 / 78$ meeting at MIT to discuss: (a) proposed "Work Breakäown structure for sodium Boiling Technology R\&D," (b) preliminary results of ORNL SBTF tests and (c) FY79-80 program proposed by MIT.

2) $11 / 3 / 78$ meeting at MIT to discuss: (a) "Work Breakdown Structure for Sodium Boiling Technolngy R\&D," (b) details of work scope of MIT program and (c) possibility of direct GE and ORNL participation in MIT program.

3) 5/17\&18/79 meeting at MIT to discuss: (a) WBS format and content, (b) draft of detailed plan for MIT/GE, HEDL, ORNL work on multi-dimensional. computer code models, (c) status of work outlined in draft plan, (d) proposed tests using THORS facility and (e). SLSF wl Test Plan. 
b. Other Meetings

1) $1 / 30 / 79$ meeting at MIT with ORNL to discuss results of SBTF Phase I Tests and possible follow-on tests.

2) $3 / 27 \& 28 / 79$ meeting at GE with GE and ORNL to: (a) prepare for WBS discussions at $5 / 79$ BONA meeting (Ref. Item 2.a.2) above) and (b) discuss current LMFBR core design trends relating to safety thermal-hydraulics.

C. Plans for FY1980*

1. Project Meetings and Reports

a. Finalize and distribute interim report [Ref. Subtask 1.b.2)].

b. Hold three informal review meetings to discuss progress of the code development effort at MIT.

c. Coordinate preparation: and distribution of working papers.outlining interim results of code development work.

d. Coordinate preparation and distribution of final reports describing results of FY1979-80 work.

e. Coordinate preparation and distribution of copies of computer code(s) and related documentation.

2. Other Activities

None planned.

\footnotetext{
*Note that the scope of work on this task will be reduced to a minimum level during FY1980 due to a decrease in the overall project funding.
} 